Portland State University

PDXScholar

\title{
Self-Concept Competency of National Aeronautics and Space Administration Research and Development Managers
}

Mark A. Beymer

Portland State University

Follow this and additional works at: https://pdxscholar.library.pdx.edu/open_access_etds

Part of the Organizational Behavior and Theory Commons, and the Urban Studies and Planning Commons

Let us know how access to this document benefits you.

\section{Recommended Citation}

Beymer, Mark A., "Self-Concept Competency of National Aeronautics and Space Administration Research and Development Managers" (1989). Dissertations and Theses. Paper 1380.

https://doi.org/10.15760/etd.1379

This Dissertation is brought to you for free and open access. It has been accepted for inclusion in Dissertations and Theses by an authorized administrator of PDXScholar. Please contact us if we can make this document more accessible: pdxscholar@pdx.edu. 


\title{
SELF-CONCEPT COMPETENCY OE \\ NATIONAL AERONAUTICS AND SPACE ADMINISTRATION \\ RESEARCH AND DEVELOPMENT MANAGERS
}

by

MARK A. BEYMER

A dissertation submitted in partial fulfillment of the requirements for the degree of

\author{
DOCTOR OF PHILOSOPHY \\ in \\ URBAN STUDIES
}

\author{
Portland State University \\ (C) 1989
}

Reproduced with permission of the copyright owner. Further reproduction prohibited without permission. 
TO THE OFEICE OF GRADUATE STUDIES:

The members of the Committee approve the dissertation of Mark A. Beymer presentod April 21, 1989.
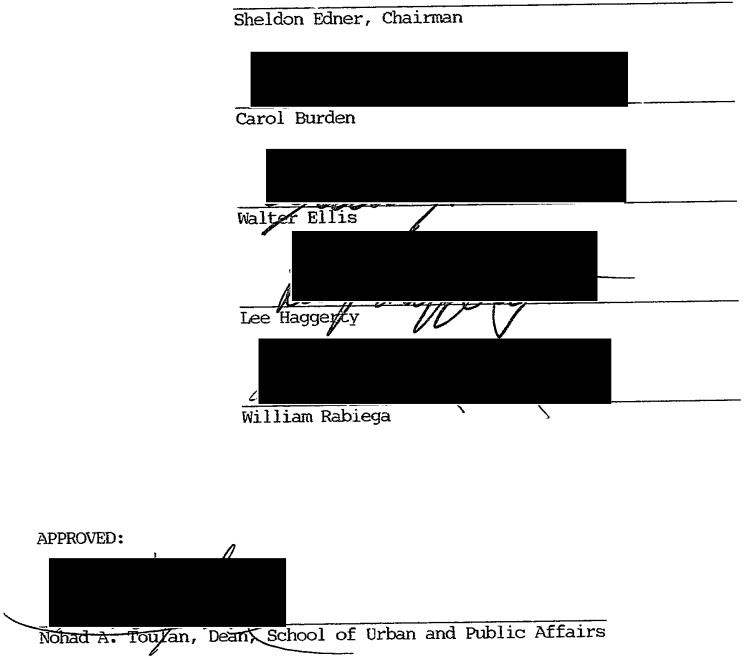

Bernard Ross, Vice Provost for Graduate Studies 
AN ABSTRACT OF THE DISSERTATION OF Mark A. Beymer for the Doctor of Philosophy in Urban Studies presented April 21, 1989.

Title: Self-Concept Competency of National Aeronautics and Space Administration Research and Development Managers.

APPROVED BY THE MEMBERS OF THE DISSERTATION COMMITTEE:

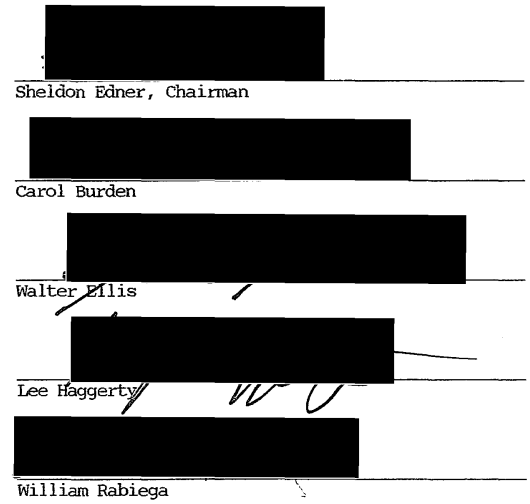

Little research has been accomplished exploring the self-concepts of scientists and engineers working in research and development organizations. Mahoney believes that idealized misconceptions of scientists threatens the very foundations of scientific knowlcdge bccause the scientists, or manager of scientists, is most deceived who is "self" 
deceived. This research investigates seventeen hypotheses relating to the self-concepts of high performing, mid-level technical managers employed in the National Aeronautics and Space Administration (NASA).

Boyatzis has stated that "true" management competencies are characteristics of a manager which differentiate superior from average and below average performance. Boyatzis, however, treats a manager's self-image (self-concept) as a "threshold" rather than a "real" competency. Lafferty's research, which has measured relationships between several lifestyle (self-concept) variables and corresponding organizational behavior, has found that performance differences between average and high performing managers are associated with differences in selfconcept construction. The researcher proposes to treat variations in self-concept measurements from managers as indications of their relative management competency. This research does not directly observe or measure management behavior but provides original normative data on the self-concept competencies of scientific and engineering managers working in an urban research and development organization (NASA).

The Level 1: Life Style Inventory, developed by Lafferty, was administered to high performing, mid-level managers (118 aerospace technical and 43 non-technical) from nine major Research and Space Flight centers, and the agency Headquarters, attending a Management Education Program. Measurement of 16 self-concept and 4 biographical variables were cormared and contrasted with self-concept measurements accomplished by Lafferty on samples of engineers, supervisors and mid-level managers. The first ten hypotheses evaluated differences in means between the test groups for the self-concept variables. NASA technical managers 
testod significantly higher than Lafferty supervisors and mid-level managers in the helpfulness, achievement, competence (perfectionism), affiliation, and self-actualize orientations. NASA technical managers were also significantly greater than Lafferty's mid-level managers in their dependence orientations. NASA technical managers have significantly less satisfaction concern and affiliation orientation than NASA non-technical managers. NASA tcchnical managers had similar selfconcept profiles to the engineers tested by Lafferty.

Hypotheses Eleven through Thirteen found no self-concept profile similarities between NASA technical managers and three strain groups testcd by Lafferty--individuals reporting symptoms of depression, ulcers and high blood pressure, respectively.

Hypothesis Fourteen found that there was significantly greater achievement motivation in NASA technical managers higher that the mean age than in NASA technical managers with less than the mean age. Hypothesis Fifteen found no significant associations between NASA technical managers with higher and lower mean tenure and measurements of lifestyle variables. Significantly more satisfaction concern, helpfulness and achievement orientations were found in managers with greater than mean time-in-grade and experience than in managers with less than mean time-in-grade and experience (Hypotheses Sixteen and Seventeen). Three major conclusions are reached.

1. NASA tcchnical managers exhibit an unusual degree of satisfaction when compared with other supervisors and mid-level managers and a self-actualizing management style. 
2. The self-concept characteristics of high perfectionism and dependence in NASA technical managers should be studied further, basec on Cooke and Rousseau's findings that high measurements in these variables are associated with a greater number of symptoms of strain and Lafferty's findings concerning associations between high measurements of these variables and disfunctional managerial behavior.

3. Evidence is provided researchers, like Garfield, that while management experience may be significantly associated with self-concept increases in achievement and helpfulness orientations, the self-concept assumptions of these managers may preclude them from significant increases in their selfactualization. 


\section{ACKNONLEDGEMENTS}

To my mother, Marjorie Beymer, for planting the desire and motivation to undertake this goal. To my father, Alvin Beymer, and my father and mother-in-law, Marlyn and Mary Anderson, for their consistent encouragement. To my all my extended family, especially Kent Anderson and Phil and Greg Beymer. To my daughters--Karen, Kristiana and Kimberly-who loved me anyway. And most of all...to my wife, Judy, without whose inspiration I could never have gained the will, support, and confidence for such a task. She is my greatest love and happiness.

To the faculty who served on my dissertation conmittee--Carol Burden, Walt Ellis, Lee Haggerty, and Bill Rabiega--who gave me such good technical counsel, despite the distance. To members of my Comprehensive Committee--Leonard Cain and Carl Abbott--who prepared me for this undertaking, with their scarce time and models of excellent thinking. And most of all to Sheldon Edner, my Dissertation Conmittee Chairman, my conscience and best: critic, who has emerged a valued friend.

To personal friends who encouraged and sustained my journey. To Dick and Carolyn Cherry, Phyllis Day, Jim and Virginia Joyner, Warren and Karen Langer, Bunny Lehton, Roland and Barbara Norris, Art and Norma Peterson, Bruce and Meribeth Roberts, Mike and Chris Taylor and Chuck and "Bunda" Zickefoose. And most of all to Bob and Helen Maltby, who provided me a computer when I had none; to Lamar and Mary Russell, who took the time to proof-read drafts; and, to Bob Lehton who can deftly provide valued advice and companionship--whether sailing or flying. 
To NASA employees, everywhere. To my NASA supervisors--Ernest Spivey and David Dickinson. To Helen Lambert, Jan Moore, and David Lesage who administered the Management Education Program and made sure I received the data. And most of all to Dale Crossman, who encouraged me to do my research with NASA and provided me the opportunity to do so.

To idealists Doug Olsen and Don Christenson. To Robert Woodward and Arthur Seamans, undergraduate Professors of History and English, respectively, whose ideals and lust for creative thinking passed on in those years challenges me to this day. To my first graduate school teachers--Milo Chapman (who introduced me to Job), Ralph Turnbull (who showed me why God created the Scots) and Richard Craghead (who taught me the importance of clarifying values). And most of all to Charles Bolton who taught me how to begin to understand social paradigms and realists. To the great scholars of my books--who surely must have other lives: Ian Barbour, Peter Berger, Mary Douglas, the Durants, Erik Erikson, Brian Hall, Lawrence Kohlberg, Thomas Kuhn, Timothy Leary, Michael Maccoby, Stephen Pepper, Jean Piaget, Carl Rogers, Edmund wilson and Ruth Wylie. To Saint Anselm and Montaigne (may they rest in peace with the knowledge that at least one American student has poured over their words). And most of all to contemporary scholars Richard Boyatzis, Seymour Epstein and Clayton Lafferty--whom I have never met.

To the voids in my life, which no other persons can ever fill. To Allie and Amy Beymer, Herman and Esther Olson, Pappy and Millie Flathers and W.I. and Geneva Gough. To USMC Officers Hugh Cameron, Bud Mason, Steve Clark, "Cochise" and many others--Semper Fi!!

To opportunity and tomorrow. 
TABLE OF CONTENTS

PAGE

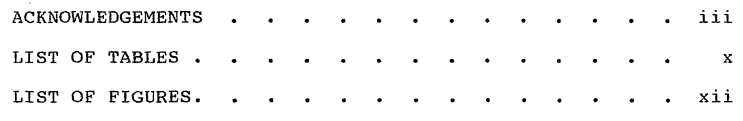

CHAPTER

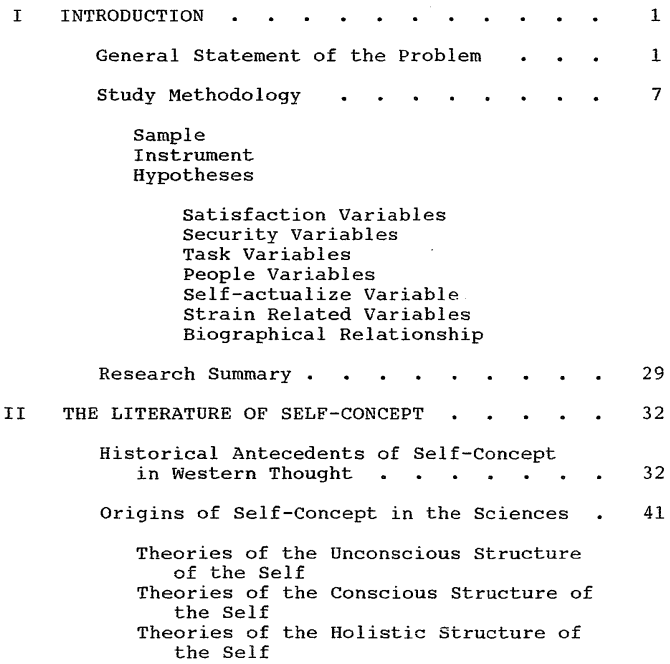

Reproduced with permission of the copyright owner. Further reproduction prohibited without permission. 
Theories of Cognitive Learning by the Self

Theories on the systemic structure of the self

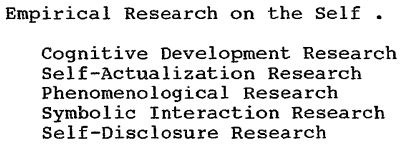

Cognitive Development Research

Self-Actualization Research

Phenomenological Research

Symbolic Interaction Research

Self-Disclosure Research

Definition of Self-Concept . . . . .

III THE LITERATURE CONCERNING THE SELE-CONCEPTS OF MANAGERS IN RESEARCH AND DEVELOPMENT ORGANIZATIONS

Self-Concept in Management Theory

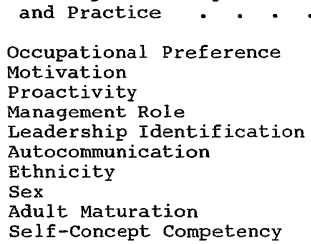

Occupational Preference

Motivation

Proactivity

Management Role

Leadership Identification

Autocommunication

Ethnicity

Sex

Adult Maturation

Self-Concept Competency

Self-Concepts of Managers in Research and Development Organizations . . . . 8

Satisfaction Competencies

Security Competencies

Task Competencies

People Competencies

Self-actualization Competency

Relationship of Managers' Self-concepts to strain

Self-Concept and Biographical Experience

Self-Concept Competency of NASA Managers 


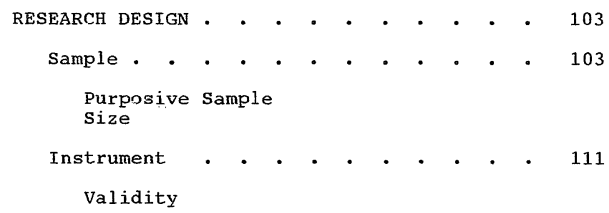

Reliability

Administration

Procedures and Methods . . . . . . 124

procedures

Methods

Problems Encountered . • • • . . 127

Biographical Variables

51-I Accident

Lafferty Samples

Statistical Significance

Summary of Research Design . . . . 134

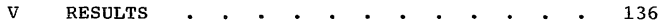

Test Groups • • • • • • • • • • 136

Satisfaction Variables Testing . . . . 136

Hypothesis One: Satisfaction Concern

Hypothesis Two: Humanistic Helpful

Lifestyle

Hypothesis Three: Achievement Lifestyle

other Satisfaction Variables

Security Variables Testing . . . . . 144

Reproduced with permission of the copyright owner. Further reproduction prohibited without permission. 


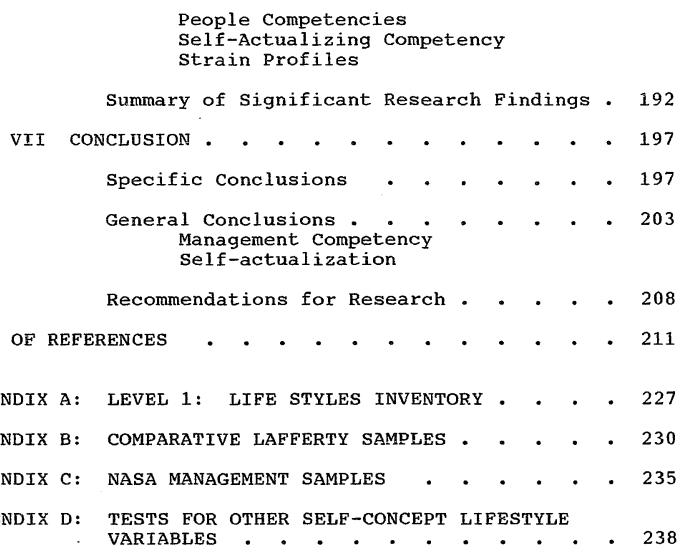




\section{LIST OF TABLES}

TABLE

PAGE

I Description of the Twelve Lifestyles

from the Life Styles Inventory * * * . 12

II Sample Construction by NASA Center . . . 104

III Comparison of Samples Studied . • • • . 105

IV Test for Hypothesis One . . . • . . . 137

$\mathrm{V}$ Test for Hypothesis Two . . . . . . 140

VI Test for Hypothesis Three . . . . . . 142

VII Test for Hypothesis Four . • . • . . 145

VIII Test for Hypothesis Five . • • . . . 147

IX Test for Hypothesis Six . . . . . . 149

X Test for Hypothesis Seven . . . . . . 151

XI Test for Hypothesis Eight . • . . . . 153

XII Test for Hypothesis Nine . . . . . . 155

XIII Test for Hypothesis Ten . . . . . . 157

XIV Test for Hypothesis Eleven . • • • • 159

XV Test for Hypothesis Twelve . . . . . . 161

XVI Test for Hypothesis Thirteen . . . . . 163

XVII Comparison of Biographical Variables:

NASA Technical and NASA Nontechnical Managers . . . . . . . . • . . 165

XVIII Sex of NASA Managers Studied • • • • . 166

XIX Test for Hypothesis Fourteen . . . . . 168

Reproduced with permission of the copyright owner. Further reproduction prohibited without permission. 
XX Test for Hypothesis Fifteen - . . . 170

XXI Test for Hypothesis Sixteen - • • • • 171

XXII Test for Hypothesis Seventeen . • • • • 173

XXIII Other Security Variables: Tests . . . 239

XXIV Other Task Variables: Tests . . . . . 240

XXV Other People Variables: Tests • • . . 241 


\section{LIST OE FIGURES}

FIGURE

PAGE

1 The Life Styles Inventory Circumplex •

2 Level 1: Life Styles Inventory

Self-Description, Page One . . . . . 228

3 Level 1: Life Styles Inventory

Self-Description, Page Two . . . . . 229

4 Lafferty Life Styles Summary Profile:

General Summary • • • • • • • • • 231

5 Lafferty Life Styles Summary Profile:

Engineers . . . . . . . . . . 232

6 Lafferty Life Styles Summary Profile:

Supervisors • • • • • • • • • • 233

7 Lafferty Life Styles Sumary Profile:

Mid-Level Managers • • • . • • • • 234

8 Lafferty Life Style profiles:

NASA Technical Managers' Profile Compared

with General Population . . • . . 236

9 Lafferty Life style profiles:

NAsA Nontechnical Managers: Profile

Compared with General Population . . . 237

Reproduced with permission of the copyright owner. Further reproduction prohibited without permission. 


\section{CHAPTER I}

\section{IN'RRODUC'I ION}

\section{GENERAL STATEMEN'T OF THE PROBLEM}

The hypothetical construct, self-concept, has often been utilized by personality theorists to explain an individual's behavior (Drude 1972, p. 1). Epstein (1973, p. 407) has elegantly described a self-concept as the selfsystem hypothesis, or self-theory, a person has of himself (herself). As the conceptual hypothesis one has of himself largely determines a person's behavior, a person's selfconcept has a major influence in his/her job performance in work organizations.

Little empirical research, however, has been performed defining the self-concepts of managers operating in a research and development ( $R \& D$ ) organization or in a government bureaucracy. The transformation of scientists and engineers into technical managers is understood to be an important process involving a change in the self-concepts of these employees (Bayton and Chapman 1972). Further, it is argued that managers in government bureaucracies have substantially different self-concepts than managers in private-sector organizations (Rhinehart, et al. 1969). 
This is a study of the self-concepts of high performing scientific and engineering managers in a federal government $R \& D$ organization. Research on the self-concepts of these $R \& D$ managers should provide needed baseline data on the psychological attributes of contemporary managers in an important sector of our technical, urban society. This information should be useful in appraising managers' selfconcept competencies which influence individual and collective performance in both government and private sector $R \& D$ organizations. An increased understanding of self-concept competency should assist in defining intervention strategies for organization design and management development programs within technical organizations.

Labels commonly associated with the theoretical construct of self include: self-concept, self-perception, self-disclosure, self-acceptance, self-esteem, self-image, self-regard, and self understanding. These labels have frequently been used interchangeably or with overlapping construction. Further, self-concept is related to several other psychological constructions such as identity, egodevelopment, and ego-ideal (Noppe 1979, p. 3). Despite the various labels or theoretical paradigms used, similar themes (i.e., identification with others, self-evaluation, body image, continuity in time, and a subjective sense of uniqueness) are often used as descriptors of this construct. 
Theoretical differences arise in whether the self is viewed as a structure or a process. "Trait" theories, which treat the self as a structure, may result in perceiving behavior as stabilized when there are changing elements. "Process" theories, which discuss the self as a changing organizer in human motivation, attitudes, and personality may de-emphasize the stable elements of "being."

liultsch and Deutsch (1981, p. 9) describe the relationship between a general representation of phenonena in scientists' paradigms of self and their world views (pepper 1942). They conclude that the relative structural stability or emphasis on process in a scientist's use of self-concept is related to his (or her) perception of the relative structural or process dimensions in his (or her) world view. The key question is "not whether the self or a self-concept exists, but rather its suitability as an operational const ruct: subject to empirical validation" (Nople 1979, p. 1). Several theorists have macle effective use of a self-concept: measure in areas affecting the study of managenent. Super (et: al., 1963) sets forth the theory that an occupational preference represents a translation of one's self-concept into vocational terms. From this theory, Starishevsky and Matlin (Super, et: al. 1963) develop a model which predicts that the relative attractiveness of an oc:cupation is a function of the degree of similarity between a person's self-concept and his concept of the occupation. 
Siggers (1971) uses the super formulation to develop a rationale proposing that perception of an occupational role may vary with the perception of an individual's occupational self-concept, which is considered a product of the genetic personality characteristics and the experiential development of a person. Sigger's research is supported by interesting findings which suggest that the dynamic pattern of maturation, supported by a continually developing skill repertoire, influences not only career choices made, but also provides for the interpretation of the function of the "self-in-occupational-role." The study concludes that career selection, which may demonstrate an appropriate consequence of the vocational development process, does not necessarily predict appropriate role performance in terms of the profession or those associated with it. However, compatibility between self-concept and a manager's role may result from the process of interactional adjustment between the two dimensions. Role definition and self-concept reside subjectively within the individual. It cannot be stated that enough flexibility within either the individual or the work assignment exists to assure congruence between these factors. An important suggestion made by siggers is that the operational exploration of self-concept be extended beyond career selection and used to consider the ongoing interaction process of adjustment and modification between the self and the organizational role of the individual.

Reproduced with permission of the copyright owner. Further reproduction prohibited without permission. 
Boyatzis: (1982, pp. 29-33) theory of management behavior describes the importance of a "threshold" selfconcept competency in a manager's job behavior (performance). His research demonstrates that where observed behavior of a management competency exists, an underlying self-concept ("self-image") of competency assists in the selection of actions to be taken. The aggregated selfconcepts of an organization's managers both interact and effect work behavior in the everyday operation and productivity of an organization.

Lafferty (1980, p. 3) and Schutz (1984, pp. 109-138) assert that there are self-concept orientations which are indicators of an individual's competence to manage, since they intervene in his behavior. Lafferty provides substantial research on the self-concepts ("lifestyle orientations") of the general population and several occupational groups--including engineers and managers. Research has also been accomplished on various self-concept profiles which are associated with debilitating physical symptoms of stress and strain (Cooke and Rousseau 1982a).

A preliminary comparison between Lafferty's samples of engineers and his samples of managerial groups (executives, mid-level managers, and supervisors), as well as his general population sample, reveal several significant differences between the sample groups. Lafferty submits that these differences in self-concept orientations between the groups as- 
sist in explaining important differences in their member's behavior (job performance) and in the probability of some debilitating physical symptoms emerging in members of these respective groups.

Research defining the self-concept competencies of an organization's management should assist key-level decision makers to be be more informed on the consequences of their three alternative courses of action when assessing management performance, those three being:

1. Doing nothing;

2. Engaging in the behavioral modification of their managers; or,

3. Engaging in changes to organizational design.

Executives tasked with improving the performance of organizations have to make the crucial decisions of how to intervene in these organizations by using one of these three actions. If decision makers know the existing self-concept competencies of an organizations' managers and understand the relationship between self-concept competencies and managerial behavior, then executives are able to make informed decisions on the relative risk of investment and return in productivity of either changing the existing competencies of their managers (and corresponding management behavior) or redesigning organizational structures to obtain the maximum benefit of management behaviors which presently exist from existing competencies, or doing nothing at all. 
Decision makers who have no valid information on either the existing or the desired (ideal) self-concepts of its organizations' managers do not have the very basic evidence on which to begin a decision analysis between alternatives of intervention strategies. This dissertation should provide useful information to decision makers charged with managing $R \& D$ organizations by researching the existing self-concept competencies of high-performing, technical managers in the case of the National Aeronautics and Space Administration.

\section{STUDY METHODOLOGY}

\section{Sample}

As the principal investigator is employed by the $\mathrm{Na}-$ tional Aeronautic and Space Administration (NASA), an excellent opportunity exists to study the self-concepts of high performing government $R$ \& $D$ managers within this agency. NASA has a technical mission and several research and development centers located across the country with management positions in aerospace engineering and other scientific areas of related specialization. While obtaining data from such a busy and geographically dispersed population initially seems difficult, the researcher discovered that a two-week Management Education Program (MEP) is held four times a year at Wallops Island, Virginia. These occasions provide opportunity for research using a purposive sample. 
The managers attending the MEP program, while not random in selection, provide a representative sample of the agency's high-performing, mid-level managers. ${ }^{2}$ Managers (GM-14/15) who have, as a result of their previous high performance, been competitively identified as "high potential" for promotion to positions of increased management responsibilities are nominated by these Centers to participate in the two-week program. These NASA managers can generally be described as mid-level, although some first-level supervisors and project managers attend the program. Fach class contains 20-35 attendees, and each Center's number of attendees equals approximately its proportion of the agency's total mid-level (grade 14/15) management positions. For this research, all attendees of the six MEP classes presented between June, 1985, and June, 1986, were administered a self-concept instrument and asked summary biographical questions. ${ }^{2}$ Respondents were then classified into one of two sample groups: technical (technical, engineering, project, program, research, and other technical management functions) and non-technical (administrative,

${ }^{1}$ Sample representation is described in the Sample section of Chapter Four.

${ }^{2}$ The flight explosion of the space shuttle challenger on January 28, 1986, and the deaths of the seven crewmembers occurred after the commencement of the study. A brief: description of the controls initiated by the researcher to determine any potential effects of the accident on the subjects is described in the Problems Encountered section of Chapter Four.

Reproduced with permission of the copyright owner. Further reproduction prohibited without permission. 
resource, and other non-technical management functions). The data from the technical managers' group ( $\&$ \& $D$ Managers) were compared and contrasted with the non-technical managers' group and data from six research samples from previous work done by Lafferty (1980, pp. 48-49; Cannarsa 1988): engineers, supervisors, mid-level managers, depressed individuals, individuals experiencing ulcers, and individuals with high blood pressure.

The Lafferty engineering sample provides excellent comparative data on self-concepts since the experience of this group best approximates the pre-supervisory experience of the NASA managers. No equivalent research sample for scientists is known to exist. Many NASA technical managers have an engineering education and journeymen level work experience and NASA technical managers who do not have engineering backgrounds at least have a more similar academic training and work experience with the Lafferty engineers than with any other known sample group.

The Lafferty supervisors' and managers' samples are important comparative groups for self-concept since most NASA GM 14/15s also have experience as a first-level supervisor, and many have made the organizational transition to being a mid-level manager. The Lafferty managers' group is probably the largest comparative group for determining normative relationships between NASA managers' self-concepts 
and the self-concepts of a sizeable sampling of existing mid-level managers.

Finally, research has found support for hypotheses linking self-concept with symptoms of strain (Cooke and Rousseau 1983a; Cooke, et al. 1985). A research value could be obtained by comparing the self-concepts of NASA managers with the self-concepts of these groups" respondents. The question arises whether $R \& D$ managers demonstrate, as a group, any relationship between debilitating strain and self-concepts. This will be tested by contrasting NASA technical managers with three groups with debilitating illnesses--depressed individuals; individuals experiencing ulcers; and, individuals with high blood pressure.

\section{Instrument}

While many exccllent instruments are avajlable to measure self-concept, the Level 1: Life Styles Inventory Self-Description was selected for several reasons. Engaging the NASA management group in the research and obtaining the support of the management trainers responsible for the MEP curriculum required the use of an instrument which could be easily administered, required a minimum amount of program time, and had a high degree of face validity when reporting results to the subjects. In addition to meeting these criteria, the Life Styles Inventory instrument possesses the advantage of having associated with it an excellent

Reproduced with permission of the copyright owner. Further reproduction prohibited without permission. 
videotape for explanatory use with subjects, in which the diagnostic model is presented by the developer, Dr. J. clayton Lafferty. While not exhausting all the important construct dimensions of self-concept, some very important self-concept variables relating to management performance, can be measured and analyzed. This will be discussed further in chapter Four.

Participant responses to the Life styles Inventory Self-Description form the data base of this study. The Lifestyles Inventory circumplex model (Conte and Plutchik 1981) was developed from a confiluent approach toward personalj.ty theory and research (Leary 1957; Freedman, et al. 1951; McClelland, et al. 1953; Rogers 1961; Sullivan 1953). The twelve lifestyles included in this model are described in Table I (Cooke and Rousseau 1982a, pp. 8-9). The Life Styles I Inventory instrument (Lafferty 1973) assumes that: the words individuals use to describe themselves are especially revealing about their self-concepts. When people use $a$ number of the same type of words to define themselves they reveal a pattern of thinking which reflects a specific self-concept (lifestyle orientation). Each lifestyle indicates a different dimension of the individual's self-concept: based in the relative strength of underlying motivational needs (concerns).

As Conte and Plutchik (1981, pp. 701-703) suggest, a circumplex model can be a valid approach for representing 
TABLE I

\section{DESCRIPTION OF THE TWELVE IITESTYLES FROM THE LIFE STYLES INVENTORY}

\section{Life style}

\section{Description}

1. BuganisticHelpfal

2. Affiliative

3. Approval

4. Conventional

5. Dependence

6. Avoidance

7. Oppositional

9. Conpetitive

10. Competence

11. Achievenent

12. Selfactualizing

Based on the assuaption that people are basically good and uill respond effectively in cooperative settings. This style characterizes individuals who enjoy teaching and assisting others and tho provide then tith positive rewards and support.

Based on needs for friendly relationships and a vide circle of friends. People exhibiting this style are cooperative varn and accepting; they share their feelings with and are triendly toward others.

Based on a concern for being accepted by others. Approvaloriented individuals try to be nice and to be liked by other people; they tend to agree with others and to do things to please then.

Based on a preoccupation with people as a source of security. The underlying dynatic is towạrd appearing normal, not rocking the boat, and following rules and seeting the expectations of superordinates.

Based on a cpncern for neither threatening nor chal lenging other people as vell as on nore general needs for physical and psyand do what they are told.

Based on needs for self-blame, feelings of quilt, and/or low selfęteen and self-efficacy. People oriented toyard avoidance stay atay fron conflict and decision situations and shift responsibility to others.

Based on needs for resisting authority and gaining recognition. Oppositional people show a tendency to be skeptical and inquisitive, to point out flaws, and to be generally critical.

Based on needs for influence and prestige and a tendency to use power to aaintain a feeling of security and self-esteen. Individuals who seek power attenpt to take charge of situations and to be tougher" than other people.

Based on a need to win and to be better than others. Individuals oriented toward competition maintain their sense of self-worth by turning everything into a contest and aeasuring their success in terms of their "opponents" perfornance.

Based on a desire to appear independent and confident and a concern for gaining satisfaction by successfully coopleting tasks. Coapetence is associated yith setting very high goals, trying harder, and seeking recognition through perfection.

Based on a need to do things well. People oriented toward achievexent are rational and effective planners, anbitious and enthusiastic, and enjoy tasks that are challenging.

Based on concẹrns for neeting one's own goals and for experiencing life and grouling. Self-actualizing individuals prefer qua jty over quantity, take pride even in siaple tassks that are done well with pleasure, and renove thenselves fron situations that are not enjoyable. 
personality structure (i.e., self-concept) when two opposing personality variables are oriented one-hundred-eighty degrees apart in contrast to another set of two opposing personality variables represented perpendicular from the first set. The twelve lifestyles variables depicted around the circumference of the Iafferty circumplex in Figure 1 (Cooke and Rousseau 1982a, p. 6), therefore, approximate selfconcept mixtures of four underlying motivational concerns (Lafferty 1980 , p. 6).

The two sets of motivational concerns underlying the Lafferty lifestyles often have been the subject of management research and literature (Rosen and Weaver 1960, Porter 1962; 1963a; 1963b; 1963c, Edel 1966, Herrick 1968, Boeyens and de Jager 1982, and Blake and Mouton 1985). These motivational concerns (needs) are very important parts of an individual's self-concept construction.

The first set of two contrasting motives has been defined by Maslow (1954), and described on the inventory as "security" or "satisfaction" concerns. Managers with high security concern tend to have an underlying self-concept motivation preoccupied with protecting the self from illness or injury, privation of status, or food and shelter. They typically avoid taking the risks which are usually an essential part of a manager's role. In contrast those managers with high satisfaction concern have an underlying self-concept motivation preoccupied with seeking satisfying

Reproduced with permission of the copyright owner. Further reproduction prohibited without permission. 


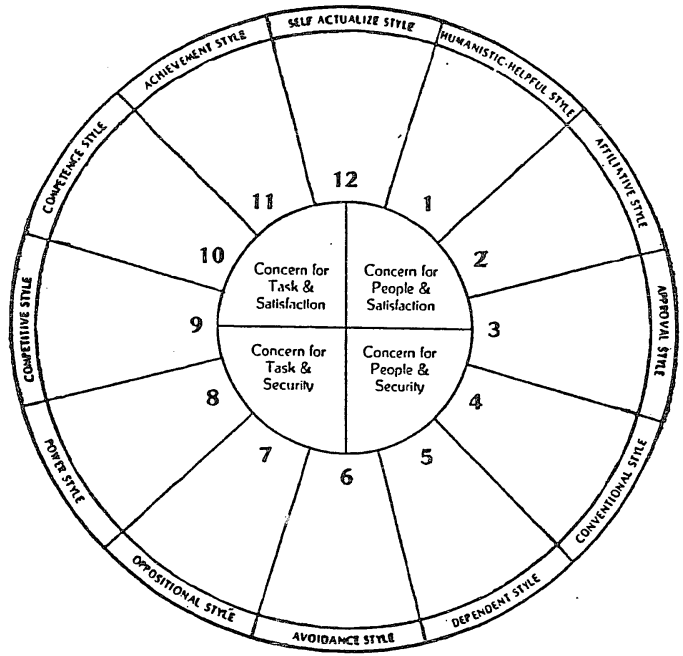

Figure 1. The Life Styles Inventory Circumplex (Adapted from Cooke and Rousseau 1982a) 
experiences for the self and they are potentialy capable of experiencing an appreciation for the pursuit of this concern by others. This satisfaction concern can generally be converted into organizationally constructive behavior, or risktaking behavior which is congruent with an organization's mission and objectives.

The second set of two contrasting motives has been defined by Blake and Mouton (1964), and described on the inventory as "people" and "task" concerns. Managers with high people concern tend to have an underlying self-concept motivation which requires a high degree of cormunication feedback and/or personal association with others. These individuals have a preoccupation with the value of "persons." In contrast, those managers with high underlÿiry task concern in their self-concepts find that it is the accomplishment of objectives which provide an important identifying element for the self. Managers may find this gratification through seeking individual or organizational objectives and goals, but it is by obtaining meaningful elements of the mission, rather than by associating with others, that the task-oriented manager finds gratification. The Lifestyles Inventory is depicted in Appendix A (Figures 2 and 3 ) and discussed further in chapter IV. The circumplex profiles of the Lafferty samples are depicted in Appendix B (Figures 4-7).

Reproduced with permission of the copyright owner. Further reproduction prohibited without permission. 


\section{Hypotheses}

The seventeen research hypotheses are categorized into seven groups of tests: Satisfaction Variables; Security Variables; Task Variables; People Variables; Selfactualization Variable; Strain Related Variables; and, Biographical Relationships.

Satisfaction Variables. Herzberg (1966) has submitted that high satisfaction concern is preferred in the selfconcepts of all employees, not only managers. Managers with a high satisfaction concern are believed to be potentially more motivated in their self-concepts to attempt a solution integrating the task and people conflicts inherent in managerial work and to concentrate on seeking out solutions to those problems which do not satisfy employees and/or key level managers (Lafferty 1980). Since NASA is primarily a technical organization with a greater number of management jobs in technical units of organization, it is believed that NASA technical managers should demonstrate a greater satisfaction concern than NASA non-technical managers, whose career paths may be more restricted within the agency and, therefore, less satisfying. A significantly higher satisfaction concern score by NASA technical managers, when compared with the NASA non-technical managers, should indicate high performing NASA $R \& D$ managers have a stronger satis- 
faction motivational need in their self-concept than high performing NASA non-technical managers have in their selfconcept construction.

Further, the research of Lafferty (1980, pp. 11-12) and Herzberg (1966) has found associations between the humanistic-helpful self-concept orientation in managers and in their performance. Managers with a helpful self-concept orientation tend to train and develop employees and motivate people with support, positive feedback, and involvement through informal team interaction. While emphasis on teamwork and helpfulness are an integral part of the NASA philosophy, commonly stated through management communication, does helpfulness score higher in the self-concept reports of technical managers where career advancement rewards for this behavior may be more likely? Is the NASA helpfulness orientation stronger among $R \& D$ managers than among engineers, supervisors or managers in general? A significantly higher humanistic-helpful lifestyle score by NASA technical managers, when compared to other groups, should indicate high performing NASA $R \& D$ managers have a stronger helpfulness orientation in their self-concept than NASA non-technical managers or Lafferty engineers, supervisors and managers have in their self-concept construction. The research of Lafferty (1980, pp. 31-32) and Mcclelland (et al. 1953, 1976) provides evidence of the importance of an achievement orientation in the self-concepts of 
managers. Achievement oriented managers tend to motivate others by encouraging them to set and achieve challenging, yet reachable, goals while remaining very effective in problem analysis, and in receiving events "objectively" and "accurately." While a great deal of emphasis is placed upon "excellence" within the NASA technical organizations directly involved in the pursuit of scientific and engineering $R \& D$ programs, do stronger achievement orientations exist within the self-concepts of NASA technical managers, where recognition and promotion may be rewarded as they perform the more direct functions? A significantly higher achievement lifestyle score by NASA technical managers, when compared with other groups, should indicate high performing NASA $R$ \& $D$ managers have a greater achievement orientation in their self-concept than NASA non-technical managers or Lafferty engineers, supervisors, or managers have in their self-concept construction.

The first three null hypotheses are:

1. There is no significant difference between the mean satisfaction concern self-concept score of the NASA technical managers and the NASA non-technical managers' mean satisfaction concern self-concept score.

2. There is no significant difference between the mean humanistic-helpful lifestyle selfconcept score of the NASA technical managers and the NASA non-technical managers' or the Lafferty engineers', supervisors' or midlevel managers' mean humanistic-helpful lifestyle self-concept scores.

3. There is no significant difference between the mean achievement lifestyle self-concept 
score of the NASA technical managers and the NASA non-technical managers' or the Lafferty engineers', supervisors' or mid-level managers' mean achievement lifestyle self-concept scores.

Security variables. In contrast to satisfaction concerns, self-concept security concerns are believed by researchers to be more negative in their effect on both the performance of employees and managers. Security concerns are understood to focus human thought and energy on protecting the status quo and not on constructive adaptation to change or problem solving. Much discussion has been provided on the security orientations of the bureaucratic cultures found in large government and private organizations. While NASA had a reputation of being "less bureaucratic" than other federal agencies during the early years following their organization in 1958, throughout the "man-on-the-moon" programs, another generation of both managers and programs has come to replace the earlier ones and the agency is now thirty years old. Since much of the NASA mission responsibility rests upon technical managers, are there any indications that there are unusually high security concerns within these managers? A significantly higher NASA technical manager's security concern score, when compared with NASA non-technical managers, would appear to indicate high performing government $R \& D$ managers have a stronger security orientation in their self-concepts than 
NASA non-technical managers have in their self-concept construction.

According to Lafferty (1980, pp. 19-20), a dependency orientation in self-concept is believed to be especially a liability to management. Dependent managers may be extremely compliant and over-appreciative of attention from people in authority. This style indicates a need to avoid threatening situations or challenging others. Since there would appear to be a great deal of contemporary dependency by NASA on both Congress for funds and contractor groups for innovative $R \& D$ technical proposals, are there any indications of an unusually high degree of dependency on the part of NASA technical managers? A significantly higher dependency lifestyle score by NASA technical managers, when compared to other groups, should indicate high performing NASA $R$ \& $D$ managers have a stronger dependency orientation in their self-concepts than NASA non-technical managers or Lafferty engineers, supervisors or managers have in their self-concept construction.

4. There is no significant difference between the mean security concern self-concept score of the NASA technical managers and the NASA non-technical managers' mean security concern self-concept score.

5. There is no significant difference between the mean NASA technical managers' dependent lifestyle self-concept score and the NASA non-technical managers' or the Lafferty engineers', supervisors', or mid-level managers' mean dependent lifestyle selfconcept scores. 
Task variables. Much has been written in management literature about the importance of task functions in organizations (Drucker 1954; Carroll \& Tosi 1973). Organizations which have a low task orjentation within their management cultures generally find that they have lower productivity. While the importance of task is emphasized by NASA's top management, the question arises: Are task concerns more important in the self-concepts of the NASA technical managers than in the self-concepts of the NASA nontechnical managers? No significantly higher or lower task concern score by NASA technical managers, when compared to the NASA non-technical managers, should indicate high performing government $R \& D$ managers have no stronger task motivation in their self-concept than NASA non-technical managers have in their self-concept construction.

The value of a competence self-concept orientation is not equally affirmed by all management scholars. Some scholars like Hall (1980b), Shtogren (1980), Anthony (1981) and Boyatzis (1982), emphasize the importance of competencies. Lafferty (1980, pp. 29-30), on the other hand, values competence but sees dangers inherent in a manager's pursuit of competence. According to Lafferty a manager who pursues competency is likely to reject emotional types of communication and seek task ability (not excellence) as the best source of security and satisfaction. He may rigidly enhance his position by developing a narrow-minded pursuit 
of a task. Any past failure may result in self-blame, because his internal standards may be too high for any human being to reach. Does the emphasis on excellence within the NASA technical management result in any indications of an unusually high degree of competence orientation? A significantly lower competence lifestyle score, when compared to other groups, should indicate high performing NASA R \& D managers have a lower degree of "competence" orientation in their self-concept than NASA non-technical managers, Lafferty engineers, supervisors or managers have in their self-concept construction.

6. There is no significant difference between the mean task concern self-concept score of the NASA technical managers and the NASA non-technical managers' mean task concern self-concept score.

7. There'is no significant difference between the mean competence lifestyle self-concept score of the NASA technical managers and the NASA non-technical managers' or the Lafferty engineers', supervisors' or mid-level managers' mean competence lifestyle selfconcept scores.

people variables. While the importance of people concern has been emphasized by a number of scholars (McGregor 1960; Blake and Mouton 1985), most scholars are quick to point out that limits must be set to the expression of these concerns in organizations. Managers with high people selfconcept concerns may not be able to function without obtaining approval from the "last dissenting individual" or may

Reproduced with permission of the copyright owner. Further reproduction prohibited without permission. 
not be able to change from conventional thinking. Do NASA managers evidence any unusually high people self-concept concerns? A significantly higher people concern score, when compared to NASA non-technical managers, should indicate high performing NASA $R \& D$ managers have a stronger people motivation in their self-concept than NASA non-technical managers have in their self-concept construction.

A people concern lifestyle that has gained attention in management science is that of an affiliation orientation. Lafferty has found that managers with high affiliation orientations tend to rely on good feelings and evidences of friendship as measures of group performance and management effectiveness. Conflict is avoided and signs of disagreement or dissatisfaction are likely to be overcome with kindness and praise. Performance evaluation and the definition of organizational objective are often difficult for managers with a high need in this area. Dô the self-concepts of NASA technical managers carry a higher need for affiliation than other groups? A significantly higher score in affiliation lifestyle by NASA technical managers, when compared to other groups, should indicate high performing NASA R \& D managers have a stronger affiliation orientation in their selfconcept than NASA non-technical managers, Lafferty engineers, supervisors and managers have in their self-concept construction.

8. There is no significant difference between the mean people concern self-concept score of

Reproduced with permission of the copyright owner. Further reproduction prohibited without permission. 
the NASA technical managers and the NASA nontechnical managers' mean people concern self-concept score.

9. There is no significant difference between the mean affiliation lifestyle self-concept score of the NASA technical managers and the non-technical managers' or the Lafferty engineers', supervisors' or mid-level managers' mean affiliation lifestyle selfconcept scores.

Self-actualization variable. The integration of task and people concerns is believed critically important to management by many scholars (Blake and Mouton 1985; Hall $1974 \mathrm{a}, 1974 \mathrm{~b}, 1980 \mathrm{a})$ Further, it is believed essential that managers find ways to self-actualize in order to enhance individual and, thus, organizational performance (Maslow 1965; Garfield 1986). Lafferty (1980) believes that managers particularly effective in integrating task and people concerns in organizations will demonstrate higher self-actualization scores on the instrument. Do NASA technical managers indicate higher self-actualization orientations? Due to the highly technical nature of the agency's mission, it would appear that NASA technical managers might have more opportunity to self-actualize than non-technical managers. A significantly higher self-actualize lifestyle score by NASA technical managers, when compared to other groups, should indicate that high performing NASA $R$ \& $D$ managers have a stronger self-actualize orientation in their self-concept than NASA non-technical managers, Lafferty engineers, super- 
visors and managers have in their self-construct constructions.

10. There is no significant difference between the mean self-actualize lifestyle selfconcept score of the NASA technical managers and the NASA non-technical managers' or the Lafferty engineers', supervisors' or midlevel managers' mean self-actualize lifestyle self-concept scores.

Strain Related Variables. The next set of hypotheses compares the lifestyle self-concept profile scores of NASA technical managers with debilitating illness self-concept profile scores of three Lafferty samples. While it is not considered probable that NASA technical managers as a group should reveal any tendencies typical of the self-concepts associated with these stress illnesses, it is believed important to measure and understand the significant differences which separate the NASA profile from the strain profiles of these three groups. Strong relationships between an achievement orientation, individual performance, organization performance, and reduced cases of depression, heart attacks and ulcers have been found, but there are other characteristics of each illness profile which needs to be compared with the NASA technical managers' sample. Lafferty's (Cannarsa 1988) profile of a depressed person (Chapter Five, Table XIV) reveals unusually high approval and dependent orientations. Mean scores in the oppositional lifestyle exceed the seventy-fifth percentile and 
mean scores in the avoidance lifestyle reaches the ninetieth percentile. In contrast to these lifestyles, other depressed person 1 ifestyle scores are typically well below the mean. Scores by NASA technical managers similar to the typical lifestyle scores for depressed persons would indicate a self-concept construction which may be susceptible to depression.

The research on ulcers indicates that they can be created by recurring and sustained feelings of helplessness. Lafferty's (Cannarsa 1988) profile of a high-risk ulcer victim (Chapter Five, Table XV) indicates a power orientation and a mean competence lifestyle score which exceeds the seventieth percentile of all respondents. The high scores on two opposite lifestyles of the circumplex model (competence and conventional) are indicative of strong self-defeating thought. Scores by NASA technical managers similar to the lifestyle scores for victims of ulcers would indicate a self-concept which may be susceptible to ulcers. In contrast, Lafferty's (Cannarsa 1988) typical profile of a high-risk coronary victim, those with high blood pressure (Chapter Five, Table XVI), depict again a high percentage of respondents with a competence lifestyle exceeding a mean of seventy-five percentile, as well as high means in most other lifestyles, excepting self-actualize, helpfulness and affiliative lifestyles. Scores by NASA technical managers similar to the lifestyle scores for coro- 
nary victims would indicate a self-concept construction

which may be susceptible to coronary illness.

The null hypotheses for these tests are:

11. There is no significant difference between the rank order of the NASA technical managers' general population percentiles of their twelve lifestyle means and the rank order of of the Lafferty depressed individuals sample's general population percentiles of their twelve lifestyle means.

12. There is no significant difference between the rank order of the NASA technical managers' general population percentiles of their twelve lifestyle means and the rank order of the Lafferty ulcer victim sample's general population percentile of their twelve lifestyle means.

13. There is no significant difference between the rank order of the NASA technical managers' general population percentiles of their twelve lifestyle means and the rank order of the Lafferty high blood pressure sample's general population percentiles of their twelvè lifestyle means.

Biographical Relationship. The final set of four hypotheses compares the association between the NASA technical managers' biographical variables and their concern/life-styles self-concept variables. The number of biographical variables was limited in the study in order to accommodate the program time available for respondents to complete both the instrument and questionnaire. Biographical variables were selected by agency training program management after considering which attributes of the 
managers' employment history might provide a significant influence on the life style variable tests.

While the association of sex with the self-concept variables are examined, no hypotheses were derived for testing these associations. This is due to an expected low number of female managers, a generational phenomena. Future studies should contain increased female participation and provide better research opportunities on this relationship. If higher, or lower, levels of a concern or lifestyle are artifacts of a NASA $R \& D$ manager's age, tenure, years in grade or management experience, than significant differences should be indicated between the means of lifestyle variables from two groups--groups consisting of managers respectively higher and lower than the means for each of these biographical variables. The knowledge of any existing relationships should be useful for program managers in determining the alternative courses of action previously mentioned on page 6 .

14. The mean concern or lifestyle scores for NASA technical managers older than the mean age is not significantly higher or lower than the respective mean concern or lifestyle scores for NASA technical managers younger than the mean age.

15. The mean concern or lifestyle scores for NASA technical managers with greater than the mean number of years tenure is not significantly higher or lower than the respective mean concern or lifestyle scores for NASA technical managers with less than the mean number of years tenure.

Reproduced with permission of the copyright owner. Further reproduction prohibited without permission. 
16. The mean concern or lifestyle scores for NASA technical managers with greater than the mean number of years time in grade is not significantly higher or lower than the respective mean concern or lifestyle for NASA technical managers with less than the mean number of years time in grade.

17. The mean concern or lifestyle scores for NASA technical managers with greater than the mean number of years management experience is not significantly higher or lower than the respective mean concern or lifestyle for NASA technical managers with less than the mean number of years management experience.

\section{RESEARCH SUMMARY}

In chapter I, difficulties in the theoretical use and application of a self-concept construction are described and brief summaries of several applications of related and effective self-concept research in areas affecting management science are'set forth. The lack of scientific research on the self-concept competency of government $R \& D$ managers is explained. It is argued that research on the selfconcepts of NASA $R \& D$ managers should be useful in determining intervention strategies for organizational design and management development programs. This is followed by an overview of the NASA sample construction and a description of the Lafferty Level 1: Lifestyles Inventory SelfDescription instrument used to measure self-concepts in the study group. Finally, seventeen hypotheses are stated which 
attempt to develop a more definitive understanding of the existing self-concepts in high performing $R \& D$ managers. Chapter II consists of a review of the literature on self-concepts, including the antecedents, scientific development, empirical research in theories leading to an application of self-concept in management practice. At the conclusion of the chapter a definition of self-concept is set forward for operational use.

Chapter III consists of an overview of existing literature pertaining to self-concept and management theory The derivation and definition of self-concept competency is explained. The final section summarizes the questions about the self-concept competency of $R \& D$ managers which arise from a review of the literature.

Chapter IV describes in detail the specific research design, including a further discussion of the sample selection, instrument, methods and procedures and problems encountered.

Chapter $\mathrm{V}$ describes the results of the data analysis conducted in the testing of the research hypotheses. Chapter VI discusses the results of the research as they relate to management theory and practice in government research and development organizations, particularly with relation to management and organizational development and to organizational design. 
Chapter VII provides a summary of the study and specific conclusions regarding management and self-concept competency. It also includes general conclusions and recommendations for additional areas of research. 


\section{CHAPTER II}

\section{THE LITERATURE OF SELF-CONCEPT}

This chapter sets forth a review of important contributions to the literature on self-concept under the following four categories:

1. Historical antecedents to the scientific study of the self-concept in Western thought; ${ }^{1}$

2. Origins of self-concept in the sciences;

3. Empirical research on the self; and,

4. Definition of self-concept.

These contributions are fundamental to an understanding of literature on the relationship between management and selfconcepts, which will be reviewed in chapter III.

\section{HISTORICAL ANTECEDENTS OF SELF-CONCEPT IN WESTERN THOUGHT}

Much of the literature containing information about how ancient man viewed the idea of "self" has not survived the carelessness of time. What has survived about men's conceptualizations of their selves is often reviewed and

\footnotetext{
${ }^{1}$ Ancient mythologies and literature include a cognitive portrayal of the self-concepts of men as well as an emotional basis (Barbour 1974; Douglas 1973). It is not within the scope of this literature review to provide an exhauscive, anthropological study of ancient self-concepts.
} 
analyzed in the humanities. ${ }^{2}$ Pre-empirical literature reveals the emergence of "self" concepts which came to be absorbed into the theoretical paradigms (Kuhn 1970) of modern scientific research.

The most important early Western literature contains the thoughts of the classical Greek philosophers--Socrates and Aristotle. Socrates in dialogue with his students taught, "know thyself." He explained that "there are many ways in which the ignorance of self may be shown...in money, in attractiveness, and in virtues" (plato c355 b.c.e.). Aristotle noted that "the mind is thinkable in exactly the same manner as other objects are" (c330 b.c.e.). These Greek scholars provided an early humanistic rationale for self-know ledge.

In contrast to many humanistic philosophers, yet similar to other middle-eastern cultures, Hebrew thinkers generally viewed the self as a conscious entity, distinct from the physical body, sometimes as an immortal "soul."3 This entity could come under the immediate and occasionally prolonged control of external self entities--supernatural "spirits," including the Spirit of God, who would compel the "possessed" individual to perform certain thoughts and actions. These supernatural spirits were often viewed as

${ }^{2}$ An excellent example of humanities research on the subject is the study of ideas on mans" "perfectibility" by Passmore (1970).

${ }^{3}$ Ezekie] 18.

Reproduced with permission of the copyright owner. Further reproduction prohibited without permission. 
irrational in their effects on the individual, ${ }^{s}$ but not always. "Wisdom," a rational, competent spirit is viewed as actively controlling the thoughts and deeds of reflective individuals to their benefit. 5

The early Christian sect believed that the spirit of the resurrected "Son of God," Jesus, possessed the "selves" of "believers." Disciples of Jesus were encouraged to be transformed with a new mind. ${ }^{6}$ and to experience a spiritual possession or "new birth" of God's self in their souls." This new mind is that of an immortal, competent and virtuous "servant" self, as distinct from the naturally "sinful," or incompetent, human self. ${ }^{3}$ Variations of the christian self-concept have predominated in Western religious culture and thought until the present time.

The literature of Rome and the early middle ages emphasized the rational basis of the human self. Epictetus observed that the rational faculty of man is unique among human faculties in making possible a right judgment of one's own appearance $(\mathrm{c} 125)$. Aurelius believed rationality made it possible for a soul to "see" itself, and to make of itself what it chooses (c175). The Christian scholar Augus-

${ }^{4}$ I Samuel 16:14.

sproverbs.

${ }^{6}$ Romans 12:1-3; I Corinthians 2:10-16.

${ }^{7}$ I John 3:5-8; Ephesians 4 and 5 .

${ }^{8}$ Galatians $5: 16-26$

Reproduced with permission of the copyright owner. Further reproduction prohibited without permission. 
tine speculated on the importance of a rational self by observing that:

t...human nature loves the knowledge of its exis-
sane mind than be glad in madness (Augustine c426).
By the end of the medieval period, the rational was still considered important to an understanding of the self, but questions persisted as to how a rational man understands that his self exists. Aquinas believed that the first thing understood by a person's intellect is its own action of understanding. He argued that the intellect does not know itself by its essence but by its action (c1273). The action of the intellect was reaffirmed as an essential part of the self.

It became a lesson to kings and scholars that selfknowledge was the starting point of leadership effectiveness. Machiavel1i (1513), the shrewd fifteenth-century author and statesman, believed to attempt to lead without first having a knowledge of self was foolhardy and sure to bring disaster and defeat. But for the common man to pursue an understanding of his self was also considered foolish and of no value.

The Renaissance and Reformation brought new stimuli to men to explore their potential and to develop new self theories. These conceptualizations still largely required a social legitimization by either an institutional church or 
by a state authority. Perhaps no figure in history had greater influence toward the individual's development of self knowledge than Montaigne. The Frenchman dryly observed that, "A man who knows himself will never mistake another man's work for his own." He believed that no description was more difficult, nor of any more utility, than one's self description. He noted that custom prevents men from doing this and deplored the attempts by others to divert him. He derided the argument that it is only appropriate for great and famous men to write about themselves. He subnitted that he was not setting forth his self-description as a "statute" but rather as a means to his own self-improvement. Montaigne wrote that if the world finds fault that he speaks too much of himself, he finds fault that they do not think of themselves at all (1588). Montaigne's boldness seemed to bring forth an abundance of literature on the self during the Enlightenment of the seventeenth and eighteenth centuries.

The British Sir Francis Bacon emphasized the diversity of self-knowledge. He thought that men ought to consider their own abilities and natures impartially, particularly in consideration of the following self-knowledges:

1. How their nature compares with that of the the times.

2. How their nature compares with the professions.

3. How their nature compares with their competitors.

4. How their nature compares with their friends.

5. How their nature sets an example (Bacon 1605). 
He confidently exclaimed, "The knowledge of ourselves has many branches" (Bacon 1605).

Thomas Hobbes' observation on the importance of motivation to the understanding of the self is a milestone of scholarship. He declared that we may discover men's motives by comparing them with our own motives and distinguishing all circumstances by which the cases may come to be altered (1651).

Descarte had a different dilemma in attempting to understand a concept of himself which resulted in the rethinking of the limits of man's rationality. He considered that he might possess no senses and that his body, figure, extension and places were possibly fictions of the mind. If this were considered true, how could anything be perceived as true? The answer for Descarte was by the action of boldly asserting the postulate that his self exists. "I think, therefore I am." The very fact that he doubted, and therefore thought, meant that he must exist (1641).

Locke, writing at the end of the seventeenth century believed that Descarte's question of man's rationality could be answered differently. He argued against those who believed that men have native ideas and original character stamped upon their minds from their very first being. To Locke, men arrived at birth with a blank slate (tabula rasa) on the knowledge of the world but knew of their own existence by intuition. "I think, I reason, I feel pleasure and 
pain: can any of these things be more evident to me than my own existence" (Locke 1690). To Locke self-knowledge was a different form of knowledge than that knowledge of other things perceived through the actions of sensation.

The idea of the human self was elusive to David Hume.

For my part, when I enter most intimately into what I call myself, I always stumble on some particular perception or other, of heat or cold, light or shade, love or hatred, pain or pleasure. I never can catch myself at any time without a perception, and never can observe anything but the perception (Hume 1740).

Despite his difficulty with defining the human self, Hume believed man to be by nature a social being. This implied to him that the human had a sex instinct which initiates the social process, develops through feelings and emotions, and finally comes under control of the rational. Hume came nearer to modern psychological sociology than any other man prior to the nineteenth century.

Jean Rousseau (1755) emphasized the comparison of species in his comments on the human self. The repeated relevance of various beings to men, and of men to men, gave rise in the human mind to the perception of certain relations between them. He noted that these relations are often expressed by the terms great, small, strong, weak, swift, slow, fearful, bold, etc. Man compared his specie to the other animals and found it to be the "highest" order, preparing the way for man's assumption of pre-eminence as an individual.

Reproduced with permission of the copyright owner. Further reproduction prohibited without permission. 
To Emmanuel Kant the Enlightenment was man's emergence from his self-inflicted immaturity--from his reliance on external authorities and reluctance to use his own reason.? He asked how man's self can have an internal intuition of itself? To the philosopher, Kant, the consciousness of self was the simple representation of the "ego." In contrast to Locke, Kant believed the form of self knowledge lay in the original constitution of the mind. The mind looks at everything through its form of intuition and biologically constructed categories of thought. Man's self conception is therefore ordered by the natural structure of this thought processes due to the nervous circujtry of the brain. The mind is no helpless tabula rasa but a positive agent, reconstructing man's self-experience as it arrives (1781). Few ideas in history have had the impact of charles Darwin's evolutionary approach to nature (1859). In all disciplines, including that pertaining to self theory, his approach to the evolution of specie provided new criteria for thought. The popular catchwords of Darwinism, "struggle for existence" and "survival of the fittest," when applied to the life of man in society, seemed to suggest that nature would provide that those with the most competitive self concepts would win, and that this process would lead to continuing improvement. To William sumner, just as survival

'Emmanuel Kant. Beantwortung der frage: was ist aufklarung? Berlinische monatsschrift. Berlin. Gesammelte Schriften, 1784, VIII, p. 35. Quoted in Brown (1968).

Reproduced with permission of the copyright owner. Further reproduction prohibited without permission. 
was the result of strength, success was the reward of virtue. Competition is a natural law as universal as the law of gravitation (1934), and a law which men ignore only to their own peril. Competency was important for the law of the survival of the fittest could have no meaning unless men's selves and bodies are presumed unequal. This perspective was to provide an important foundation for management science as it originated in the late nineteenth and early twentieth century.

Frederich Nietzsche (1889) believed the ultimate test of a self--of a man, of a group, or of a species--is biological energy, capacity and power. The goal of human society should be the development of finer and stronger individuals with superior self-concepts. Nietzsche failed to recognize the value in social instincts. He believed that the self theories of "supermen" must be reinforced by external philosophies of egotism and individualistic impulses (Durant 1962). Nietzsche himself died insane.

The poet Robert Burns (1897) summarized the common curiosity about the self in writing a poem about observing the twitching and squirming of a genteel woman in church responding to the sensations of an undetected louse crawling on her body.

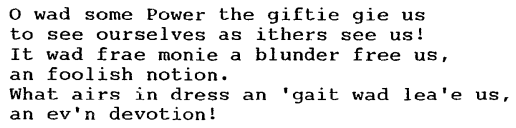

Reproduced with permission of the copyright owner. Further reproduction prohibited without permission. 
The evidence of antecedent literature provides an uncompleted mosaic on the history of the self-concept. No unified structure or process of the self emerges. Further, a strict scientific method had yet to be applied in the analysis of men's self theories. But these early writings, and others, provide much of the stimulus and ideas that the newly developing behavioral sciences use in the theoretical construction of the self-concept.

\section{ORIGINS OF SELF-CONCEPT IN THE SCIENCES}

The science of Psychology developed in the nineteenth century as a child of philosophy and medicine. ${ }^{10}$ Early psychology can be divided into two distinguishably different groups--personality theorists ${ }^{11}$ and the experimental psychologists, who tended at first to pursue a "stimulusresponse" model of of investigating human behavior. It was clear that early experimental psychology had little to say about the problems of interest to personality theorists who in turn had little interest in the problems of importance to the experiment psychologists. Both schools were largely indebted to Darwin's scientific influence and developed their own empirical rigor (Hall and Lindzey 1970, pp. 12-13). From experimental psychology, learning theorists in par-

\footnotetext{
${ }^{10}$ The experimental physiology branch of medicine. ${ }^{11}$ Early personality theorists were largely clinicians.
}

Reproduced with permission of the copyright owner. Further reproduction prohibited without permission. 
ticular grew to join personality theorists in the study of the self. This is not to imply that modern self theory has not been influenced by an understanding of behavioralist research.

Consistent with the critical scientific thought of the times, many early behavioral psychologists questioned the existence of a human self, fearing that the term was an artifact of the ancient mythological understanding of the soul and spiritual possession. Stephenson (1953) took issue with the behavioralist's doubt over the existence of a human self and on the value of psychological research on the subject. He argued that an individual could think and talk about himself just as he thinks and talks about other things. Stephenson believed that self-reflections are as much a part of behavior as anything else the individual does. The relative importance of the conscious and unconscious construction of the self had been an ancient debate ${ }^{12}$ and it emerged again as an issue in the study of the human "psyche" (psychology) and in studies of human society and organization (i.e., sociology, etc.) (Wylie 1961, pp. 1-5).

Theories of the Unconscious Structure of the Self

On the issue of self construction, Freud supported the importance of the unconscious determinants of behavior.

\footnotetext{
${ }^{12}$ In early writings this issue was discussed in terms of the relative rationality or irrationality of man.
} 
Freud believed that the unconscious is the true psychic reality; in its inner nature just as much unknown to us as the reality of the external world, and it is just as imperfectly communicated to us by the data of our consciousness as in the external world by the reports of our sense organs (Freud 1900). Psychoanalysis is first learned on oneself, through a systematic study of one's own personality, avoiding "self" perceptions and studying disturbances and disintigrations of the ego. ${ }^{13}$

Freud observed that there are people in whom the mental faculties of self-criticism and conscience rank exceptually pronounced. The faculties are unconscious and unconsciously produce guilt effects of the greatest importance which influence behavior and men's conscious ideas about themselves. Freud's emphasis on the study of the unconscious determinants of the self led to a new understanding of being human (Hall and Lindzey 1970, pp. 29-77).

Like Hume, Freud believed in the importance of the sexual drive which is a major impulse and must be controlled by the ego system of the self. An evaluation of the ego's ability to control sexual disturbances toward disintegration of the self was a major thrust of Freud's research.

Freud also initiated much research on the nature of personality "identification." Identification can be defined

${ }^{13}$ To Freud, the self is equal to the interaction between the id, ego, and superego systems. 
as the incorporation of the qualities of an external object into one's self.14 A person who identifies with another person will begin to resemble that person in his (or her) thought and behavior. A child who identifies with his parent will assimilate the characteristics of his parent. According to Freud, the tendency to copy and imitate persons is an important factor in molding the self and for him there were five different processes (Hall 1954, pp. 74-78):

1. Narcissistic Identification: One's self love identifies with other persons who have similar physical or mental characteristics as the self has and one's self begins to take on new thoughts and behavior generalized from these other persons.

2. Goal-oriented Identification: One's self identifies with the goal of another person resulting in an increasing generalization by the self to the characteristics of this other person in the process of pursuing the common goal.

3. Object-Loss Identification: One's self attempts to "recover" a lost loved person by making himself/herself like the other person.

4. Authority Identification: One's self identifies with an authority figure and one's thoughts and

${ }^{14}$ usually a person.

Reproduced with permission of the copyright owner. Further reproduction prohibited without permission. 
behavior begins to match the authority figure out of fear rather than love.

5. Eating Identification: A primitive desire to eat something in order to be like that eaten. ${ }^{15}$

Identification "constructs" the self by producing resemblances between a person and other people. To Freud, the motive force for identification, aside from the narcistic variety, is provided by frustration, inadequacy and anxiety (feelings of incompetence) in order to maintain mastery of ideas tending to disintegrate the self.

Erik Erikson, in the neo-Freudian tradition, emphasized self identity. Self identity emerges from all those unconscious experiences in which a temporary diffusion of self-concept was successfully contained by a renewed and more realistic self-definition and social recognition. Erikson describes a series of eight biologically and socially ordered crises and stages which must be resolved by the self in his or her lifetime in order to maintain a healthy integration of self $(1950)$. It is important to understand that Erikson is asserting that this is a largely unconscious process, or that the individual is not engaged in a conscious, rational analysis. He points out that under stress man is capable of taking on a regressive, even punitive self-concept. Further, he believes that environ-

${ }^{15} \mathrm{~A}$ native hunter eats the heart of a lion in order to become as brave as a lion. A Christian takes the wafer and wine to become like Jesus (Hall 1954, p. 78).

Reproduced with permission of the copyright owner. Further reproduction prohibited without permission. 
mental conditions of smoldering guilt and open violence often threaten all human adaptedness or competence. Erikson has pointed out that case histories in counseling rarely take into account a patient's life work. He points out that even in the most gifted minds, experience must validate verifiable fact by way of a mutual reinforcement within a unified world image. ${ }^{15}$ Erikson found himself studying the lives of religious innovators that border areas where neurotic and existential conflict meet and where the self struggles for conscious awareness of a new self theory (1975, pp. 98-109).17

\section{Theories of the Conscious structure of the Self}

In contrast to Freud, William James (1890) asserted that the central part of the self is felt. The entire feeling of the self was one of bodily activities. The experience of self and "not. self" can only be known through reflection on sensual data. It is only through the exertion of its own powers that the mind become aware of its existence. At a certain age the child begins to identify objects as "me" or "mine." James believed this is the child's first awareness of having a self, and is preliminary to a child's development of a "social" self through his evaluation of other selves.

${ }^{16}$ See also Frankl (1963).

${ }^{1.7}$ Gandhi and Luther.

Reproduced with permission of the copyright owner. Further reproduction prohibited without permission. 
Properly speaking, a man has as many social selves as there are individuals who carry an image of him in their mind...he has as many different social selves as there are distinct groups of persons about whose opinion he cares (James 1970, p. 374).

If the "me" is understood as the object, then the "I" is that portion of the person that does the viewing--the subject. The "I" and "me" achieve a quality of consistency from day to day and connectedness from role to role. Taken together they function to determine the feeling of the self that the individual has (James 1970, p. 374).

To Charles Cooley (1970, pp. 81-135), the selfidentity of each person awaits one's feeling of control over the immediate environment. This self-identity is an enduring creation which reaches a position from which one can, to a degree, imagine how he or she appears to others. The child begins to anticipate the actions and thoughts of others.

Cooley's theory of child development led to his theory of the "looking glass self" (1970, pp. 211-263). This theory encompassed three dimensions:

1. People make a self-presentation and try to imagine the impression formed of themselves by other persons.

2. People imagine a judgment of their selfpresentation.

3. People experience an emotional reaction to this reflected evaluation.

Reproduced with permission of the copyright owner. Further reproduction prohibited without permission. 
Two implications of Cooley's theory made an impression on George Herbert Mead--selectivity and reflectivity. Mead, recognized as the founder of the symbolic interactionist school of theory, believed that each person reacts selectively to his environment giving each insight a slightly different perspective (Adler and Adler 1980, pp. 30-34). We also employ our reflective nature to continually engage in an internal dialogue, plotting out possible scenarios and courses of actions that can be modified or revised at any time but which result in some form of social action. Mead rejected the simple "stimulus-response" formula of behaviorism for a "stimulus-organization-response" model. Like Dewey (1922), he believed that learned symbols of the self--that is, self-images--were very important in determining what individuals do. One could say that individuals who have been taught to think of themselves as "tough" and "agressive" will do tough and agressive things.

Phenomenologists are more concerned with the ways in which individuals consciously construct a personal meaning of things. They see the social world as made up of many more individual constructions than do the symbolic interactionists who emphasize the ways in which significant others influence individuals to share symbols and, therefore, common patterns of action (Douglas, et al 1980, pp. 17-18). Berger and Luckmann (1966) describe a three step phenomenological process in the development of the conscious self.

Reproduced with permission of the copyright owner. Further reproduction prohibited without permission. 
1. Externalization: The self's nature is expressed to activity resulting in social forms and patterns.

2. Objectivation: Human activity is expressed to the self in a form that confronts the actor as objective or apart from himself.

3. Internalization: The objective world is incorporated into the self's consciousness in the process of socialization.

Theories of the Holistic structure of the Self

Carl Jung believed the self unifies the conscious and unconscious aspects of personality holding all the self's systems together. The self's desire for unity motivates man's behavior and causes him to search for wholeness. To assist man there are some unconscious symbols, which he inherits biologically, which assist him in unifying the self. ${ }^{13}$ At the center of Jung's theory of the self (1953) are three pairs of important and opposing self attributes. A person's self may be described as somewhere between the two relative ends of the continuum of each pair (O'Brien $1985): 19$

${ }^{18}$ mandala symbol (Jung, et al. 1964). See also LeviStrauss (1963a; 1963b), Eliade (1961) and Neumann (1954).

19Jungian self-concept theory is often represented in contemporary psychology through Temperament Theory (Myers 1962, 1980; Keirsey and Bates 1984).

Reproduced with permission of the copyright owner. Further reproduction prohibited without permission. 
1. Extroversion/Introversion: The introvert is reflective on experience (relatively conscious) while the extrovert in unreflective and action oriented (acting without consciousness).

2. Sensation/Intuition: The sensing person is a systematic, detail conscious literal. The intuiting person has insights, sees future possibilities in an effort to get the big picture, without conscious thought of the details or elements of the system.

3. Thinking/Feeling: Once information is obtained, the thinking person is logical and objective. The feeling person makes judgments from an unconscious set of values and standards.

Another important development in holistic self theory was the development of literature on "life styles." To Adler (1931) the style of life is the principle of organization by which the individual self functions and the "whole" that commands the parts. Adler believed that men's selves shared the common goal of superiority 20 but that there are many ways of pursuing this goal. An intellectual has one style of life and an athlete another. All of an indivi-

20 Adler's idea of superiority in humans should be compared and contrasted with modern Biosocial Theories of Aggression emphasizing biological responses to population density as manifested by humans through territoriality and hierarchy (Van den Berghe 1974). 
dual's behavior flows from their style of life and one perceives, learns, and retains what is congruent with this life style, ignoring everything else. The style of life is a compensation for a particular inferiority (incompetence). If a child is physically weak his thinking style wili be one to produce physical strength. If a child is dull it will be to achieve intellectual superiority (Hall and Lindzey 1970, p. 126).

Goldstein (1939) believed that a normal, healthy organism is one where "self-actualization" comes from within, overcoming the disturbances arising out of its conflict with the environment. Actualization expressions are the competent performances of the organism in managing the environment. Abraham Maslow was influenced by Goldstein in his research on the healthy self. Maslow believed man's inner nature is not strong and overpowering like the instincts of animals, but weak and delicate. It is easily overcome by habit, cultural pressure and hostile attitudes. But given permission by the environment, man's self may press toward its actualization (1968).

Car1 Rogers (1961, pp. 225-270) argued that a person cannot actualize himself unless he is able to discriminate between progressive and regressive ways of behaving.21

${ }^{21}$ Keirsey and Bates (1984, p. 60$)$ state that after lower order needs are satisfied, not all individuals seek self-actualization. Only persons with intuitive-feeling temperaments, comprising about $12 \%$ percent of the U.S. population, can be motivated to seek self-actualization. 
There is no inner voice that informs him which is the forward or correct path. Man's needs may evoke appropriate behavior even though the needs are not consciously symbolized or experienced. If self and experience are incongruent, then man's unconscious may work at cross purposes to defeat a motive's subsystem to actualize the self. Human experience at any given time constitutes the phenomenal field only known to the person himself. How the individual behaves depends on this phenomenal field (subjective reality). The phenomenal field at the time of behavior is made up of conscious (symbolized) and unconscious (unsymbolized) experiences. A man's self may discriminate and react to an experience not symbolized, frustrating his attempts to actualize around a symbolized goal. Further, some perception may remain untested, or inadequately tested by the self, causing the man to behave inappropriately (Rogers 1959). Rogers created a strong argument for the importance of understanding the development of perceptions (cognitions). It became increasing clear that learning theories could make important contributions to understanding how an individual comes to think about himself.

\section{Theories of Cognitive Learning by the Self}

Jean Piaget (1965) believed the maturational development of the self is through a series of cognitive stages requiring a sequence of certain social and sensual experiences 
(Pulaski 1971; Beard 1972). For Piaget, adaption is the essence of both biological and intellectual functioning. In contrast to Darwin's meaning of the "survival of the fittest," Piaget's meaning implies more than just survival. piaget teaches that man modifies the environment to his own ends. An essential part of man's biological inheritance is a mode of intellectual functioning which develops in stages and tends to be relatively constant for long periods of time, perhaps nearly a lifetime. This functioning is characterized by the self's ability to organize the myriad of sensations and experiences encountered into some kind of order. The self adapts to his/her environment by means of the dual and continuous processes of assimilation and accommodation.

Piaget believed that accomodation is the outgoing process of changing a person's mental schemata (structures of perceiving, understanding and thinking about the world and oneself) in order to adapt to new experiences. It is the process of accomodation by which a person improves his schemata (i.e., child, adult, scientist). Although some degree of accomodation goes on constantly, schemata tend to be relatively stable.

Even more common than accomodation is the process of assimilation where everything we experience is interpreted in the light of what we already know and believe. The mean ing of a stimulus is determined by the existing schemata 
which a person uses to recognize and interpret it. This modification of the stimulus into a part of a person's total cognitive world is what Piaget means by assimilation. When a schemata is stable and can easily assimilate new experiences, a state of equilibrium exists. If accomodation occurs, so that a new schemata can assimilate incongruent experiences, the new equilibrium is established with the intention of better adaptation (Block, 1982). Cognitive-development theories of the self have arisen, influenced by Piaget, which make the following assumptions (Kohlberg 1969, pp. 348-349):

1. Human devejopment involves basic transformation of perceptions which must be explained by the whole systems of internal relations.

2. Human development of perception (cognitive structure) is the result of processes of interaction between the structure of the organism and the structure of the environment, rather than being the direct result of maturation or the direct result of learning.

3. Perceptions are always structures (schemata) of action.

4. The direction of development of cognitive structure is toward greater equilibrium in the organism-environment interaction. 
5. Affective development and functioning and cognitive development and functioning are not distinct domains. They are parallel, representing different perspectives and contexts in defining structural change.

6. There is a fundamental unity of personality organization termed the ego, or the self. Various strands of social development (i.e., psychosexual, moral, etc.) are united by their common reference to a single concept of self in a single social world. Social development is the structuring of the (1) concept of self, (2) in its relationship to its concepts of other people, and (3) conceived as being in a common social world with social norms and rules.

7. Social cognition always involves the awareness that the other is in some way like the self, and that the other knows or is responsive to the self in a system of symbiotic expectations. 8. The direction of self development is toward an equilibrium or reciprocity between the self's actions and those of others.

\section{Theories on the Systemic structure of the Self}

To Allport (1961) it is the system of personality traits rather than the self-concept that is important to 
man's ego involvement. He believed there is no self-concept that acts as an entity distinct from personality traits. Epstein submits that a self-concept is in reality a self-theory. It is a theory that the individual has unintentionally constructed about himself as an experiencing, functioning person, and it is part of a broader theory which he maintains with respect to his entire array of significant experiences. There are major postulate systems for the operation of the world, the operation of the self, and for their interaction (Epstein 1973, p. 407). Self-theory has a conceptual purpose for optimizing the pleasure/pain balance of the individual over the course of a lifetime. Two other functions, which are related to the first, are to maximize the level of self-esteem and to organize the data of experience in a manner that can be dealt with effectively. To Epstein it is important why invalid self-theories are not self-correcting. One reason is that individuals under stress protect their existing organization of selftheory by avoiding attempts to assimilate incongruent information. Another reason a self-theory may not be correcting is because of unconscious repression. If an individual has learned to reduce his anxiety by failing to make certain observations or to use certain symbols with their respective meanings to identify his actions, he has eliminated himself from having experiences that could correct his faulty concepts (Epstein 1973, p. 409).

Reproduced with permission of the copyright owner. Further reproduction prohibited without permission. 


\begin{abstract}
Epstein maintains that recognizing that an individual's self-theory, like any other theory, is a hierarchically organized problem-solving conceptual system, explains its total disorganization when a foundational postulate is invalidated. Once it is understood that a selftheory is necessary to function, and that any theory is better than none, it becomes apparent why people desperately defend unrealistic concepts or values.
\end{abstract}

\title{
EMPIRICAL RESEARCH ON THE SELF
}

The empirical study of self-concept is impeded by two major issues. The first issue concerns the failure of a comprehensive, consistent statement defining the nature of the self-concept (Noppe 1979, p. 2). The second issue concerns the general lack of theoretical integration in the scientific study of the self (Wylie 1961, pp. 2-5). Regardless of these obstacles, several empirical studies on the self have emerged which have a significant bearing on this research. An understanding of their importance is fundamental to exploring the literature on the self-concept in management science, and further research on self-concept.

\section{Cognitive Development Research}

Most cognitive developmental research has used children or adolescents as subjects. A most important research relating to self-concept was completed by Illene Noppe 
(1979, pp. 115-119) who examined the effects of age and levels of cognitive development on the self-concept. The unexpected findings included:

1. Subjects described themselves predominantly in terms of their social roles, relationships, and interpersonal feelings, regardless of age or cognitive level.

2. Cognitive disequalibrium between developmental stages did not result in a measurable decline in self-esteem.

3. Self-concept (theory) is highly related to and influenced by social interaction, age and sex indicating that a careful consideration of the symbolic interaction perspective is in order.

4. Self-concept is best studied from a multifaceted framework. Multiple self-concept instruments are recommended to overcome several measurement problems.

\section{Self-Actualization Research}

As described earlier, Maslow viewed the actualization of the self in an organismic paradigm--the active self, precarious linked to and limited by the environment. Maslow's often used theoretical model proposed five levels of basic needs common to all humans. According to Maslow (1954), the need levels emerge in a hierarchical order, the 
lower needs being satisfied to some extent before the higher needs begin to emerge. Maslow proposed that human needs emerge in the following order, from lower to higher: physiological, safety, love (belonging), self-esteem--to the highest need, self-actualization. Validation studies, such as that completed by Harbaugh (1972), have had several important findings affecting this important model of the self's motivation. Harbaugh found no support for an esteem level apart from the belonging and self-actualization need levels. Four additional findings were confirmed as a result of Harbaugh's analysis:

1. The higher the occupational level, the greater the concern about the higher levels of hierarchy needs.

2. The greater the income the greater the concern about the higher levels of hierarchy needs.

3. The higher the level of education the greater the concern about the higher levels of hierarchy needs.

4. Urban backgrounds tend to be associated with concern about the higher levels of needs of the hierarchy while rural background tended to be associated with the lower levels of hierarchy needs.

Mathes and Edwards (1978) found that Maslow's hierarchical theory of motivation should be modified to include 
only two or three levels. Security was shown to be a prerequisite to self-actualization, while belongingness and esteem were shown not to be essential prerequisites. These finding, together with others (Alderfer 1972; Mitchell and Moudgill 1976), would seem to indicate that selfactualization needs emerge, with or without the satisfaction of belongingness and self-esteem needs, when physiological and security needs are satisfied.

\section{Phenomenological Research}

Several findings derived by Donald Taylor (1.953) in a series of phenomenological studies are significant for an understanding of the self-concept.

1. The self-concept remains relatively stable over time intervals up to $71 / 2$ months.

2. Immediate changes in the external environment do not usually immediately alter the self-concept significantly.

3. Stability of self-concept. for college and adult populations may differ significantly •

4. Traumatic or euphoric experiences may alter the self-concept.

5. Repeated self-description appears to increase the consistency of the self-concept.

6. Consistency of self-concept bears a small positive relationship to positive self-concept.

Reproduced with permission of the copyright owner. Further reproduction prohibited without permission. 
7. Repeated self-introspection tends to result in some reorganization of the self-concept.

8. Most persons have positive self-concepts.

\section{Symbolic Interaction Research}

A group of symbolic interactionist studies have evaluated the congruence (similarity) between an individual's self-perceptions and the way he believes himself perceived by others. A number of these studies have shown that the perceived reactions of others to one's self is closer to one's self-concept than are the actual reactions to the self by others (Miyamota and Dornbusch 1956; Sherwood 1965; Quarantelli and Cooper 1966; Walhood and Klopfer 1971; Orpen and Bush 1974). The minimal associations between self-perceptions and others' actual evaluations reveal that people do not accurately perceive others' opinions of them and that these opinions either minimally influence self-judgments or are curvilinearly related (Reese 1961). Since these studies reported no change over time or direction of influence, it is impossible to assess causality (Shrauger and Schoeneman 1979, p. 558).

The most sophisticated symbolic-interactionalist research remains a study by Manis (Shrauger and Schoeneman 1979, p. 559). His most significant finding was that the subjects final self-ratings were more similar to other's initial ratings of them than to their own initial self- 
rating. In addition, other's second ratings of a subject were no more similar to the subject's initial selfperceptions than were their first ratings.

This suggests that other's impressions were not substantially influenced by a subject's initial selfevaluation. The subject's self-perceptions changed in the direction of a friend's initial judgments of them, but only when the designated friend had initially described them more favorably than subjects had described themselves (Manis $1955)$.

\section{Self-Disclosure Research}

Sidney Jourard (1964, p. 5) has maintained that unless a person makes himself known to others one cannot know his own self. Jourard suggests that people censor their behavior and disclosures in order to construct in the mind of the other person a concept of themselves which they want him/her to have. This type of disclosure can lead to selfalienation or construction of a false self-system (Laing 1962, pp. 73-74). In their research Jourard and Lasakow (1958) found:

1. Men do not disclose as much about themselves as women.

2. Married subjects disclose most to spouses. 3. Subjects tended to disclose more about themselves to people who resembled them in various 
ways than to people who differed from them. The target person in self-disclosure is perceived by the subject as similar to the discloser's self.

\section{DEFINITION OF SELF-CONCEPT}

The human self-concept has been variously defined in scientific research but the idea of a self-concept structured from the various hypotheses one constructs about himself (herself) is most persuasive. The self-concept, therefore, becomes a self-theory consisting of various hypotheses which an individual continually tests and examines in social interaction with other people (Epstein 1973, p. 407) and which range widely in content and scope (Noppe 1979, pp. 115-119). The characteristics of this self-theory include (Epstein 1973):

1. The self is a subsystem of internally consistent, hierarchically organized concepts contained within a larger and more elaborate conceptual system.

2. The self contains different empirical selves, such as an intellectual self, social self, psychological self and physical self.

3. The self is a dynamic construction that changes with experience. It appears to adapt to environmental change and demonstrates a tendency to assimilate increasing amounts of information,

Reproduced with permission of the copyright owner. Further reproduction prohibited without permission. 
thereby manifesting something like a growth principle. It's construction is characteristically more "integrative" than "integrated" (Pepper 1942; Hilgard 1949; Block 1982).

4. The self is constructed out of experience, particularly out of everyday interpersonal relationships with significant others with whom the selff interacts regularly.

5. It is a functional requirement for a person that the construction of the self-concept remain organized. Threats to organization result in anxiety and attempts to defend the self against threats. If the defense is unsuccessful, stress increases to the ultimate result of disorganization.

6. There is a basic motivation for self-esteem which strongly relates to the construction of the self-system.

7. The self-concept has at least two basic functions:

a. The self theorizes the data of experience, particularly interpersonal interaction, into a predictable series of events.

b. The self organizes attempts to fulfill needs while avoiding disapproval and anxiety. 
While the self-concept has an unconscious dimension, which can be difficult for science to evaluate and explain, it is clear that an analysis of an individual's conscious thought orientation (perceptions) can be useful in defining an important part of the individual's self-concept--that part which substantially affects his behavior. The responses to questions about an person's conscious selfconcept can also be useful in determining some of the underlying motivational--and often unconscious--determinants of a person's behavior (Levine 1980; Cook and Lafferty 1981). Management researchers have only recently become generally aware of the value of this knowledge in the development of theory associating the self-concepts which a manager actually possesses with management behavior--either high performing or otherwise. Theories evaluating the association between managers' self-concept and performance are useful in explaining both why managers behave in a certain manner and under what circumstances managers may modify their behavior.

Reproduced with permission of the copyright owner. Further reproduction prohibited without permission. 
CHAPTER III

THE LITERATURE CONCERNING THE SELF-CONCEPTS OF MANAGERS IN RESEARCH AND DEVELOPMENT ORGANIZATIONS

The first section of this chapter will evaluate selfconcept in the literature of management theory and practice leading to a definition of self-concept competency. Following this study, the second section of the chapter will provide a statement identifying some of the questions which arise concerning the self-concept competencies of $R \& D$ managers which the present research will explore. The final section will summarize the present study on the self-Concept Competency of NASA Technical Managers.

\section{SELF-CONCEPT IN MANAGEMENT THEORY AND PRACTICE}

The role of the self-concept in management theory and practice has not been firmly established in professional literature. Generally, a substantial argument has been maintained by many notable scholars and practitioners that an employer has no business with a man's personality.

Employment is a specific contract calling for specific performance, and for nothing else...Management and manager development deal with the skills people need... They should concern themselves with change in behavior likely to make a man more effective. They do not deal with who a 
man is--that is, with his personality or his emotional dynamics... Attempts to change a man's personality are bound to fail in any event. By the time a man comes to work his personality is set. The task is not to change his personality, but to enable him to...perform... (Drucker 1973, p. 3).

This statement reflects the traditional view on defining and utilizing studies of the self in the area of management development. Prior to the 1960 s much research was directed to the skills or behaviors required in a manager's role but little study was given to how a manager perceived himself, or how a manager felt about his activity.

Research in the last twenty-five years, however, has indicated that not all elements of the adult self are fixed and incapable of change, nor is it necessarily in the interest of organizations to insulate their managers from understanding the important elements of their self-concepts. "T-Group" and other management development activities emerged during these years providing organizational leaders an opportunity to examine their feelings, attitudes, and motivations at personality levels underlying the public skill level of performance.

\section{Occupational Preference ${ }^{2}$}

Oppenheimer (1964) found no support for a hypothesis stating that cognitively complex people have a higher degree of similarity between their self-concepts and their occupational preferences than cognitively simple people. This

\footnotetext{
${ }^{1}$ See also Super's theory in Chapter One, pages 3-4.
} 
final finding suggests that cognitively complex people are not more accurate than cognitively simple people in translating their self-concepts and in formulating occupational preferences for management.

Dore (1970) utilized Super's theory in researching managers from a medium sized company and found:

1. The greater the agreement between a self-concept measure and a required self measure (measurement of a manager's role requirements), the greater the job satisfaction.

2. The greater the agreement between a self-concept measure and an ideal self measure, the greater the job satisfaction.

3. The greater the agreement between a required self measure and an ideal self measure, the greater the job satisfaction.

These findings indicate the importance of organizational role expectations (required self measures) and standards of competency (ideal self) to the manager in the emergence of self-concept satisfaction.

\section{Motivation}

Self-concept motives like power, prestige, adventure, need for accomplishment, security, status and professional excellence were recognized but given little systematic treatment in the classical management writings of Barnard 
(1938), Gordon (1945), Henry, (1948) and Griffin (1949). Cummings and Elsalmi (1968) noted that the subject of managerial motivation received increased attention subsequent to 1959 , beginning with the research of Porter. Porter's research $(1962,1963 a)$ conflicted with Rosen and Weaver's earlier finding (1960) regarding the motivational similarity between managerial levels. He found that a researcher must consider the type of human need, as well as a manager's level, in order to obtain a systematic understanding of motivation in a manager's self-concept. Modifying the Maslow model to include a need for autonomy, existing between the self-esteem and self-actualization levels, Porter concluded that higher-level managers perceived more need fulfillment than did those of lower levels, regardless of age. While higher-level managers perceived more fulfillment of the higher-ordered needs (autonomy and selfactualization), lower-level managers got more fulfillment of the lower-level needs (security and social). Middle managers arrayed thenselves between the two levels.

Herrick (1968) in his research of government managers using Maslow's theory found that, contrary to expectation, higher graded managers perceived a greater importance of social needs than did lower graded managers, and that older managers perceived social needs as more important than younger managers. 
Charles Garfield (1986) found in his study of selfactualizers that at times managers were prevented from actualizing because of a focus on security needs. On other occasions, managers were prevented from gaining satisfaction of their higher order needs because they had no powerful cognitive image of peak performance, no role model--or even the language to give the image an outline--drawing them toward the future. Further, it is important to successful managers that they accurately inventory personal strengths. Peak performing managers are only casually concerned with a general assessment. What they are most interested in is how their strengths fit with the demands of their work and their organization. He believes the difference between peak performing managers and average managers are much smaller than most people believe, but that it is a self-concept difference that makes all the difference.

Maccoby (1976) argues that Maslow's theory is particularly misleading about motivation and its relation to work. According to Maccoby, Maslow's psychology--and that of most management theorists--has no place for the real experience of corporate life. Maslow's "Eupsychian Management" (1965) ends up supporting the values of hierarchy, mechanistic thought, idealization of success, and careerism. Maslow's highest ideal of self-actualization is asocial, exclusively concerned with limitless individual expressiveness. To Maccoby, Piaget's research (1965) has demonstrated 
that moral development, overcoming egocentrism and gaining a sense of reciprocity with others is essential to the intellectual development of the competent self. Herzberg's motivation-hygiene (two factor) theory (1966) presented an alternative motivational model to Maslow's or Porter's hierarchies of needs, but evidence that the two factor theory is an over-simplified model of the world has accumulated (Dunnette 1955; Rosen 1963; Friedlunder 1963, 1964; Gordon 1965; Centers and Bugental 1966; Burke 1966; Wernimout 1966; Ewen, et al. 1966; Graen 1966a, 1966b, Lahiri and Srivastra 1966; Dunnette, et al. 1967; Henrichs and Mischkind 1967; Wolf 1967; Hulin and Sinith 1967; House and Wigdor 1967; Whitsett and Winslow 1967; Lindsay, et al. 1967). Generally, the evidence indicates that motivators and hygienes are neither unidimensional nor independent, that either type of factor can produce job satisfaction or job dissatisfaction and that self factors are generally more strongly related to both overall job satisfaction and overall job dissatisfaction than the environmental factors (Cummings and Elsalmi 1968). Elsalmi (1968) found that both job context and job content factors contribute to feelings of job satisfaction and job dissatisfaction. Two factor theory remains only a partial explanation of self-concept motivation in managers or employees (Snyder and Ferguson 1976).

Reproduced with permission of the copyright owner. Further reproduction prohibited without permission. 
Recent management research in motivation and the self-concept has focused attention on achievement. Veroff, et al. (1960) and Meyer, et al. (1961) discovered that when compared to other employees in various occupations, managers scored significantly higher in achievement motivation than other employees. Manager's needs for affiliation and power also varied with occupational status. McClelland's (1965) theory of motivation acquisition proposes that the more an individual can perceive and experience a newly conceptualized motive as an improvement in his self-image, the more the motive is likely to influence future thoughts and actions. Further, changes in motives are more likely to occur if the setting dramatizes the importance of self-study and lifts it out of the routine of everyday life. It is also important that changes in motives are more likely to occur and persist if the new motive is a sign of membership in a new reference group.

\section{Proactivity}

Ralph Stogdill (1981) and Bernard Bass in their excellent study of leadership found that of the many traits and factors associated with a leader's self, one must participate. $^{2}$ Both the knowledge of an individual's self-

\footnotetext{
${ }^{2}$ Bass has provided new editions of stogdill's book. The second finding fundamental to the scope of this research was that to remain acceptable to others as a leader, one must exhibit behavior interpreted by others as competent.
}

Reproduced with permission of the copyright owner. Further reproduction prohibited without permission. 
concept, which defines his proactive need for interaction with others, and a knowledge of the organizational effects of variances in the quantity and quality of participation are important to understanding the context of interpersonal needs. Seventy-four percent of the key-level managers surveyed in a study of cross cultural settings (Japan, Great Britain, United States) by Blake and Mouton (1968) reportedthat breakdowns in interpersonal communications were the greatest barrier to corporate "excellence."

Boyatzis (1982, pp. 71-79) assessed managers' proactivity using the McBer and Company picture story Exercise ${ }^{3}$ which provided him with self-concept scores. He found that proactivity was significantly related to managerial performance, but in a curvilinear manner. A comparison of groups with t-tests indicated that superior and poor managers had significantly higher self-concept proactivity scores than did average managers. Further, public sector managers had significantly higher self-concept proactivity scores than did private sector managers. Among public sector managers, superior and poor performers had higher self-concept proactivity scores than did average performers at near significant levels.

Boyatzis interpreted this to suggest that certain poor managers, with self-concepts high in proactivity, may take initiative and instigate activity so often that it may be

${ }^{3}$ Thematic Apperception Test form (Murray 1938).

Reproduced with permission of the copyright owner. Further reproduction prohibited without permission. 
inappropriate at times. They also might be doing it in such a manner as to violate organizational norms. While they may have high self-concept proactivity, they may be so action oriented to taking initiative that their performance suffers. It would appear that trait levels of high magnitude self-concept proactivity are not enough to assure adequate performance. The self must be motivated to obtain and maintain a qualitative dimension in interpersonal communication, in additional to the quantitative.

Hall (1974a) administered The Personal Relations Survey (Hall and Williams 1967) to corporate managers (above the first line supervisory level). The results indicated that managers reported a significantly greater preference for obtaining information than they do for disclosing information. He concluded that this tendency suggests a low level of interpersonal trust and willingness to take interpersonal risks, coupled with an inordinate desire for structure. Hall also found that managers are most willing to deal openly and candidly with others when they have an authority advantage. This is noticeably present in their dealings with superiors where they were least open in providing information. A general pattern of facade ${ }^{4}$ was found where managers are preoccupied with acquiring informa-

${ }^{4}$ See also Goffman $(1959 ; 1961 ; 1963 ; 1971 ; 1974)$. Goffman views the self-concept as defined by an individual's perception others' behavior toward himself (herself).

Reproduced with permission of the copyright owner. Further reproduction prohibited without permission. 
tion, but few are willing to provide it (Luft and Ingham 1955; Luft 1969; Hall 1974a).

Hall (1974a) continued in his research to explore the self's use of exposure and feedback relative to management style (Blake and Mouton 1964). Significantly, he found that the maximum balance and magnitude of exposure and feedback was associated with a management style conceptually integrating a task and people self-concept orientation. Hall believes his data confirms the contentions of Blake and Mouton that how a manager perceives his interpersonal communication is an important facet of a manager' style of activity.

In a follow-up study using The Personal Relations Survey, Hall (1974b) tested for the presence of security and reciprocity influences in a manager's communication. The results of the study provide evidence supporting the belief that it is a sense of personal security in a manager's self-concept, rather than feelings of trust, as earlier believed, which governs the use of both exposure and feedback. Hall concluded that current management practices serve to model and magnify the importance of security rather than the utility of trust. Further, the results of the reciprocity hypothesis test confirmed that subordinates do tend to mirror behaviors which managers have used in relating to them (Hall 1974b).

Reproduced with permission of the copyright owner. Further reproduction prohibited without permission. 


\section{Management Role}

Robert Merton (1957) used the terms "cosmopolitan" and "local" to describe the latent social roles of different types of community leaders. Gouldner $(1957,1958)$ in his studies of American organizations evaluated evidence of two latent social identities derived from the definitions set forth by Merton:

1. Cosmopolitans: Those individuals with a selfconcept low on loyalty to the employing organization, high on commitment to specialized skills, and likely to use an outside reference group orientation (i.e., professional organization, etc.).

2. Locals: Those individuals with a self-concept high on loyalty to the organization, low on commitment to specialized role skills, and likely to use an inside reference group orientation.

It was noted that the new scientifically based professions, including many technical management roles, are expected to be cosmopolitan in their orientation, that is, to have loyalties which "cut across" localistic or national groupings. When modern managers are contrasted with ordinary workers, the managers are characterized by a greater concern for efficiency and less concern for the social structure. Gouldner (1958) argues that every social system, including the modern organization, requires that its members 
have some degree of loyalty to it as.a distinctive social structure. His research demonstrated that a member's inhibition of expertise by loyalty considerations is a variable changing with the extent of the threat to which an organization is exposed, real or perceived.

\section{Leadership Identification}

Michael Maccoby studied corporate managers in an attempt to understand their self-concepts. Using methods developed in collaboration with Erich Fromm (From and Maccoby 1970), he found four types of self-concepts which he believes are common in large corporations (Maccoby 1976). According to Maccoby, each type of self-concept has its respective strengths and weaknesses:

1. Craftsman: Motivated to build products of high quality, interested in the process of making something. As a leader, he is a master builder and paternalistic master of apprentices. His common weakness is a self-concept perfectionism and he often fails to develop the organizational skills necessary for cooperative teamwork.

2. Jungle Fighter: Motivated to experience life and work as a battle where winners destroy the losers. He is brave and protective to his "family" and ruthless toward competitors. His

Reproduced with permission of the copyright owner. Further reproduction prohibited without permission. 
common weakness is his dominating attitude which drives away independent subordinates. 5

3. Company Man: Motivated to service and institution building, he is concerned with the human side of the company, committed to corporate integrity and controlling incompetent subordinates. His common weakness is that under pressure he may become too fearful and conservative.

4. Gamesman: Motivated to take calculated risks he thrives on competition and is fascinated by techniques and new methods. He is a fair and team player. His common weakness is his rashness, his tendency to create a fantasy world, to lie and to manipulate.

Maccoby expresses concern that a modern selfdevelopment ethic is needed incorporating new ideals, not just at the top, but at all levels of organizations.

\section{Autocommunication}

Lotman (1977) identified two types of communication, which distinguish cultural groups or cultures to varying degrees. The first type is the traditional sender-receiver mode of transferring information. The second mode of communication is not directed to another person at all, but is

${ }^{5}$ Reference the discussion of William Sumner in Historical Antecedents... in Chapter Two.

Reproduced with permission of the copyright owner. Further reproduction prohibited without permission. 
directed to a sender's self-concept. Lotman terms this second mode autocommunication. The phenomenon of communicating to oneself is a self-structuring process that produces "mythic" information i.e., the symbols and shared images that form the nucleus of any culture). Examples of this information processing are diary writing, autobiographies and monologues.

Barnlund (1971) argues in his intrapersonal communications model that the diary writer, while writing in his diary, is in fact cueing himself at the same time. Similarly, when a manager is writing a memo, he is both informing the other person and "cueing" himself, or effecting change or reinforcement in his self-concept. This occurs of course, not only by means of memorandums but also by other means of communication (i.e., verbal) as well. In this autocommication system a qualitative change takes place in the person or persons receiving the communication, which leads to the enhancement of the receiver's self-concept or to similar self-concepts of others in the group. This change may lead to a displacement of context and thus an interjection of a code transforming the original message into a new one. A particularly strong message may result in a major reconstruction of the self-concept.

The self-concept from a Chief Executive officer (CEO) or from planning managers may send a strategic, long-range planning message to other members of management in order to 
be implemented. But a secondary, often unconscious, purpose may be to enhance the CEO's self-concept, or that of the initiating managers or of the corporate "image." If one reads the corporate long-range planning report and understands it as a planning report he uses the first code (mode). If one starts feeling great about it and relates to it in his present context, then he is using a second code (mode). This is very often what happens to an organizational plan; it is written and read to make the organizational managers and planners feel like heroes and seers. plans may be completed to affirm one's self-concept to oneself as well as to others and to initiate the feeling of how well things are organized. The planner or strategist may in fact be only "surfing" or riding on the wave of trial-and-error activities and events in the environment. He may not really be in total control or implementing his plan. He just hangs on because events overtake him swiftly regardless of the substance of his plans (Broms and Gahmberg 1983, p. 490). A plan is made for the nonrational (unconscious) part of managers and employees as well as for the rational part, and the manager sometimes intuitively knows that. 6

\section{Ethnicity}

$$
\begin{aligned}
& \text { Watson (1974) studied black and white managers who } \\
& \text { were selected from organizational members of the Fortune } \\
& \text { 'See also the double-loop theory of Argyris (1977). }
\end{aligned}
$$


Directory. Participating organizations randomly selected a black manager and then selected a white manager to be a subject in a control group according to the following criteria: age, type of work, level of education and tenure. In order to evaluate the self-concept, an instrument was used to provide a self-concept score, self-acceptance score, an ideal self-concept score and a divergence score (difference between self-concept and ideal self-concept). The Thematic Apperception Test was used to measure levels of achievement motivation. Results revealed no significant differences between the two managerial groups on any of the four scores obtained from the tests. Watson concluded that black managers, when otherwise qualified, should be assigned to management roles.

\section{Sex}

Herrick (1968) studied managers (grade 11 and above) in ten executive departments of the Federal Government employed in Washington D.C. Hypotheses were related to civil service grade, age of the organization, sex, level of the position holder, age of the manager, and tenure. Among his findings was that female managers perceive a greater deficiency in the fulfillment of social needs than do their male counterparts.

Davidson and Cooper (1983) discovered that women managers are experiencing significantly more stress manifes- 
tations than are male managers and infer that this is a result of conflict in their perception of job and family roles affecting their self-concepts.

\section{Adult Maturation}

Levinson (1978) studied men, including business managers, in an attempt to distinguish stages of adulthood, similar to the research of sheehy (1974). The central theme of Levinson is that every male experiences four overlapping and sequential eras: childhood and adolescence (ages 0-22); early adulthood (ages 17-45); middle adulthood (ages 40-65); and later adulthood (ages $60+$ ). Within the sequence of these eras are "periods," alternating between "transitions" and "structures." Levinson specifically studied business managers and attempted to document their changes in selfconcepts which he believes are interrelated with career transitions and periods of increased ambiguity about the value of their achievement motivation and the value of the specific work they have been managing (1978). Cain (1979) has suggested several major weaknesses in Levinson's study, however it is important that Levinson has attempted to document the self-concept schemata transitions in managers as they age and relate them to environmental interactions, including the workplace.

Howard and Bray (1980) examined data from the Bell System's Longitudinal Management progress Study which fol- 
lowed college graduates hired into managenent and noncollege graduates hired for non-management jobs but promoted into management before the age of 32 . Mid-life was a crisis in self-concept to only a minority of participants, apparently because the majority of participants experienced a gradual increase in incongruity between their self-concept and their managerial role and that whatever crisis may have occurred had likely been bridged much earlier, perhaps by adaption as early as the eighth year after employment, when a cumulative total of forty percent of the graduates had left the company to obtain other employment (Howard and Bray $1980)$.

\section{Self-Concept Competency}

While the study of job competencies (including management competencies) is common in employee development and performance evaluation programs, "self-concept competency" is a term used in the present research to describe a particular type of competency often described as important by other researchers, but not specifically defined by this term in their research. A discussion of the background of the study of self-concept as a job competency is important to understanding its application in the present research. The two leaders in research relating to self-concept as a job (management) competence are Boyatzis (1982) and Lafferty $(1980)$.

Reproduced with permission of the copyright owner. Further reproduction prohibited without permission. 
A job competency is "an underlying characteristic of a person which results in effective and/or superior performance in a job (Klemp 1980)." Boyatzis (1982) research into the job competencies of managers has been representative of recent management theory which has realized the importance of the relationship between self-concept and performance. Performance, or specific behavior, is the manifestation of a specific competency in the context of the demands and requirements of a specific job and particular organizational environment (White 1959). To define a management competency, therefore, one must determine what behaviors were and their place in a system and sequence of performance and what the results or effects were and what the intent or meaning of the behavior and results by managers performing these behaviors were (Boyatzis 1982, p. 22).

It is through such a definition that the concept of a management competency represents a true ability. A manager's set of competencies reflect what he or she can do, not necessarily what he or she does all the time regardless of the situation and setting. Boyatzis submits that there is evidence that indicates that possession of management competencies precedes and leads to effective and/or superior performance in that job. The individual possessing these characteristics may or may not know they exist and, in this sense, they may be unconscious. 
Boyatzis believes that to have a full understanding of what a person brings to a managerial position, one must be able to conceptually distinguish among types and levels of competencies. He describes a manager's generic knowledge, motives, traits, self-concepts, or skills essential to performing a job as threshold competencies. Threshold competencies are essential to performing a job but are not causally relatei to superior job performance. They are, therefore, different levels of competencies. On the other hand, those characteristics that differentiate superior performance from average and poor performance are competencies in a different sense--they are types of skilis required in the functional and situational demands of specific jobs. It is important to Boyatzis that researchers understand that for a competency to exist there must be a demand for it from the environment (organization). At that time, the levels of threshold competencies, including the level of the selfconcept, will together, interactively, determine the relatively high or low performance by the manager of whom the response is required.

Lafferty (1980, p. 4) theorizes his research on management competency differently. His model accepts the self-concept as a "level" of management competency, but as a uniquely important one--since in his research differences in lifestyles (self-concept competencies) are associated with differences in management performance. Lafferty has con- 
cluded, through his extensive study in organizational and management development, that the collective life style profiles of an organization's managers appear to be related to the organization's ability to solve problems, initiate change, and perform effectively.

The self-concept construction of Lafferty departs from Maslow (1954) and other need theorists (Porter 1962, 1963a; Alderfer 1972; Mitchell and Moudgill 1976; Mathes and Edwards 1978) in two important ways:

1. Twelve lifestyles are presumed to adequately reflect the complex nature of human behavior and thought (Mc Clelland 1965; MCGregor 1960; Rogers 1961; Sullivan 1953). These lifestyles are associated with Maslow's needs but, in some cases, a particular need is associated with two or three distinct styles.

2. Lifestyles are not hypothesized in all cases to be ordered in a hierarchical manner but expected to be positively or negatively related to one another because of their strong links to needs that are clearly hierarchically ordered and incompatible.

Research by Lafferty on three levels of management (supervisors, mid-level managers, and key-level managers) has theorized and measured associations between management lifestyles and management behaviors (1980, p. 44):

Reproduced with permission of the copyright owner. Further reproduction prohibited without permission. 
1. Supervisors: ...displaying a strong concern for security with respect to both people and task. Their primary style is Dependency, which is typical of the supervisory role. Other characteristics common to this organizational level include high Conventionality (they tend to work by the book); high Avoidance (they may find it difficult to order former work peers to do a job); high Opposition (a defense against the need to be close to people); and high Power (they frequently have to throw their weight around)... They need to win but they also want to be accepted.

2. Mid-level Managers: ...are still rather high in the people-security quadrant, but have lower task-security needs. Their primary style is still Dependency (along with Avoidance), but it is not as pronounced as in the supervisors. Power and opposition styles are lower, and larger extensions in the Self-Actualizing, Humanistic-Helpful and Affiliative styles are evident.

3. Key-level Managers: overal1, ...upper level managers (have) a good balance of people-oriented and task-oriented thinking. Their primary style of Affiliative is well above average, along with their back-ups in Self-Actualizing and Humanistic-Helpful. Dependency and Power decreases considerably for these people.

Recent research on the self-concept, like that contributed by Boyatzis and Lafferty, have led many psychologists working on personnel issues to recognize that, "the self-concept and self-reports have again assumed a centrally important role in psychological research and theory" (Levine 1980). The question appears to be how to understand and use the relationship between self-concept and competence. Should self-concept be perceived as a threshold competency, or level of another more visible behavior? Should self-concept be perceived as a separate competency, 
uniquely important and distinct from other competencies? This researcher finds the arguments of Lafferty persuasive and hypothesizes the self-concept as a competency whose structural subsystem can be partially defined by instrumentation. Part of the subsystem structure (lifestyles) can also be understood as self-concept "competencies," in a subordinate sense, or styles of thinking about the self which are associated with individual and organizational performance. The profile of 1 ifestyle competencies provides an overall indication of a manager's "self-concept competency."

\section{SELF-CONCEPTS OF MANAGERS IN RESEARCH AND DEVELOPMENT ORGANI ZATIONS}

Bayton and Chapman found that the salient motivations of most scientists and engineers working as managers were substantially different from those of most specialists (1972, pp. 7-9). Their research also indicated that individuals who reject the managerial value system are likely to be poor performance risks if assigned management roles. Bernice Eiduson (1962, pp. 149-189) set forth several self-concept "types" of scientists and engineers based on her research.
1. Scientist as Discoverer
2. Scientist as Genius
3. Gentleman Scientist
4. Successful Scientist 
While these self-constructions may motivate a scientists research activity they may also carry beliefs (hypotheses) which limit his or her competency to perform management behaviors. Specialists may believe that if a man or a woman is a "real" scientist, tied up with the main goals of science, other functions are of lesser value and their self-concept rejects administrative duties. Eiduson believes scientific mores often lead to an inability to engage in management activity.

It appears as if those specialists who do attempt to transition into management often make several erroneous assumptions based on their experience.

The basic assumption is that having been in research, the research manager "knows" research people and will know how to manage them. The second assumption is that human behavior is anarchic and chaotic and impervious to systematic understanding; the behavior of scientists being especially chaotic and peculiar. Third, research management assumes that the organizational environment consists only of facilities, salary scales, and merit and achievement awards. Fourth, research management assumes that tempering its authority with friendly informality of a "happy family" variety contributes to a colleague system. Fifth, research management assumes that defining its method of supervisory selection as "natural leadership" will avoid organizational rigidity and contribute to flexibility. The fact that all of these assumptions are fallacious is not without its impact on strain in the laboratory (research) organization (Marcson 1960, p. 9).

It is clear to some researchers (Eiduson 1962, pp. 189-197; Mahoney 1974, pp. 6-9) that there has been an implicit research norm excluding the scientist or engineer 
from study. As long as this norm exists men can continue to spin half-truths of "storybook" scientists without too much fear of challenge. Mahoney (1974, pp. 12-13) declared that as long as scholars avoid studying scientists, researching the psychological or social factors influencing their behaviors, they will remain self-deceived. He believes that the idealized misconceptions of the scientist threatens the very foundation of scientific knowledge because the scientist, or manager of scientists, is most deceived who is "self" deceived. The final section of this chapter provides a statement concerning questions which arise about the self-concept competency of NASA technical $R \& D$ managers from a reading of self-concept literature. No research has been published which evaluates the self-concept competencies of $R \& D$ managers and seeks answers to these questions.

\section{Satisfaction Competencies}

Satisfaction needs should reflect a positive, and desirable, motivation of managers, as theorized by Maslow (1968). The greater the satisfaction needs expressed by $R$ \& D managers, the greater the self-concept potential for focusing thought on behaviors which are useful to organizations and healthy for managers (Porter 1962, 1963a; Alderfer 1972; Mitchell and Mougdill 1976; Mathes and Edwards 1978; Lafferty 1980).7 How does the satisfaction concern of NASA

\footnotetext{
${ }^{7}$ See ...Holistic structure of the Self (Chapter Two).
} 
R \& D managers compare with that of the NASA non-technical managers working in the same organizations, particularly if these technical managers are in the majority of positions which are both critical to NASA achieving its mission and the majority of growth-oriented positions from which the executives of the future will be selected? How does it compare with the satisfaction concerns of engineers, firstlevel supervisors and mid-level managers in general? Low levels of technical manager satisfaction may indicate the need for decision makers to study this problem further within the agency, particularly with respect to the existing "required selves" and "ideal selves" of agency managers."

By many accounts, the achievement motivation of an organization's managers is important, both with respect to the individual health of these managers and, therefore, a high level of activity (Cooke and Rousseau 1982a), and to the organization's ability to solve a greater number of complex tasks in a reduced time period (Veroff, et al. 1960; Meyer, et al. 1961; Mcclelland 1965; Lafferty 1980).9 How does achievement competency (motivation) in the selfconcepts of NASA R \& D managers compare with achievement competency in non-technical managers from the same organization and with the achievement competency of engineers, first-level supervisors, and mid-managers in general? Low

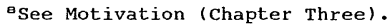

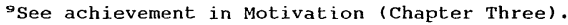


levels of achievement competency may provide decision makers with an indication that they need further research on agency hiring procedures, work-force socialization, or management selection procedures. ${ }^{10}$

Helpfulness is often encouraged as an ideal of behavior for all levels of employees in NASA but sometimes there is also a more cynical attitude expressed at the operating level that one must "help oneself" first in order to recieve promotions and monetary reward, compromising the more altruistic approach to sharing technical assistance in a technical organization. There is much management literature which emphasizes the need in technical organizations to build helpfulness and mutual trust (Gouldner 1957, 1958; Glaser 1965; Schein, et al 1965; Tagiuri 1965). How does helpfulness competency (motivation) in the self-concepts of NASA $R \& D$ managers compare with helpfulness competency in the self-concepts of non-technical managers from the same organization and with the helpfulness competency of engineers, first-level supervisors, and mid-level managers ingeneral? Low levels of helpfulness competency may indicate the need for decision makers to consider interventions to raise existing levels of helpfulness. ${ }^{22}$

$1{ }^{\circ}$ Low levels of achievement motivation in agency managers might be particularly dangerous in agency strategic planning efforts. See Autocommunication (Chapter Three).

${ }^{11}$ Low levels of helpfulness motivation in agency managers might indicate a "jungle fighter" approach to challenges. See Leadership Identification (Chapter Three). 


\section{Security Competencies}

Security needs should reflect a negative and undesirable motivation of managers, as theorized by Maslow (1968). The greater the security need expressed by $R \& D$ managers, the greater the self-concept potential for detracting thought from behaviors which are useful to organizations toward thought on self preservation and behaviors which may have a more destructive effect on the interaction of its employees (Porter 1962, 1963a; Alderfer 1972; Mitchell and Mougdill 1976; Mathes and Edwards 1978; Lafferty 1980). How does the security concern of NASA $R$ \& $D$ managers compare with that of the NASA non-technical managers working in the same organizations, particularly if these technical managers are in the majority of positions which are both critical to NASA achieving its mission and the majority of growth-oriented positions, from which the executives of the future will be selected? How does it compare with the security needs of engineers, first-level supervisors and mid-level managers in general? Relatively high security needs should provide decision makers with an indication that they need to consider further research into the background, socialization, and practices of agency managers.12

${ }^{12}$ High levels of security motivation in managers might indicate "jungle fighter" or "company man" approaches to challenges. See Leadership Identification (Chapter Three). 
Managers with high dependency needs are not viewed to be as effective in their organization application of management competencies (Lafferty 1980, pp. 19-20). High dependency needs are generally believed to be deficiencies in managerial self-concept competencies. How does the dependency competency of NASA $R \& D$ managers compare with the dependency competency of NASA non-technical managers from the same organization and with the dependency competencies of engineers, first-level supervisors and mid-level managers in general? As with security, high levels of dependency should provide decision makers with a reason to research the background, socialization, and practices of agency managers. ${ }^{23}$

\section{Task Competencies}

Task needs motivate managers towards the completion of goals and objectives, as theorized by Blake and Mouton $(1964 a)$. The greater the task need expressed by $R \& D$ managers, the greater the self-concept potential for directing thought toward behaviors which are oriented toward the completion of organizational goals and objectives. How does the task need of NASA $R \& D$ managers compare with that of the NASA non-technical managers working in the same or-

\footnotetext{
${ }^{13} \mathrm{High}$ levels of dependency motivation in managers might indicate a high degree of codependency (Kerr 1988, pp. 40-52), or an excessively "local" self-concept, with an excessive amount of inside reference group orientation. See Management Role (chapter Three). It might also be normative for $R$ \& D managers, if their is a high level of risk in the organization's environment.
} 
ganizations, particularly if these technical managers are in the majority of positions which are both critical to NASA achieving its mission and the majority of growth-oriented positions, from which the executives of the future will be selected? How does it compare with the task need of engineers, first-level supervisors and mid-level managers in general? Unusually low or high (combined with low people motivation) task motivation should indicate to decision makers the need for further research on the agency hiring practices, work force socialization, and management selection procedure. 14

Paradoxically, managers with high "competency" needs are not viewed to be as effective in their organization application of management competencies (Lafferty 1980, pp. 29-30). High competency needs are generally believed to be deficiencies in managerial self-concept competencies, because they con-ceptually "individualize" behavior and tend to detract from the social aspects of performance. How do the competency needs of NASA $R \& D$ managers compare with the competency needs of NASA non-technical managers from the same organization and with the competency needs of engineers, first-levelsupervisors and mid-level managers in

1.4 Unusually high scores might indicate an excessive "cosmopolitan" approach to management, with an excessively high orientation to outside reference groups and low loyalty to organizations. Unusually low scores might indicate the reverse situation with an excessively high loyalty to organization and low outside reference group loyalty. See Management Role (Chapter Three).

Reproduced with permission of the copyright owner. Further reproduction prohibited without permission. 
general? High competency needs might indicate a need for decision makers to research agency managers "ideal self" measures to determine if there is a need for intervention. ${ }^{25}$

\section{People Competencies}

People needs motivate managers towards affiliation with other people, conformity and the satisfaction of other peoples needs, as theorized by Blake and Mouton (1964a). The greater the people need expressed by $R \& D$ managers, the greater the self-concept potential for directing thought toward behaviors which are oriented toward affiliation with other people, conformity and the satisfaction of other people's needs. How does the people concern of NASA R \& D managers compare with that of the NASA non-technical managers working in the same organizations, particularly if these technical managers are in the majority of positions which are both critical to NASA achieving its mission and the majority of growth-oriented positions, from which the executives of the future will be selected? How does it compare with the people need of engineers, first-level supervisors and mid-level managers in general? Excessively $k$ ighpeople concern might indicate that decision-makers should research agency hiring procedures, work force socialization, or management selection practices.16

\footnotetext{
${ }^{15}$ See Occupational Preference (Chapter Three). ${ }^{16}$ See also Blake and Mouton (1985).
}

Reproduced with permission of the copyright owner. Further reproduction prohibited without permission. 
Managers with high affiliation needs are viewed to be effective in their organization application of management competencies (Lafferty 1980). Paradoxically, an extremely high affiliation need is generally believed by Lafferty (1980) to be a deficiency in managerial self-concept competencies, because it may compromise performance by prioritizing affiliation at the expense of task. How does the affiliation competency of NASA $R$ \& $D$ managers compare with the affliation competency of NASA non-technical managers from the same organization and with the affiliation competencies of engineers, first-level supervisors and midlevel managers in general? Excessively low needs to affiliate might indicate that decision makers need to evaluate agency hiring procedures, work force socialization or management selection practices. ${ }^{17}$

\section{Self-Actualization Competency}

The needs for self-actualization should reflect a positive, and desirable, motivation of managers, as theorized by Maslow (1968). The greater the actualization needs expressed by $R$ \& $D$ managers, the greater the selfconcept potential for focusing thought on behaviors which integrate people and task concerns and are useful to or-

17High affiliation motivation may indicate a healthy proactivity but it may indicate also a major problem if there is not a significant quality to the activity (See Proactivity (Chapter Three). High scores might also indicate an excessive "cosmopolitan" managerial orientation. 
ganizations and healthy for managers (Porter 1962, 1963a; Alderfer 1972; Hall 1974a, 1974b; Mitchell and Mougdill 1976; Mathes and Edwards 1978; Lafferty 1980; Garfield 1986). How does the actualization need of NASA R \& D managers compare with that of the NASA non-technical managers working in the same organizations, particularly if these technical managers are in the majority of positions which are both critical to NASA achieving its mission and the majority of growth-oriented positions from which the executives of the future will be selected? How does it compare with the actualization needs of engineers, first-level supervisors and mid-level managers in general? Low levels of self-actualization might indicate decision makers need to review work force socialization and management training and practices.18

\section{Relationship of Managers" Self-Concepts to Strain}

The results of Holmes' and Rahe's research (1967) indicated that the experiencing of several life events in a relatively short period of time is associated with physiological illness, especially during the year succeeding the events. These researchers hypothesized that a person exposed to many potentialiy stressful situations, loses the

${ }^{10}$ See Theories of the Holistic structure of the Self (Chapter Two); Self-Actualization Research (Chapter Two); Motivation (Chapter Three); and, Proactivity (Chapter Three). See especially Garfield (1986).

Reproduced with permission of the copyright owner. Further reproduction prohibited without permission. 
necessary energy to respond, and a medical illness arises. They concluded that a strong interrelationship exists between stress and illness. In reviewing the research of Holmes and Rae, Lafferty hypothesized that self-concept has an even more significant effect on illness previously believed.

Subsequent research has found support for hypotheses linking self-concept with symptoms of strain (Cooke and Rousseau 1982a; Cooke, et al. 1985). For most of the strains measured, the five personal orientations of selfimage, locus of control, interpersonal orientation, goal orientation and time orientation explained a greater percent of the variance than did age and income (Cooke, et al. 1985). These results provided support for the hypothesis that different self-concepts lead to different symptoms of strain. Among the other findings was that self-image was found to have a significant relationship with medical problems. The implication are two-fold. First, models of stress and strain should consider the possibility that selfconcepts have direct effects on individuals' health and well being. Second, different self-concepts are likely to be systematically related to different symptoms of strain. The question arises, "Is there a significant relationship between the self-concepts of NASA $R \& D$ managers and the self concepts of respondents reporting symptoms of three recently researched illnessess--depression, ulcers and high

Reproduced with permission of the copyright owner. Further reproduction prohibited without permission. 
blood pressure?" High associations between respondents showing symptoms of strain and NASA managers should indicate a need for decision makers to research further the hiring procedures, work force socialization and management selection practices. 19

\section{Self-Concept and Biographical Experience}

Most researchers submit that the experience of individuals changes their self-concepts to a degree (Taylor 1953; Jourard 1964; Epstein 1973), although at least one, Manis (1955), suggests that this change may be limited in its direction. 20 Both Boyatzis (1982) and Lafferty (1980) submit that the differences in experience for managers are critical with regard to the relationships between selfconcept and performance. Is age, years of management experience, or years of employment at NASA associated with changes in lifestyle preferences in the self-concepts of NASA R \& D ranagers? Significant associations between lifestyles and these biographical measures should demonstrate that there are changes in the managers' self-concepts which are related to aging, specific work experiences, from association with cohorts, or from historical circumstances.

\footnotetext{
${ }^{19}$ See Phenomenological Research (Chapter Two). 2o See Symbolic Interaction Research (Chapter Two).
}

Reproduced with permission of the copyright owner. Further reproduction prohibited without permission. 


\section{SELF CONCEPT COMPETENCY OF NASA MANAGERS}

The understanding of the association between selfconcept and behavior (individual performance) is an important one for decision makers, consultants and mid-level managers involved with NASA organizational performance. Improvements (changes) of behavior from average to high performing by managers appears to be preceded by changes in self-concept structure (lifestyles). Since changes to these lifestyles (motivational hypotheses) are more likely, if a manager can perceive and experience them as an improvement (competency) in his self-image, and since this new selfconcept hypothesis will more likely be tested if the setting (management development) dramatizes the importance of selfstudy, 21 it is believed that the approach used in this research has merit by calling attention to the existing structure of agency high performing managers' self-concept competency, and that this baseline structure can be used in planning required interventions.

This research is organized to evaluate the hypotheses that NASA technical managers have about themselves with the intention of determining the existing self-concept competency structure. The research does not directly observe or measure management behavior but rather leaves this evaluation to other researchers. The focus of this study is

${ }^{21}$ See Motivation (Chapter Three). See especially McClelland (1965). 
on measuring the self-concepts of NASA technical managers, and in measuring differences between them and normative engineers', supervisors', and mid-level managers' selfconcepts (Lafferty's samples), where associations between measurements and behavior have been previously hypothesized and researched. The self-concepts of NASA technical managers are also compared with the NASA non-technical managers' self-concepts. Further, the technical managers' self-concept is examined for indications of strain. And, finally, older and younger, more tenured and less tenured and more experienced and less experienced managers are tested for differences in lifestyle scores to determine associations between biographical measurements and selfconcept. 


\section{CHAPTER IV}

\section{RESFARCH DESIGN}

Chapter IV discusses the technical approach to this study. Four general areas of the approach are discussed: Sample, Instrument, Procedures and Methods, and Problems Encountered. The research design is then sumarized.

\section{SAMPLE}

This research has at its core the understanding of self-concept competency in high performing NASA technical managers. Approximately 1900 of the 2570 total NASA grade GM 14/15 managers are aerospace technical (AST) managers. They are employed at nine major sites in the United states (Table II). These AST managers may also view themselves as possessing engineering, project, program, resource, research or other role responsibilities in addition to their technical identity (Table III).

"High Performing" $R \& D$ managers are defined as those AST Managers receiving formal performance appraisal scores in the top $50 \%$ of their peer group, as evaluated by their managers.

Anticipated administrative problems in conducting a random sampling resulted in a decision to pursue a purposive 
TABLE II

SAMPLE CONSTRUCTION BY NASA CENTER

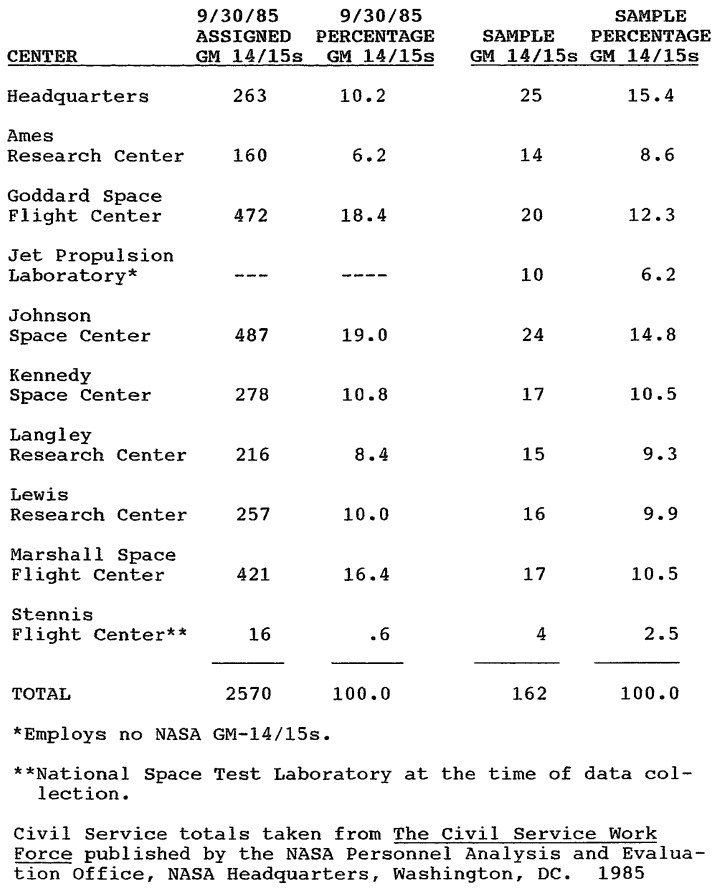

Reproduced with permission of the copyright owner. Further reproduction prohibited without permission. 
TABLE III

COMPARISON OF SAMPLES STUDIED

NASA SAMPLE

(PERCENTAGE)

\begin{tabular}{lccc} 
FUNCTION & \multicolumn{1}{c}{ TECHNICAL } & NONTECHNICAL & TOTAL \\
\cline { 2 - 4 } TECHNICAL & 12 & 0 & 12 \\
& $(7.5 \%)$ & $(0.0 \%)$ & $(7.5 \%)$ \\
ENGINEERING & 38 & 0 & 38 \\
& $(23.6 \%)$ & $(0.0 \%)$ & $(23.6 \%)$ \\
PROJECT MANAGEMENT & 28 & 0 & 28 \\
& $(17.4 \%)$ & $(0.0 \%)$ & $(17.4 \%)$ \\
FEOGRAM MANAGEMENT & 21 & 0 & 21 \\
& $(13.0 \%)$ & $(0.0 \%)$ & $(13.0 \%)$ \\
ADMINISTRATIVE & 0 & 22 & 22 \\
& $(0.0 \%)$ & $(13.7 \%)$ & $(13.7 \%)$ \\
RESOURCE & 1 & 12 & 13 \\
& $(.6 \%)$ & $(7.5 \%)$ & $(8.1 \%)$ \\
RESEARCH & 16 & 0 & 16 \\
& $(9.9 \%)$ & $(0.0 \%)$ & $(9.9 \%)$ \\
OTHER & 2 & 9 & 11 \\
& $(1.2 \%)$ & $(5.6 \%)$ & $(6.8 \%)$ \\
& - & - & 161 \\
& $(73.3 \%)$ & $(26.7 \%)$ & $(100 \%)$
\end{tabular}

NUMBER OE MISSING OBSERVATIONS $=1$

IAFFERTY ENGINEERS $\quad 52$

$\begin{array}{ll} & 496\end{array}$

IAFFERTY MID-LEVEL
MANAGKRS

Reproduced with permission of the copyright owner. Further reproduction prohibited without permission. 
sample for investigation. These anticipated problems include:

1. Identifying the population of high performing agency managers to sample. Performance is generally reviewed and rated annually and the results of performance reviews are maintained at each of the nine NASA Centers subject to Privacy Act considerations. ${ }^{2}$ Further, the gains and losses of managers due to hirings, promotions, resignations and retirements result in a substantial research challenge to identify just who the universe of high performing managers might be at any single point in time, without at least a critical delay effecting the sampling process. 2. obtaining a satisfactory return rate for completed instruments. Costs involved to identify the sample's composition and to require the subjects' presence in at least nine geographically dispersed survey sites, in order to brief the subjects and gain their cooperation, are prohibitive. Distributing the instrument without a briefing but with a letter of explanation was not projected to obtain an adequate return rate, given the time constraints of such a busy

\footnotetext{
U.S.C. 522A).
}

Reproduced with permission of the copyright owner. Further reproduction prohibited without permission. 
and diverse group of subjects. Similar surveys have not yielded satisfactory return rates. In similar circumstances purposive sampling is recommended (Babbie 1973, pp. 106-107).

\section{Purposive Sample}

The decision not to randomize and to uncomplicate the design by using the available source of subjects is not without costs. This linits the investigator's ability to strictly generalize findings beyond the spacific sample studied. The investigator is unable to estimate the degree of departure from representation (sampling error). However, the nonprobability sample is appropriate in similar situations where expense is prohibitive. Bailey $(1978$, p. 83) states:

The advantage of purposive sampling is that the researcher can use his or her skill and prior knowledge to choose respondents. For example, he or she may seek the "average American housewife" or the "all-American boy."...Another ploy is to seek deviant cases rather than average respondents, in order to see what makes them depart from the norm.

This explanation describes the present study. In reality the researcher is examining the MEP subjects to find the self-concept competency of the "all-American NASA technical manager," or, in this case, the average of the "high performing NASA technical managers," to determine where self-concepts of technical managers depart from the selfconcepts of "high performing non-technical managers" from 
the same organization and self-concepts of "normal" engineers, first-level supervisors and mid-level managers' self-concepts. Since departures from self-concept norms have been associated with corresponding changes of management behavior in other studies, this data may now be useful to predict associated behaviors of NASA managers. Since this behavior may be more or less effective or productive in management, it may be viewed as a competency. The norm (or, more precisely, norms) will be Lafferty's samples of engineers, supervisors and mid-level managers and NASA's high performing non-technical managers taken from the same MEP classes (Table III).

The selection of managers to attend the MEP program is accomplished competitively by NASA Centers. Each Center is assigned a number of spaces approximately proportionate to its number of eligible managers (Table II). At each Center a Board of Executives determines attendence from among eligible managers nominated by their Directors. The reputation of a manager for contributing to the Center's mission, along with his Director's recommendation, is weighed in the selection process. Since a relatively small percentage of those nominated are selected to attend, it assures the stated criteria of "high potential" for promotion to positions of increased management responsibility is met. "High performance" is, therefore, a necessary but not a sufficient criteria for determining promotion. At the supervisory and 
middle-management level many positions have a marked contribution to Center performance but do not possess the "breadth" of exposure to certain agency issues which would qualify the incumbent for positions of increased grade. An incumbent may be a "high performing" manager but not have opportunity to attend the MEP and gain entrance to the sample due to the specialized nature of his position.

It should be noted that the Jet Propulsion Laboratory, while possessing no Grade $14 / 15$ managers, comprises $6.2 \%$ of the sample. Further, while NASA Headquarters has a higher than proportionate representation, Goddard, Johnson and Marshall have a lower than proportionate respresentation. Nevertheless, the sample approximates the population targeted for the study group.

At a minimum, it can be determined that the tests remain statistically inferential for examining differences between the structures of self-concept competency in high potential (high performing) NASA technical managers and the high performing non-technical managers attending the NASA MEP, during 1985-86 where the entire populations was surveyed during the study period and with the general samples of Lafferty engineers, supervisors and mid-level managers. In summary, there is explanatory strength in measuring subjects from this purposive sample of NASA R \& D managers to determine their differences from subjects in the other representative samples. While non-probability sampling 
limits the primary researcher from strictly generalizing the results to all NASA high performing $R$ \& $D$ or government high performing $R \& D$ managers, it will provide useful information which can be of value to the federal government for understanding a valuable human resource.

\section{Size}

As non-probability sampling does not provide the researcher with information on sampling error, the question of size at first appears of no consequence. Yet one might argue that if one could obtain the measures of a nonprobability sample consisting of $90 \%$ of the population would it not carry a high degree of expectation for explanation, especially if certain controls would assure that no known group of deviants is unmeasured. An understanding of an adequate sample size as if it were a probability sample would appear to be prudent and informative for evaluating the size of the existing sample.

The NASA population of 2570 grade $14 / 15$ managers in 1985 consisted of 1925 technical and 645 non-technical managers. A preliminary estimation of the technical to nontechnical manager ratio of NASA managers was made at $3: 1$. To assure at least the large sample requirement of 30 for the smallest cell (nontechnical managers), a minimum sample of 120 was estimated. Increasing the predicted cell size of the non-technical managers from 30 to 40 provides sig- 
ificant additional confidence (Warwick and Linger 1975, pp. 69-107). The total target size of the NASA managers' sample was, therefore, set at 160. The total of 162 managers actually surveyed consisted of 118 technical managers and 43 non-technical managers (with one manager not reporting).

\section{INSTRUMENT}

Issues relating to the validity and reliability of the instrument form two of the three bases for determination of the instrument's suitability. The final suitability issue relates to the administration of the instrument.

\section{Validity}

The semantical root of the word "validity" is the same as that of the word "value," and both words are derived from a root term meaning strength. The validity of a measurement consists in "what" one is able to accomplish with it. This "what" rests on the context of a measurement's use. Validity is not determined soley by an instrument and a scale of measurement, nor by the intrinsic nature of the magnitude being measured. A researcher must consider the inquiring functions which the measurement is intended to perform. The fundamental question of validity is always whether the measures have been derived so that they can serve effectively as a means to the given end. The usual characterization of measurement validity is that it measures 
what it purports to measure. Basically, this is determined in all research designs in two important and related ways (Kaplan 1964, pp. 198-199):

1. Definitions

2. Empirical Connections

Following a discussion of these determinants, the context involved in the instrument's application will be discussed.

\section{Definitions.}

Self-concept: The self theory of an individual's mental construction of himself (herself), which is comprised of "concepts of self" ranging widely in content and scope (See Self-Concept at the end of chapter Twol.

Lifestyles: A combination of motivations (values), leading to attitudes, and then to behaviors that have consequences for the individual's perception (orientation) of his (her) relations to the environment (Cooke and Lafferty 1981 , pp. 3-5). They are "hypotheses" about the self which the individual constructs for functioning.

Motivations: Primary forces aimed at satisfying human needs. Once needs are satisfied, they no longer motivate, and other needs emerge with their corresponding motivations. Most human behavior has the purpose of satisfying needs as expressed in motivation. Values are prioritized motivations which carry a relative strength in the lifestyle 
depending on the relative strength of the underlying need (Raths, et al 1966).

Physiological strain: The symptom array of dysfunctional human organismic responses to genetic, lifestyle and environmental causative factors (Cooke and Rousseau 1982b).

Competency: The adaptive fitness for a human to do what needs to be done in order to deal with the environment (Hall 1980, p. 34). This implies that the more competent one is, the more able one is to interact effectively with the social and physical surroundings (White 1959; Block 1982).

Managerial Competency: An underlying characteristic of a person which results in effective and/or superior performance in a management job (Klemp 1980).

Manager's Self-Concept Competency: The profile of the self-concept construction of a manager's hypotheses of himself (herself), which enables him (her) to do what needs to be done in organizations in order to deal effectively with the organizations' internal and external environment. It contains different dynamic lifestyle orientations, constructed from interpersonal experience, which are a combination of the manager's values. Measurement of this competency indicates:

1. A manager's organization of the data of experience, particularly that of interpersonal in- 
teraction, which he (she) uses to predict action and reaction in the environment.

2. A manager's attempts to fulfill needs while avoiding disapproval and anxiety.

Empirical Connections. The construction of the LifeStyle I Inventory has been introduced in chapters I and III. ${ }^{2}$ The twelve lifestyles defined by Lafferty (1980, pp. 11-34) are viewed as a combination of values contributing to the construction of a self-concept.

Maslow's distinction between lower-order needs and higher-order needs (1954) provide the basis for the identification of two general types of lifestyle concerns-"security" and "satisfaction." The security lifestyles are conventional, dependence, oppositional, avoidance, and power. The satisfaction lifestyles are humanistic-helpful, affiliative, competence, achievement, and self-actualizing. The remaining two life-styles--approval and competetitive-are motivated by both security and satisfaction concerns. Blake and Mouton's distinction between task and people orientations (1964), stogdill's (1963) distinction between initiating structure and consideration, and Katz's (et al. $1959)$ distinction between production-centered and employeecentered behavior, provide the basis for the identification of two additional types of lifestyle concerns--"task" and

\footnotetext{
${ }^{2}$ Chapter One, pp 8-13; Chapter Three, pp 75-77.
} 
"people." The task lifestyles are oppositional, power, competitive, competence, and achievement. The people lifestyles are dependence, conventional, approval, affiliative, and humanistic-helpful. The self-actualizing lifestyle is viewed as an integration of task and people concerns and the avoidance lifestyle is seen as a lifestyle without an integration of task and people needs.

There are several important aspects of the framework underlying the relations between the lifestyles (Lafferty 1981, pp. 10-11).

1. Individual self-concepts are expected to have attributes of more than one life-style and these multiple lifestyles can interact in positive and negative ways.

2. The twelve lifestyles are expected to cluster into the four general groups of concerns consistent with their respective underlying needs and values.

3. Some of the lifestyles are expected to be positively interrelated, others are expected to be negatively interrelated, and yet others are expected to be relatively independent of one another in their interactions within the selfconcept.

The lifestyles instrument was designed to maximize content validity (Cooke and Lafferty 1981, p. 3) by sub-

Reproduced with permission of the copyright owner. Further reproduction prohibited without permission. 
stantially representing the concepts about which the theorized descriptions of the lifestyles were to be made (Bohrnstedt 1970, p. 91). Each lifestyle was conceptually stratified into its major structures to reflect the ways in which orientations (or closely-related variables) were defined in existing literature. Multiple terms were generated to capture the "shades of meaning" associated with each strata. Finally, potential terms were pretested in counseling settings to identify those items which best reflected the structure of the orientations ( 1 ifestyles) being measured (Cooke and Lafferty 1981, p. 13).

It was determined by Lafferty that twenty items (single words or short phrases no more than seven words in length) were needed to adequately measure each of the Jifestyles and to reflect the various meanings attached to each concept. These words and phrases are developed to measure the lifestyles in terms of either attitudes, behaviors, or reactions (i.e., the perceived reactions of other people to the respondent or the respondent's reactions to others). It is expected that these twenty items reflect subdomains of self-concept stratification within each lifestyles. For example, the self-concept subdomains for an achievement style include the interest in understanding why things happen, pursuit of self-set goals and accomplishing goals well. The items used to measure each self-concept orientation were also intended to vary in intensity. For example, the

Reproduced with permission of the copyright owner. Further reproduction prohibited without permission. 
achievement lifestyle includes the relatively moderate item "enjoys a challenge." as well as the relatively extreme item "enjoys difficult tasks." Subsequent research has revealed the instrument possesses a continuum of intensity for each of the twelve dimensions (Lafferty, et al. 1980, p. 11). Respondents are asked to write the number " 2 " next to a term if it is "strongly like you (most of the time)," the number " 1 " if it is "like you quite often," or a "0" if it is "essentially unlike you." The self-concept instrument design requires 240 responses (20 terms times 12 ifestyles) be selected. Forms which can be scored and interpreted include no missing data. Each of the twelve lifestyle variables, therefore, may vary from 0 to 40 on its index. Each of the four motivational concern variables may vary from 0 to 200 on its index.

Results of the construct validity studies revealed (Cooke and Lafferty 1981, pp. 20-24):

1. Strong positive correlations were found between lifestyles close to one another on the clock. With few exceptions, the magnitude of the positive correlations decreases as the "clock" distance between lifestyles increases.

2. Lifestyles strongly associated with higher-order needs correlate negatively with those strongly associated with lower-order needs. Importantly, the achievement, self-actualizing, and humanis- 
tic styles correlate negatively with the avoidance style.

3. Some of the correlations beween the lifestyles on the "people" side of the clock and those on the "task" side of the clock are close to zero. Many of these correlations, however, are positive and significant, although lower than that of the correlations between 1 ifestyles that are less distant from one another.

Since the lifestyles were not hypothesized to be orthogonal, and multiple measures of all twelve lifestyles were not currently available to generate a matrix (Campbell and Fiske 1959), a modified and less rigorous strategy than factor analysis was initially used to determine convergent and discriminant validity. Correlations were computed between each of the 240 terms on the instrument and the twelve lifestyle measurements. Correlations of each term to the twelve indices were then compared to find if the item correlated more strongly with its own index than with any of the other eleven indices. A majority (91.3\%) of the terms correlated most strongly with their own lifestyle indices. Later analysis, attempting to explore the underlying factor structure of the instrument, found that in contrast to the four quadrants conceptualized by Lafferty, three factors could be generated which together explained a total of $72 \%$ of the common variance in the lifestyles (Cooke and

Reproduced with permission of the copyright owner. Further reproduction prohibited without permission. 
Rousseau $1982 \mathrm{~b}$, p. 4). The first factor is characterized by high factor loadings for approval, conventional, dependent, and avoidance lifestyles (25.6\% of the common variance). This factor reflected an orientation toward people and security. The second factor is defined by high loadings for achievement, self-actualizing, humanistic/ helpful, and affiliative $(24.8 \%$ of the common variance). The second factor reflected a satisfaction orientation combining people and task concern. The third factor is characterized by high loadings for oppositional, power, competitive, and competence $(21.6 \%$ of the common variance). The third factor reflects a task and security concern.

Ware (et al. 1985) subsequently tested the factor structure of the instrument in order to examine this discrepancy between Lafferty's theory and Cooke and Rousseau's findings. In contrast to the principal components methods used by Cooke and Rousseau (1982, p. 25), a principal-axis factor analysis was used to generate the factor matrix followed by varimax and oblique rotations. If a similar factor pattern was uncovered when varying both the populations of participants and the methods of extraction, then greater confidence could be placed on the generality of the inventory's factory structure. Principal axis is also believed by the researchers to be a more appropriate technique, given the types of variables used in the study. principal axis techniques do not make the assuption of 
error-free measurement and produce more conservative (i.e., lower) loadings. Principal axis analysis does not mix common and unique variance (Ware, et al. 1985, p. 966).

The Ware analysis produced three factors, similar to Cooke and Rousseau, using the Kaiser criterion but four clear factors, similar to that theorized by Lafferty, using Cattell's scree test (Cattell 1966). Research has indicated that the Kaiser criterion occasionally underestimates the correct number of factors (Gorsuch 1983). According to Cattell, the Kaiser criterion is in error five times as often as the scree test (Cattell 1978). Child (1973) has determined that the Kaiser criterion is most appropriate with between 20 and 50 variables, but is prone to underextraction with less than twenty variables. Ware (et al. 1985, p. 966-968) found that Lafferty's four-factor solution was statistically significant.

In assessment center criterion validity studies, the promotability of 26 line managers was predicted by considering their achievement, self-actualizing, and humanistichelpful scores. In $82 \%$ of the cases, results were predictable when compared with the judgements that a three-person professional assessment team made on the basis of interviews, tests of intelligence and observation of managerial skills (Lafferty 1971, pp. 25-28).

Morris (1980) placed 108 managers with oppositional, approval, and dependence lifestyles into teams to compete in 
a simulation against 102 managers with achievement, selfactualizing, and humanistic-helpful styles who were also placed into teams. As predicted, the latter teams were significantly more likely than the former to cooperate, pool resources, and perform effectively demonstrating support for a criterion validity.

Lifestyles are theorized to be related to physiological strain for two reasons. First, certain lifestyles are believed to reflect "stress within the system," which the subject "bring's with him" to the situation" (McGrath 1976, p. 1369). Security-oriented self-concept orientations in particular are believed representative of this type of stress and may be directly related to strain. Second, people reporting different lifestyles are likely to react differently to the same stressful situations as a result of their different self-concept orientations. Satisfaction self-concept orientations are expected to reduce the negative effects of stressful environmental effects and security self-concept orientations are expected to increase these effects. To summarize, the satisfaction lifestyles should correlate negatively, and the security lifestyles positively, with the frequency of medical problems reported by respondents. The results indicated that two security orientations (avoidance and oppositional), and one satisfaction orientation (competence) are positively related to strain, and one satisfaction orientation (self-actualizing)

Reproduced with permission of the copyright owner. Further reproduction prohibited without permission. 
and one security orientation (conventional) are negatively related to medical problems (Cooke and Lafferty 1981). While more research is needed, recent research has provided strong indications of relationships between self-concept and symptoms of strain.

Contextual Application. The fundamental question remains whether the measures have been derived so that they can serve effectively as a means to the end of understanding the self-concepts of high performing government $R \& D$ managers. This researcher believes that the instrument is an excellent one, adequate for the project, but not without limitations. Certainly, the structure of the human selfconcept consists of more dimensions than the twelve lifestyle and four underlying concern dimensions measured by this instrument. Further, additional criterion validitation studies are needed to be completed, and published, relating the scores on this instrument to performance ratings assigned employees and, in particular, technical managers. Despite these shortcomings, this instrument has many strengths for application in research on $R \& D$ managers. Its construction, with dimensions widely discussed in management research, appears to have strong validity for measuring the self-concept structure it claims to measure. The basic circumplex model gives it an ease of interpretation or utility (Conte and Plutchik 1981), particularly with 
regard to identifying the self hypotheses which relate to a manager's work environment, duties, and interpersonal style.

\section{Reliability}

Reliability is the consistency of the instrument's ability to measure (Bailey 1978, p. 61). Elmers and Lafferty (1980) tested the internal reliability of the Level I:

Life Styles Instrument. Using a sample of 354 persons responding to Level $I$ in 1970 , a split-half technique was employed using the spearmann-Brown Reliability Formula and the Spearmann-Brown Correction Formula (Kerlinger 1973, p. 451). The Spearmann-Brown Reliability produced a range of corrected reliability coefficients from a low of .9003 (power lifestyle) to a high of .9541 (oppositional lifestyle). The average reliability coefficient was .9232, and all lifestyles are well above the accepted range.

\section{Administration}

The consideration given to the selection of the instrument from an administrative perspective has been mentioned. ${ }^{3}$ As the Management Education Program requires the use of an instrument that permits attendees, as both subjects and clients, to reflect upon their self-concepts while reviewing data provided to them during the seminar on management competencies and organizational climate, the principal researcher proposed this instrument to the NASA

$$
{ }^{3} \text { Chapter one, pp 6-8. }
$$


Management Education Program training staff. They reviewed the instrument and accepted it for the dual use of both management research and management development. The ease of administration and scoring, perceived face validity and explanatory videotape and handbook accompanying the instrument were all factors in this selection.

\section{PROCEDURES AND METHODS}

The design of the research is Ex post Facto ${ }^{4}$ which has three inherent Iimitations (Kerlinger 1973, p. 390):

1. The inability to manipulate independent variables.

2. The lack of power to randomize.

3. The risk of improper interpretation.

Nevertheless, quasi-experimental design is often essential to research in the social and managenent sciences due to the inability of the researcher to effect extensive experimental controls. When guided by adequate hypotheses, the results of ex post facto research should be useful since the experimenter does have control over measurement of the dependent variable for a posttest (Bailey 1978, pp. 209210). In this self-concept research, lifestyle and concern self-concept competency variables are theorized as dependent in their origination yet may, in turn, act as independent variables in other research. Self-concept variables are

\footnotetext{
¿quasi-experimental.
}

Reproduced with permission of the copyright owner. Further reproduction prohibited without permission. 
considered the result of a combination of genetic and socialization factors which in a manager's self-concept competency, or incompetency, have an independent effect on organizational climate and decision-making.

\section{Procedures}

During the initial day at the MEP, instructions are provided to the subjects on completing the Lifestyles I Inventory by the MEP management training staff. No mention of the research is made in the instructions. Subjects are advised:

1. That all results will be held confidential.

2. To complete the instrument as honestly as possible.

3. That they will receive feedback on the results.

After completion, subjects score their own instruments with the included instructions and with assistance provided by the MEP management training staff. Subjects are then provided feedback on the Lafferty Lifestyles model and assistance is given by the MEP staff to each subject on interpreting their scores. Subjects are instructed to retain their results for future comparison and reflection with other organizational data to be provided during the MEP sessions. As the MEP nears completion, subjects are informed by the staff of the research project. The twelve lifestyles scores along with other test results and biographical infor- 
mation, is then requested to be copied by respondents onto a summary sheet. Providing this information is strictly voluntary and no names are requested. While only one subject elected not to respond, one hundred fifty two cases were obtained with complete data. One-hundred fifty eight subjects had enough data to clearly define them into a sample and include data for hypotheses testing. The completed summary form was photocopied by the MEP staff and mailed to the primary researcher.

Upon receipt, the primary researcher assigned a subject number to each summary form and entered the results into a statistical package for the Social Science (spss) computer data file. Information on the data file was verified against the data on the summary forms by subject number prior to running any statistical tests. The data file is then used with the various spss programs requested by the primary researcher for hypotheses testing. The comparative Lafferty samples profiles are reported in Appendix B (Figures 4-7). NASA technical manager's and NASA nontechnical managers self-concept profiles are derived and reported in Appendix C (Figures 8-9).

\section{Methods}

The eighteen hypotheses making up this research are defined in chapter I (pages 14-27). These hypotheses are categorized into seven groups for analysis: Satisfaction

Reproduced with permission of the copyright owner. Further reproduction prohibited without permission. 
Variables; Security Variables; Task Variables; People Variables; Self-actualize Variables; strain related Variables; and, Biographical Relationships.

The first five groups are evaluated, using standard tests for an analysis of two means, comparing the NASA technical managers' sample means with the NASA non-technical managers' sample and, in turn, the Lafferty engineers', supervisors' and mid-level managers' sample means. Acceptance and rejection regions for z-tests at .05 level of significance are defined for each hypothesis and evaluated. The results are reported in Chapter Five.

The sixth group, strain Related Variables, is evaluated using Kendall's nonparametric "coefficient of concordance." This test is particularly suited to an evaluation of the relative agreement or association in the lifestyle variables scores of the NASA technical managers" sample and the scores of the three Lafferty strain Related Samples--those of individuals experiencing depression, ulcers and high blood pressure. The raw score of each lifestyle is converted to a percentile of the general population sample and these percentiles are rank ordered within each test sample. The coefficient of concordance, $W$, expresses the average agreement, on a scale from .00 to 1.00 , between the ranks. W can be expressed as the ratio between the "between-groups" (or ranks) sum of squares and the "total" sum of squares of a complete analysis of variance of the 
ranks. If there were no association whatever between the two respective test groups, then the rank-order coefficient of correlation should be near zero. On the other hand, if there is agreement between the two test groups, then the coefficient should be significantly different from zero (Kerlinger 1973, pp. 292-295). To evaluate the significance of $W$, Kendalls $\mathrm{E}$ ratio test is used, which is significant at the .01 level (Kendall 1948). The results of these tests are also reported in chapter Five.

The seventh group, Biographical Relationships, is evaluated by dividing the scores for each biographical variable into two groups: (1) those reporting higher than the means of the biographical variables measured (age, tenure, years in grade, management experience); and, (2) those reporting lower than these same means. The technical managers' mean scores for concern and lifestyle variable are then tested between the high and low groups for each of the four biographical variables. Acceptance and rejection regions for z-tests at .05 level of significance are defined for each hypothesis and evaluated. The results are also reported in Chapter Five.

\section{PROBLEMS ENCOUNTERED}

Four problems became apparent in the conduct of the research. The first problem relates to biographical variables, the second to the 51-L accident, the third to the 
Lafferty samples and the final problem to tests of statistical significance. Each problem was satisfactorily resolved and an brief summary of each resolution follows.

\section{Biographical Variables}

It soon became apparent that while the biographical section of the pre-existing summary sheet used to compile biographical data had several limitations, the primary researcher was restricted from making changes due to his organizational distance from the MEP program operations. Time review constraints stated by the MEP staff meant that in order to maintain their cooperation, changes to the existing form should be minimized. Since many of the other elements of the MEP were undergoing simultaneous change, there was little time remaining by the staff to focus on extensive revision of the sumnary form.

of particular concern to the primary researcher was:

1. The lack of specific educational background information.

2. The lack of Aerospace Technician background information.

3. The lack of information on specific level of management assignment.

4. The lack of specific information on history of subject performance in $R \& D$ work.

Reproduced with permission of the copyright owner. Further reproduction prohibited without permission. 
5. The lack of clear descriptions for functional areas listed on the sumary form.

The first four deficiencies listed above result in a reduced ability to explain results. This additional information would be valuable but is not necessary to the success of the design. The final problem requires the researcher to use special care in the coding of the functional area information, as reported by subjects, to assure correct data entry. None of these flaws in themselves, nor is the accumulation, considered fatal.

Traditionally, program, project, engineering, resaarch and technical areas have been management assignments for aerospace technicians, and therefore $R \& D$. Accordingly, any indication of this responsibility resulted in an assignment to the technical manager's sample. An indication of resource or administrative functions, without one of the five technical categories being indicated, resulted in an assignment to the nontechnical manager's sample. Each summary form where "other" is indicated was reviewed and a judgement decision made as to assignment. Generally, these indications were such non-technical management fields as legislative affairs or procurement.

While the definitions were less explicit than the researcher desired, each NASA function carries with it a generally accepted meaning within the agency cultural vocabulary and this meaning was used by the researcher. 


\section{Mission 51-L Accident}

The accident, which occurred midway in the study, raised the question of its immediate effect on the subjects. But as the confidentiality of the subjects was an issue, no suitable means existed to retest the initial group for effects. Differences between the pre 51-L and post 51-L groups were measured, however, but there were no significant differences between the two groups attributable to the accident and the results are not reported. The main research concern by NASA management was that irresponsible research, conducted without a valid statistical basis, might lead to a public misunderstanding of the organization's management. Since the research was not designed to test for these types of considerations, there are no conclusions set forth regarding the association between NASA managers' selfconcepts and the tragic Mission $51 \mathrm{~L}$.

\section{Lafferty Samples}

Information on the Irafferty supervisors' and mid-level managers' samples (Lafferty 1980, pp. 48-49) provides adequate information for a comparison of the descriptive statistics required. The initial Lafferty engineers' samples reported means and sample size but no standard deviation information. Further sample data was requested from Lafferty and provided by the Director of Product Development and Research, Human Synergistics, Dr. John 
Cannarsa (1988). None of the Lafferty samples were random in origin but all are large samples taken from the extensive validity testing initially accomplished across many organizations and subsequent measurement has reinforced the description offered by these results. They provide the best source of data for comparison with the NASA technical managers' sample and adequate description exists to be confident in results.

\section{Statistical Significance}

As nejther the NASA nor the Iafferty samples are random in origin the question arises as to the methods to be used in defining the descriptive statistics. It is necessary to explore the background and substance of related arguments. In the context of some who have interpretied Fisher's (1951) classical work, one who uses statistical tests on a population commits the serious error of overgeneralization to possibly unknown but certainly inappropriate "other" circumstances. Wherever one can, by definition, provide only nonprobability samples then descriptive statistics are valid to the study of that "real" population. In contrast, when one has a probability (random) sample, those with inferential statistical hypothesis tests are appropriate.

There is inherent reality to descriptive statistics (i.e., means, standard deviations, ranges) that directly 
measure concrete single variables. Here the scores themselves provide anchors for perception and analysis. However, statistics which portray concepts, such as covariance, have no such built in reference points for analysis. Using the example of a Pearson's product-moment correlation coefficient of, for instance, -.83 lends itself only to the interpretation that there is an inverse association between two variables. How strong that association is depends on a point of reference which can be anywhere between plus or minus 1.00 . If one wishes to interpret the strength of the correlation portrayed by this statistic, a statistical hypothesis test is required, whether it is executed or not.

In comparing the NASA technical managers with the NASA non-technical managers and Lafferty samples, no difficulty is evident in hypotheses testing. The effect is to limit the hypotheses that can be tested between the NASA technical managers and Lafferty samples to the individual lifestyles. The total of the four concern variables (satisfaction, security, task, and people) could not be tested between these groups. As a result hypotheses were not set forth, although the results might prove interesting.

While correlations between lifestyle/ concern variables and biographical variables were derived, the researcher elected to derive hypotheses and test for differences between the means reported by high and low groups 
of managers for each biographical variables, as explained in the Methods section of Chapter Four. This is especially valid in this research since there is some degree of internal relationship between the four biographical variables. The results between the high and low groups can easily be compared for each of the four biographical measures, to determine relative strength of between biographical variables on their association with the lifestyle and concern variables. Again the difficulty is not in testing the stated hypotheses, nor in finding adequate evidence, but rather in not being able to find additional data that would be rather interesting.

\section{SUMMARY OF RESEARCH DESIGN}

The design of the research is to obtain valid results defining the self-concept competency of NASA technical managers in comparison with NASA non-technical managers, engineers, supervisors, and mid-level managers. Hypotheses were derived which are tested by three methods.

The first ten hypotheses $(1-10)$ are tested for significance by comparing the means of the NASA technical managers' lifestyles and concern variables with the means of the NASA non-technical managers' and Lafferty samples' lifestyle and concern variables (Significance $=.05) . \mathbf{S i g -}$ nificant findings indicate important departures from other

Reproduced with permission of the copyright owner. Further reproduction prohibited without permission. 
groups of managers and indicate a greater or less selfconcept competency, depending on the variable tested.

The second three hypotheses (11-13) are tested for significance by using Kendall's nonparametric coefficient of concordance to evaluate the similarity of rank order between the lifestyle percentiles of NASA technical managers and the rank order lifestyle percentiles of individuals experiencing three symptoms of strain. If significant differences between the NASA technical managers and strain groups do not exist, then it is an indication that high numbers of NASA managers might be expected to evidence strain symptoms, particularly in times of stress.

The final four hypotheses (14-17) are tested for significance by breaking NASA technical managers' into two groups for each biographical variable at their respective means. NASA managers older and younger than mean age, greater and less than mean tenure, greater and less than mean years Grade $14 / 15$ and greater and less than mean years experience as a manager are given standard tests for significance between the two respective groups. The results provide data indicating how the self-concept competency of NASA technical managers are associated with age, tenure, years experience at Grade $14 / 15$ and management experience. 


\title{
CHAPTER V
}

\section{RESULTS}

TEST GROUPS

\begin{abstract}
As previously stated ${ }^{1}$, the eighteen research hypotheses are categorized into seven groups of tests for reporting purposes: Satisfaction Variables; Security Variables; Task Variables; People Variables; Self-Actualize Variable; Strain Related Variables; and, Biographical Relationships. The results of hypotheses testing are reported within this chapter. Testing completed on other lifestyle variables not included in the hypotheses testing is reported in Appendix D.
\end{abstract}

\section{SATISFACTION VARIABLES TESTING}

\section{Hypothesis One: Satisfaction Concern}

The NASA non-technical managers' mean satisfaction concern (Table IV) is 5.6 raw points higher than the NASA technical managers' mean satisfaction concern, and testing established this difference as significant (.05). The means of both NASA groups are considerably higher than the means of Lafferty supervisors and mid-level managers. The NASA

${ }^{1}$ See Hypotheses in Chapter One. 
TABIE IV

TEST FOR HYPOTHESIS GNE

\section{Samole}

NASA Technical Mgrs. NASA Non-technical Mgrs.

Lafferty Engineers

Lafferty Supervisors

Lafferty Mid-Level Mgrs. 4500
Mean

$\underline{\text { n }}$

117

41

52

496

\section{Satisfaction S.D. Variance}

$\begin{array}{lll}138.47 & 21.67 & 469.58 \\ 144.07 & 19.15 & 366.62 \\ 137.80 & --- & - \\ 123.98 & - & - \\ 121.42 & - & -\end{array}$

1. NULU HYPOTHESIS ONE: There is no significant difference between the mean satisfaction concern self-concept score of the NASA technical managers and the NASA non-technical managers' mean satisfaction concern self-concept score.

2. ALTERNATE HYPOTHESIS ONE: The mean satisfaction concern selfconcept score of the NASA technical managers is significantly different from the NASA non-technical managers' mean satisfaction concern self-concept score.

3. TEST:

$$
z=-2.04
$$

4. REJECTION REGION:

$$
\text { Significance }=.05 ; z>1.96 ; \text { or }\langle-1.96
$$

\section{RESULTS:}

Rejected; NASA technical managers' mean satisfaction concern selfconcept score is significantly lower from the NASA non-technical managers' mean satisfaction concern self-concept score. 
technical managers" satisfaction mean is similar to the mean satisfaction score of the Lafferty engineers.

The NASA technical managers' scores have a greater variance around their means than the NASA non-technical managers' scores. As the researcher is provided only the Lafferty sample results (rather than the raw data), and Lafferty does not summarize concern data in his test results for satisfaction, security, task or people concern, standard deviations and tests of significance cannot be compared between the NASA and Lafferty samples for these variables. 2 In general, test results demonstrate that there is a basic difference in satisfaction concern between the selfconcepts of the NASA technical and non-technical managers. Technical managers demonstrate less satisfaction concern in their self-concepts than their non-technical counterparts. While significant contrasts between the NASA groups and the Lafferty groups cannot be tested, it is apparent that both NASA groups have greater satisfaction concern than the Lafferty groups. It is clear that the NASA non-technical managers' satisfaction is high for any test sample.

\section{Hypothesis Two: Humanistic Helpful Lifestyle}

Tests between the NASA technical managers' mean humanistic-helpfulness lifestyle mean and the NASA nontechnical managers', Lafferty engineers', Lafferty

${ }^{2}$ See Statistical Significance in Chapter Four. 
supervisors', and Lafferty mid-level managers' humanistichelpfulness lifestyles' means discovered significant differences between the NASA technical managers and two of the Lafferty groups (Table V). The mean of the NASA technical. managers' scores is found to be significantly higher than the means of the Lafferty supervisors and mid-level managers' scores (.05). No significant differences are revealed in the tests between NASA technical managers and the NASA non-technical managers or Lafferty engineers.

standard deviation for the NASA technical managers scores is less from their mean than are the standard deviations of the Lafferty supervisors and managers. This would indicate that NASA technical managers are more uniform about their higher humanistic-helpful lifestyle mean than are the Lafferty supervisors and mid-level managers around their means. The NASA non-technical managers' standard deviation closely approximates that of the Lafferty engineers and both are nearly a half unit lower than the standard deviation of the NASA technical managers' scores.

These findings strongly suggest that NASA technical managers have an increased motivation towards helpfulness in their self-concepts than do the supervisors and mid-level managers tested by Lafferty. The means of the NASA technical and non-technical managers' helpfulness lifestyles exceed the sixty-fifth percentile when compared with the Lafferty General Population Profile (Appendix B: Figure 4) 
TABLE V

TEST FOR HYPOTHESIS TMO

Sample

NASA Technical Mgrs.

NASA Non-technical Mgrs.

Lafferty Engineers

Lafferty Supervisors

Lafferty Mid-level Mgrs.
Mean

n Helpfulness

29.55

30.61

30.70

27.15

26.63
S.D.

5.42

4.99

5.00

6.83

7.52
Variance

29.38

24.90

25.00

46.65

56.55

1. NULL HYPOTHESIS TWO: There is no significant difference between the mean humanistic-helpful lifestyle self-concept score of the NASA technical managers and the:

a. NASA non-technical managers', or the

b. Lafferty engineers',

c. supervisors', or

d. mid-level managers"

mean humanistic-helpful lifestyle self-concept scores.

2. ALTERNATIVE HYPOTHESIS TWO: The mean humanistic-helpful lifestyle self-concept score of the NASA technical managers is significantly different from the NASA non-technical managers', or the Lafferty engineers', supervisors', or mid-level managers' mean humanistichelpful lifestyle self-concept scores.

3. TEST:
a. $\quad z=-1.14$
b. $\quad z=-1.35$
c. $\quad z=+4.14$
d. $\quad z=+5.73$

4. REJECTION REGION: Significance $=.05 ; z>1.96 ;$ or $<-1.96$

5. RESULTS:

a. Accepted; There is no significant difference.

b. Accepted; There is no significant difference.

c. Rejected; NASA technical managers' mean humanistic-helpful lifestyle self-concept score is significantly higher than the mean Lafferty supervisors" humanistic-helpful lifestyle selfconcept score.

d. Rejected; NASA technical managers' mean humanistic-helpful life style self-concept score is significantly higher than the mean Lafferty mid-level managers' humanistic-helpful lifestyle selfconcept score. 
and strongly confirm this as an identifying characteristic of NASA management, including $R$ \& $D$ managers. It is higher, although not significantly so, than in the self-concepts of Lafferty Engineers.

Interestingly, the humanistic-helpful lifestyle characteristic is even stronger in the NASA non-technical managers' self-concepts than in the self-concepts of their technical counterparts (although this mean is not significantly higher). If the NASA technical manager has a self-concept motivation to be helpful, the NASA nontechnical managers has an even greater motivation to be so.

\section{Hypothesis Three: Achievement Lifestyle}

The test between the NASA technical managers' achievement lifestyle mean and the NASA non-technical managers', Lafferty engineers', Lafferty supervisors' and Lafferty mid-level managers' achievement lifestyle means reveals significant differences between the same test groups that differed in helpfulness (Table VI). NASA technical managers indicate even higher $\mathrm{z}$ scores when tested for achievement than for helpfulness against these groups. As with the humanistic-helpful lifestyle, test comparisons with the NASA non-technical managers and Lafferty engineers were not significant, although both NASA groups indicated higher means in achievement than in helpfulness. 
TABLE VI

TEST EOR HYPOTHESIS THREE

Sample

NASA Technical Mgrs. NASA Non-technical Mgrs. Lafferty Engineers

Iafferty Supervisors

Lafferty Mid-level Mgrs.

\author{
Mlean \\ n Achievement
}

117

41

52

496

4500
31.04

31.46

30.50

27.62

26.27
S.D.

5.45

5.04

5.40

8.29

8.43

\section{$\underline{\text { Variance }}$}

29.70

25.40

29.16

68.72

71.06

1. NULL HYPOTHESIS THREE: There is no significant difference between the achievement lifestyle self-concept score of the NASA technical managers and the:
a. NASA non-technical managers' or the
b. Lafferty engineers',
c. supervisors', or
d. mid-level managers'

mean achievement lifestyle self-concept scores.

2. ALTERNATIVE HYPOTHESIS THREE: The mean achievement lifestyle selfconcept score of the NASA technical managers is significantly different from the NASA non-technical managers', or the Lafferty engineers', supervisors', or mid-level managers' mean achievement lifestyle self-concept scores.

3. TEST:
a. $z=-.45$
b. $z=+.60$
c. $z=+5.51$
d. $z=+9.35$

4. REJECTION REGION: Significance $=.05 ; z>1.96 ;$ or $z<-1.96$

5. RESULTS:

a. Accepted; There is no significant difference.

b. Accepted; There is no significant difference.

c. Rejected; NASA technical managers' mean achievenent lifestyle self-concept score is significantly higher than the mean achievement lifestyle self-concept score of the Lafferty supervisors.

d. Rejected: NASA technical managers' mean achievement lifestyle self-concept score is significantly higher than the mean achievement lifestyle self-concept score of the Lafferty mid-level managers. 
Again, standard deviations are relatively low for the NASA technical and non-technical managers when compared to the Lafferty supervisors and mid-level managers. They are also low when compared in achievement to the Lafferty General Population standard deviations (Appendix B: Figure 4). There is a tendency for the NASA technical and nontechnical managers to be more uniform about their achievement means than with the Lafferty supervisors and mid-level manager groups. NASA achievement standard deviations are similar to the those of the Lafferty Engineering group.

High achievement in their self-concepts is found to be an identifying characteristic of both the NASA technical and non-technical managers. As with helpfulness, the NASA nontechnical manager has an even greater achievement lifestyle in his self-concept than his technical counterpart.

\section{Other Satisfaction Variables}

A complete list of satisfaction variables includes the competence, achievement, self-actualize, helpfulness, and affiliative lifestyles. The competence lifestyle is also a task concern variable and the affiliation lifestyle is also a people concern variable. These lifestyles are reported with their respective alternative concern group. The selfactualize lifestyle is reported as a separate group.

Reproduced with permission of the copyright owner. Further reproduction prohibited without permission. 


\section{SECURITY VARIABLES TESTING}

\section{Hypothesis Four: Security Concern}

The mean security concern of the NASA technical managers is approximately two raw points higher than the mean of the NASA non-technical managers. The means of both NASA groups are considerably lower than the means of the Lafferty engineers and supervisors, and somewhat similar to the means of the Lafferty mid-level managers. Testing for a difference in security concern (Table VII) between the NASA technical managers and the NASA non-technical managers yielded no significant results $(.05)$.

The NASA non-technical managers vary less around their mean than do the NASA technical managers. Standard deviations and significance cannot be compared between the NASA and Lafferty samples for the reasons previously stated. ${ }^{3}$ Test results demonstrate that there is no basic difference in security concern between the self-concepts of NASA technical and NASA non-technical managers. While significance between the NASA and the Lafferty groups cannot be tested, it is apparent that the NASA groups, similar to the Lafferty mid-level managers, are considerably less concerned about security than the Lafferty engineers or supervisors.

\footnotetext{
${ }^{3}$ See Statistical Significance in Chapter Four.
} 
TABLE VII

TEST FOR HYPOTHESIS FOUR

Sample

NASA Technical Mgrs.

NASA Non-technical Mgrs.

Lafferty Engineers

Lafferty Supervisors

Lafferty Mid-level Mgrs.
Mean

n Security

117

42

52

496

4500
47.83

45.71

51.00

50.05

44.60
S.D. Variance

20.62

$17.01 \quad 289.31$

- - - -

1. NULU HYPOTHESIS FOUR: There is no significant difference between the mean security concern self-concept score of the NASA technical managers and the NASA non-technical managers' mean security concern self-concept score.

2. ALTERNATIVE HYPOTHESIS EOUR: The mean security concern self-concept score of the NASA technical managers is significantly different from the NASA non-technical managers' mean security concern self-concept score.

3. TEST: $z=+.65$

4. REJECTION REGION: Significance $=.05 ; z>1.96$; or $\langle-1.96$

5. RESULTS:

Accepted; There is no significant difference. 


\section{Hypothesis Five: Dependent Variable}

The NASA technical managers' dependent lifestyle is significantly greater $(.05)$ in their self-concepts than in those of the Lafferty mid-level manager' self-concepts (Table VIII). Tests between the NASA technical managers' dependent lifestyle mean and the dependent lifestyle means of the other samples were not significant.

NASA non-technical managers' scores indicate that they do not have quite the intensity of dependent lifestyle motivation than do the NASA technical managers. Both the NASA samples indicate less dependency than the Lafferty Engineers but slightly more than the Lafferty Supervisors. NASA non-technical managers' scores demonstrate less deviation from their means than do the scores of the NASA technical managers. The variance of both groups is less than with the Lafferty samples.

The dependent lifestyle motivation also appears to be an identifying characteristic of the NASA technical and non-technical managers' self-concepts, when their lifestyle means are compared to those of the general population (Appendix B: Figure 4; Appendix C: Figures 8 and 9 ) and mid-level managers, although it is not as strong a defining indicator as the helpfulness and achievement lifestyles. 
TABLE VIII

\section{TEST FOR HYPOTHESIS FIVE}

\section{Sample}

NASA Technical Mgrs.

NASA Non-technical Mgrs.

Lafferty Engineers

Lafferty Supervisors

Lafferty Mid-level Mgrs. 4500
Mean

n Dependent

117

41

52

496
15.20

14.51

16.10

14.41

11.57

\section{S.D.}

4.99

4.56

5.10

6.08

6.76
Variance

25.90

20.76

26.01

36.97

45.70

1. NULU HYPOTHESIS FIVE: There is no significant difference between the mean NASA technical Managers' dependent lifestyle self-concept score and the:

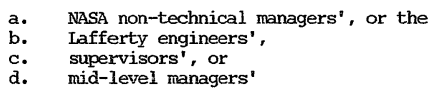

mean dependent lifestyle self-concept scores.

2. ALTERNATIVE HYPOTHESIS FIVE: The mean dependent lifestyle selfconcept score of the NASA technical managers is significantly different from the NASA non-technical managers', or the Iafferty engineers', supevisors', or mid-level managers' mean dependent lifestyle self-concept scores.

3. TEST:
a. $z=+.81$
b. $z=-1.07$
c. $z=+1.49$
d. $z=+7.72$

4. REJECTION REGION: Significance $=.05 ; z>1.96 ;$ or $z<-1.96$

5. RESULTS:
a. Accepted; There is no significant difference.
b. Accepted; There is no significant difference.
c. Accepted; There is no significant difference.
d. Rejected; NASA technical managers" mean dependent lifestyle self-concept score is significantly higher than the mean dependent lifestyle self-concept score of the Lafferty mid-level managers.




\section{other Security Variables}

A complete list of security variables includes the conventional, dependent, avoidance, oppositional and power lifestyles (Figure 1). The conventional lifestyle is also a people concern variable and the power lifestyle is also a task concern variable and they are discussed in these respective test group hypotheses reports. Tests were also accomplished on the avoidance and oppositional lifestyles (Appendix D: Table XXIII).

\section{TASK VARIABLES TESTING}

\section{Hypothesis Six: Task Concern}

While NASA non-technical managers demonstrate a slightly stronger task concern (Table IX) than NASA technical managers, this difference is not considered significant (.05). Both groups' task concern means are similar to those of the Lafferty engineers and are considerably greater (approximately 6-10 raw points) than the task concern means of the Lafferty supervisors and mid-level managers.

NASA technical managers deviate less from their mean than do the NASA nontechnical managers. Standard deviations and significance for the Lafferty groups cannot be obtained for the reasons previously stated.4

\footnotetext{
${ }^{4}$ See Statistical Significance in Chapter Four.
} 
TABLE IX

TEST EOR HYPOTHESIS SIX

\begin{tabular}{|c|c|c|c|c|}
\hline Sarmple & $\underline{\mathbf{n}}$ & $\begin{array}{l}\text { Mean } \\
\text { Task }\end{array}$ & S.D. & Variance \\
\hline NASA Technical Mgrs. & 117 & 76.07 & 19.56 & 382.75 \\
\hline NASA Non-technical Mgrs. & 41 & 77.63 & 21.36 & 456.14 \\
\hline Lafferty Engineers & 52 & 76.80 & - & --- \\
\hline Lafferty Supervisors & 496 & 70.36 & --- & --- \\
\hline Lafferty Mid-level Mgrs. & 4500 & 67.25 & -_-- & $--\infty$ \\
\hline
\end{tabular}

1. NULL HYPOTHESIS SIX: There is no significant difference between the mean task concern self-concept score of the NASA technical managers and the NASA non-technical managers' mean task concern self-concept score.

2. ALTERNATE HYPOTHESIS SIX: The mean task concern self-concept score of the NASA technical managers is significantly different from the NASA non-technical managers' mean task concern self-concept score.

3. TEST: $\mathrm{z}=-.41$

4. REJECTION REGION: Significance $=.05 ; z>1.96$; or $z<-1.96$

5. RESULTS:

Accepted; There is no significant difference.

Reproduced with permission of the copyright owner. Further reproduction prohibited without permission. 
NASA technical and NASA nontechnical managers' selfconcepts are not significantly different in their task orientation. Task concern in both NASA samples is considerably less than for people concern. This characteristic is shared in the self-concepts tested from the Lafferty samples.

\section{Hypothesis Seven: Competence Lifestyle}

NASA technical managers are significantly different (.05) from the Lafferty supervisors and mid-level managers groups when tested for the competence lifestyle (Table $x$ ). NASA technical managers demonstrate a much higher competence lifestyle mean than these groups, a slightly higher competence lifestyle than the Lafferty engineers, and a lower competence lifestyle than the NASA non-technical managers. NASA technical and non-technical managers deviate less from their competence variable means than do the Lafferty supervisors and mid-level managers deviate, and more than the Lafferty engineers deviate.

The competence lifestyle is also an identifying characteristic of the NASA technical and non-technical managers' self-concepts. Both of these groups exceed the Lafferty groups in demonstrating a competence motivation in their self-concepts.

Reproduced with permission of the copyright owner. Further reproduction prohibited without permission. 
TABLE $\mathrm{X}$

TEST FOR HYPOTHESIS SEVEN

Sample

NASA Technical Mgrs.

NASA Non-technical Mgrs.

Lafferty Engineers

Lafferty Supervisors

Lafferty Mid-level Mgrs. 4500
Mean

n Competence

$117 \quad 19.81$

$41 \quad 20.63$

$52 \quad 18.70$

$496 \quad 18.11$

17.85
S.D.

5.40

6.36

4.90

6. 68

7.31
Variance

29.19

40.44

24.01

44. 62

53.44

1. NUL HYPOTHESIS SEVEN: There is no significant difference between the mean competence lifestyle self-concept score of the NASA technical managers and the:

a. NASA non-technical managers', or the

b. Lafferty engineers',

c. supervisors', or

d. mid-level managers'

mean competence lifestyle self-concept scores.

2. ALTERNATIVE HYPOTHESIS SEVEN: The mean competence lifestyle selfconcept score of the NASA technical managers is significantly different from the NASA non-technical managers', or the Lafferty engineers", supervisors', or mid-level managers' mean dependent lifestyle self-concept scores.

3. TESTS:
a. $z=-.80$
b. $z=+1.32$
c. $z=+2.93$
d. $z=+3.84$

4. REJECTION REGION: Significance $=.05 ; z>1.96 ;$ or $z<-1.96$

5. RESULTS:

a. Accepted; There is no significant difference.

b. Accepted; There is no significant difference.

c. Rejected; NASA technical managers' mean competence lifestyle self-concept score is significantly higher than the mean competence lifestyle self-concept score of the Lafferty supervisors.

d. Rejected; NASA technical managers' mean competence lifestyle self-concept score is significantly higher than the mean competence lifestyle self-concept score of the Lafferty supervisors. 


\section{other Task Variables}

A complete list of task variables includes the achievement, competence, competitive, power, and oppositional lifestyles (Figure 1). The achievement lifestyle is also a satisfaction concerr variable and the oppositional lifestyle is also a security concern variable. These variables are discussed in the reports from their respective hypotheses testing groups. Tests were also completed on the competitive and oppositional lifestyle variables (Appendix D: Table XXIV).

\section{PEOPLE VARIABLES TESTING}

\section{Hypothesis Eight: People Concern}

The NASA technical managers' people concern score is slightly more than two raw points lower than the NASA nontechnical managers' score (Table XI), a difference which is not statistically significant $(.05)$. The means of both groups are quite less than that of the Lafferty Engineers, and yet are considerably more than those means of the Lafferty supervisors and mid-level managers.

NASA technical managers have a greater variance around their mean than the non-technical managers demonstrate. As before, the variance scores cannot be contrasted between the NASA and Lafferty groups. 5

\footnotetext{
${ }^{5}$ See Statistical Significance in Chapter Four.
} 
TABLE XI

TEST FOR HYPOIHESIS EIGHT

\begin{tabular}{lrrll} 
Sample & \multicolumn{5}{c}{} & $\begin{array}{c}\text { Mean } \\
\text { People }\end{array}$ & S.D. & Variance \\
NASA Technical Mgrs. & 117 & 100.70 & 17.80 & 316.83 \\
NASA Non-technical Mgrs. & 41 & 102.32 & 16.76 & 280.92 \\
Lafferty Engineers & 52 & 105.00 & - & -- \\
Lafferty Supervisors & 496 & 95.19 & -- & - \\
Lafferty Mid-Level Mgrs. & 4500 & 90.47 & --
\end{tabular}

1. NULL HYPOTHESIS EIGHT: There is no significant difference between the mean people concern self-concept score of the NASA technical managers and the NASA non-technical managers' mean people concern self-concept score.

2. ALTERNATIVE HYPOTHESIS EIGHT: The mean people concern selfconcept score of the NASA technical managers is significantly different from the NASA non-technical managers' mean people concern self-concept score.

3. TEST: $z=-.52$

4. REJECTION REGION: Significance $=.05 ; z>1.96$; or $z<-1.96$

5. RESULTS:

Accepted; There is no significant difference. 
NASA technical and non-technical managers are similar in the people concern of their self-concepts. People concern scores for each group of NASA managers' tested about $133 \%$ of the task concern scores, demonstrating a relatively high scale orientation toward people. These people concern scores are about $70-75 \%$ of the satisfaction concern scores, and about $200+\%$ of the security concern scores

\section{Hypothesis Nine: Affiliation Lifestyle}

A significant $(.05)$ difference was found to exist between the NASA technical managers' and the NASA nontechnical managers' and the Lafferty supervisors' and midlevel managers' affiliation lifestyle scores (Table XII). The affiliation lifestyle score of the NASA technical managers was similar to that of the Lafferty engineers. The standard deviation of the NASA technical managers" scores was also similar to the standard deviation of the Lafferty engineers. It was less than the scores of the Lafferty supervisors and mid-level managers and greater than the standard deviation of the NASA non-technical managers. While the affiliation lifestyle score of the NASA technical managers is significantly higher than those of the Lafferty supervisors and mid-level managers, it is significantly lower than that of the non-technical managers.

Reproduced with permission of the copyright owner. Further reproduction prohibited without permission. 
TABLE XII

TEST FOR HYPOTHESIS NINE

\begin{tabular}{|c|c|c|c|c|}
\hline Sample & $\underline{\mathbf{n}}$ & $\begin{array}{c}\text { Mean } \\
\text { Affiliation }\end{array}$ & S.D. & Variance \\
\hline NASA Technical Mgrs. & 117 & 29.30 & 6.27 & 39.31 \\
\hline NASA Non-technical Mgrs. & 41 & 31.34 & 4.41 & 29.23 \\
\hline Lafferty Engineers & 52 & 29.80 & 6.20 & 38.44 \\
\hline Lafferty Supervisors & 496 & 26.86 & 6.98 & 48.72 \\
\hline Lafferty Mid-level Mgrs. & 4500 & 27.10 & 7.21 & 51.98 \\
\hline
\end{tabular}

1. NULL HYPOTHESIS NINE: There is no significant difference between the mean affiliation lifestyle self-concept score of the NASA technical managers and the:

a. NASA non-technical managers', or the

b. Lafferty engineers',

c. supervisors', or

d. mid-level managers'

mean affiliation lifestyle self-concept score.

2. ALTERNATIVE HYPOTHESIS NINE: The mean affiliative lifestyle self-concept score of the NASA technical managers is significantly different from the NASA non-technical managers', or the Lafferty engineers', supervisors', or mid-level managers' mean dependent lifestyle self-concept scores.

3. TESTS:

$\begin{array}{ll}\text { a. } & z=-2.00 \\ \text { b. } & z=-.49 \\ \text { c. } & z=+4.14 \\ \text { d. } & z=+3.79\end{array}$

4. REJECTION REGION: Significance $=.05 ; z>1.96 ;$ or $z<-1.96$

5. RESULTS:

a. Rejected; NASA technical managers' mean affiliative lifestyle self-concept score is significantly lower than the mean affiliative lifestyle self-concept score of the NASA nontechnical managers.

b. Accepted; There is no significant difference.

c. Rejected; NASA technical managers' mean affiliative lifestyle self-concept score is significantly higher than the mean affiliative lifestyle self-concept score of the Lafferty supervisors.

d. Rejected; Rejected; NASA technical managers' mean affiliative lifestyle self-concept score is significantly higher than the mean affiliative lifestyle self-concept score of the Lafferty mid-level managers. 
It is, however, another distinctive self-concept attribution of both NASA groups.

\section{other People Variables}

A complete listing of people variables includes the humanistic-helpfulness, affiliation, approval, conventional, and dependent lifestyles (Figure 1). The humanistichelpfulness lifestyle is also a satisfaction concern variable and the dependent lifestyle is also a security concern variable. Each of these lifestyles are reported in their alternative hypotheses testing group. Tests were also performed on the approval and conventional lifestyle variables (Appendix D: Table XXV).

\section{SELF-ACTUALIZE LIFESTYLE}

\section{Hypothesis Ten: Self-Actualize Lifestyle}

While the NASA technical managers' self-actualize lifestyle (Table XIII) was not significantly different from the NASA non-technical and Lafferty engineers' selfactualize lifestyles, the tests were significant when contrasted with the Lafferty supervisors and mid-level managers' self-actualization (.05). NASA technical managers have significantly higher self-actualization than the selfactualization reported in the self-concepts of these two groups.

Reproduced with permission of the copyright owner. Further reproduction prohibited without permission. 
TABLE XIII

TEST FOR HYPOTHESIS TEN

\section{Sample}

NASA Technical Mgrs. NASA Non-technical Mgrs.

Lafferty Engineers

Lafferty Supervisors

Lafferty Mid-level Mgrs. 4500
Mean

I Self-Actualize S.D. Variance

28.77

30.02

28.10

24.24

23.57
6.14

5.45

5.90

6.98

7.49
37.64

29.72

34.81

48.72

56.10

1. NULL HYPOTHESIS TEN: There is no significant difference between the mean self-actualize lifestyle self-concept score of the NASA technical managers and the:

a. NASA non-technical managers', or the

b. Lafferty engineers',

c. supervisors", or

d. mid-level managers'

mean self-actualize ifestyle self-concept score.

2. ALTERNATIVE HYPOTHESIS TEN: The mean self-actualize lifestyle score of the NASA technical managers is significantly different from the NASA non-technical managers', or the Lafferty engineers', supervisors', or mid-level managers' mean dependent lifestyle self-concept scores.

3. TESTS:
a. $z=-1.25$
b. $\quad z=+.68$
c. $\quad z=+7.08$
d. $z=+9.12$

4. REJECIION REGION: Significance $=.05 ; z>1.96$ or $z<-1.96$

5. RESULTS:

a. Accepted; There is no significant difference.

b. Accepted; There is no significant difference.

c. Rejected; NASA technical managers' self-actualize lifestyle self-concept score is significantly higher than the mean self-actualize lifestyle self-concept score of the Lafferty supervisors.

d. Rejected; NASA technical managers' self-actualize lifestyle self-concept score is significantly higher than the mean self-actualize lifestyle self-concept score of the Lafferty mid-level managers. 
NASA technical managers' self-actualize standard deviation is greater than those of the NASA non-technical managers and Lafferty engineers and less than those of the Lafferty supervisors and non-technical managers.

It appears that both NASA managerial groups have been relatively successful in obtaining a self-concept integration of task and people concerns and in pursuing satisfaction. While both scores are distinctive, it is the nontechnical managers' self-actualize lifestyle which appears to be the most significant in its departure from the selfconcepts of other groups, including those of the Lafferty general population samples (Appendix B: Figure 4).

\section{STRAIN RELATED VARIABLES}

\section{Hypothesis Eleven: Depressed Individuals}

Kendall's "coefficient of concordance" was computed, determining the relative agreement or association between the lifestyle variable scores of the NASA technical managers" lifestyle means and the means of the Lafferty sample of individuals who had reported a medical diagnosis of depression (Table XIV). This coefficient, $w=.19$, is quite low and statistically not significant at the .01 level. It is apparent that there is little agreement between the two groups of scores.

A careful examination finds much to contrast between the lifestyle scores of NASA technical managers and those in- 
TABLE XIV

TEST FOR HYPOTHESIS ELEVEN

\section{Lifestyle}

1. HumanisticHelpful

2. Affiliative

3. Approval

4. Conventiona 1

5. Dependent

6. Avoidance

7. Oppositional

8. Power

9. Competitive

10. Competence

11. Achievement

12. Self-

Actualize

$$
\text { Depression Sample }
$$

Raw

Score/tile/ Order

$\begin{array}{rrr}9.0 & 11 & (11) \\ 11.0 & 13 & (9.5) \\ 13.0 & 67 & (3) \\ 8.0 & 25 & (5.5) \\ 13.0 & 60 & (4) \\ 15.0 & 90 & (1) \\ 12.0 & 85 & (2) \\ 1.0 & 25 & (5.5) \\ 3.0 & 19 & (7) \\ 5.0 & 13 & (9.5) \\ 11.0 & 14 & (8) \\ 5.0 & 3 & (12)\end{array}$

Tech. Mgrs. Sample

Raw \% Rank

Score/tile/ order

1. NULL HYPOTHESIS ELEVEN: There is no significant difference between the rank order of the NASA technical managers' general population percentiles of their twelve lifestyle means and the rank order of the Lafferty depressed individuals sample's general population percentiles of their twelve lifestyle means.

2. ALTERNATE HYPOTHESIS ELEVEN: The rank order of the NASA technical managers' general population percentiles of the twelve lifestyle means and the rank order of the Lafferty depressed individuals sample's general population percentiles of their twelve lifestyle means are significantly different.

3. TEST: $\mathrm{W}=.19 ; \mathrm{F}=.23$

4. REJECTION REGION: Significance $=.01 ; \mathrm{F}<4.47$

5. RESULTS: Rejected; There is a significant difference between the two groups' rank ordered percentiles of their respective twelve lifestyle means. 
dividuals experiencing depression. While the lifestyle scoring the highest percentile in the depression sample is avoidance, it is the lowest lifestyle percentile scored by NASA technical managers. In contrast, the highest lifestyle percentile scored by the NASA technical managers is selfactualize and this lifestyle is the lowest percentile scored by the depression sample. It is also noteworthy that the third ranked depression lifestyle, approval, is the eleventh lifestyle ordered by the NASA technical managers. Only in the affiliative, dependent and competitive lifestyles does there appear to be much agreement between the two groups. The null hypothesis is not confirmed. NASA technical managers, as a group, have little self-concept similarity with those individuals experiencing depression.

\section{Hypothesis Twelve: Individuals Experiencing Ulcers}

As with hypothesis eleven, the computed Kendall coefficient, $w$, indicating the relationship between NASA technical managers and the Lafferty sample of individuals experiencing ulcers was quite low $(.39)$ and statistically not significant (Table XV). The highest ranked ulcer sample lifestyle is the competence lifestyle which is the second ranked lifestyle by NASA technical managers. The highest ranked NASA technical manager lifestyle is self-actualize which, in contrast, is ranked eleventh by the ulcer sample. Power appears as the second ranked ulcer sample lifestyle and is

Reproduced with permission of the copyright owner. Further reproduction prohibited without permission. 
TABLE XV

TEST FOR HYPOTHESIS TWELVE

\section{Lifestyle}

1. HumanisticHelpful

2. Affiliative

3. Approva 1

4. Conventional

5. Dependent

6. Avoidance

7. Oppositional

8. Power

9. Competitive

10. Competence

11. Achievement

12. Self-

Actualize

\section{Ulcers Sample}

Raw \% Rank

Score/tile/order
Tech. Mgrs. Sample

$$
\begin{gathered}
\text { Raw } \% \text { Rank } \\
\text { Score/tile/Order }
\end{gathered}
$$

$\begin{array}{rrr}29.55 & 66 & (6) \\ 29.30 & 61 & (9.5) \\ 11.79 & 60 & (11) \\ 14.86 & 64 & (8) \\ 15.20 & 71 & (3.5) \\ 5.38 & 58 & (12) \\ 6.67 & 65 & (7) \\ 5.71 & 61 & (9.5) \\ 12.83 & 70 & (5) \\ 19.81 & 74 & (2) \\ 31.04 & 71 & (3.5) \\ 28.77 & 78 & (1)\end{array}$

1. NULL HYPOTHESIS TWELVE: There is no significant difference between the rank order of the NASA technical managers' general population percentiles of their twelve lifestyle means and the rank order of the Lafferty ulcer victim sample's general population percentiles of their twelve lifestyle means.

2. ALTERNATE HYPOTHESIS ELEVEN: The rank order of the NASA technical managers' general population percentiles of their twelve lifestyle means and the rank order of the Lafferty ulcer victim sample's general population percentiles of their twelve lifestyle means are significantly different.

3. TEST: $W=.39 ; F=.64$

4. REJECTION REGION: Significance $=.01 ; \mathrm{F}<4.47$

5. RESULTS: Rejected; There is a significant difference between the two groups' rank order percentiles of their respective twelve lifestyle means.

Reproduced with permission of the copyright owner. Further reproduction prohibited without permission. 
ranked a low 9.5 (equal to affiliative) by the NASA technical managers. Besides competence, the two groups had relative agreement in the oppositional and competitive lifestyles. It is important to note that achievement ranks a low eleventh by individuals experiencing ulcers. The null hypothesis is not confirmed. An evaluation of the two groups finds little similarity between NASA technical managers and the Lafferty sample of individuals experiencing ulcers.

\section{Hypothesis Thirteen: Individuals with High Blood Pressure}

Kendall's coefficient of concordance was computed at .39 for association between the samples of NASA technical managers and the Lafferty sample of individuals with high blood pressure (Table XVI). The leading percentile lifestyle for the high blood pressure sample is, as with the ulcer sample, competence while this is the number two ranked NASA technical manager lifestyle percentile. The leading NASA technical manager lifestyle percentile is selfactualize and this lifestyle ranked 11.5 and equal to helpfulness by the high blood pressure sample. The NASA technical managers ranked helpfulness sixth by percentile. The high blood pressure sample ranked avoidance 3.5 (equal to the competitive lifestyle), while the NASA technical managers ranked avoidance twelfth. In addition to the competence lifestyle, there is relative agreement between ap- 
TABLE XVI

\section{TEST FOR HYPOTHESIS THIRTEEN}

High Blood Pressure Sample Raw \% Rank

Lifestyle Score/tile/order

\begin{abstract}
Tech. Mgrs. Sample Raw \% Rank Score/tile/order
\end{abstract}

1. HumanisticHelpful

$\begin{array}{rrr}26.0 & 50 & (11.5) \\ 26.0 & 71 & (2) \\ 11.0 & 58 & (9.5) \\ 14.0 & 60 & (7.5) \\ 13.0 & 60 & (7.5) \\ 7.0 & 69 & (2.5) \\ 6.0 & 62 & (6) \\ 6.0 & 63 & (5) \\ 13.0 & 69 & (3.5) \\ 21.5 & 79 & (1) \\ 28.0 & 58 & (9.5) \\ 23.0 & 50 & (11.5)\end{array}$

29.55

68

$29.30 \quad 61 \quad(9.5)$

3. Approval

4. Conventional

5. Dependent

6. Avoidance

7. Oppositional

8. Power

9. Competitive

10. Competence

11. Achievement

12. Self-

Actualize

11.79

14.86

15.20

60

64

5.38

6.67

5.71

58

65

12.83

19.81

$61(9.5)$

31.04

70

74

(11)

(8)

(3.5)

(12)

(7)

(5)

$28.77 \quad 78$

1. NULL HYPOTHESIS ELEVEN: There is no significant difference between the rank order of the NASA technical managers' general population percentiles of their twelve lifestyle means and the rank order of the Lafferty high blood pressure sample's general population percentiles of their twelve lifestyle means.

2. ALTERNATE HYPOTHESIS ELEVEN: The rank order of the NASA technical managers' general population percentiles of their twelve lifestyle means and the rank order of the Lafferty High Blood Pressure general population percentiles of their twelve lifestyle means are significantly different.

3. TEST: $W=.38 ; \mathrm{F}=.61$

4. REJECTION REGION: Significance $=.01 ; \mathrm{F}<4.47$

5. RESULTS: Rejected; There is a significant difference between the two groups' rank order percentiles of their respective twelve lifestyle means.

Reproduced with permission of the copyright owner. Further reproduction prohibited without permission. 
proval, conventional, oppositional, and competitive lifestyles.

The null hypothesis is, therefore, not confirmed. Overall there is little similarity between the self-concepts of NASA managers and the self-concepts of individuals experiencing high blood pressure.

\section{BIOGRAPHICAL RELATIONSHIPS}

An initial comparison of biographical variables between the NASA samples (Table XVII) discloses that the NASA technical managers' sample has a mean age of 47.39 years, or 3.6 years above the mean age of 43.76 years characteristic of the NASA non-technical managers' sample. The mean tenure of NASA employment for the technical managers' sample is 20.57 years, which is 5.36 years longer than NASA nontechnical managers' sample $(15.21$ years $)$. NASA technical managers' sample mean time in grade $14 / 15$ is 8.49 years, or 1.41 years longer than the mean of 7.08 years time in grade reported by the NASA nontechnical managers. The mean management experience of 9.61 years by the NASA technical managers also exceeds that of the NASA nontechnical managers' sample mean of 7.86 years by 1.75 years. A break-down of the sexual identity of the respective NASA sample members is reported in Table XVIII.

As the focus of this study is on NASA technical managers, the following four hypotheses address the 
TABLE XVII

COMPARISON OF BIOGRAPHICAI, VARIABLES:

NASA TECHNICAL AND NASA NON-TECHNICAL MANAGERS

TECHNICAL MANAGERS NON-TECHNICAL MANAGERS

BICGRAPHICAL VARTABLE MEAN S.D. MIEAN S.D.

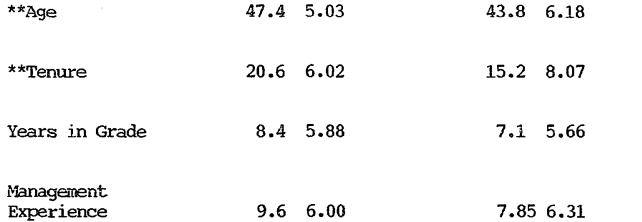

**Significant difference tested between NASA sarnples (.05). 
TABLE XVIII

SEX OF NASA MANAGERS STUDIED

POPULATION

(PERCENTAGE)

\begin{tabular}{lccc} 
SEX & TECHNICAL & NON-TECHNICAL & TOTAL \\
\cline { 3 - 4 } & 107 & 34 & 141 \\
$(70.4 \%)$ & $(22.4 \%)$ & $(92.8 \%)$ \\
FEMALE & 4 & 7 & 11 \\
& $(2.6 \%)$ & $(4.6 \%)$ & $(7.2 \%)$ \\
& - & - & \\
TOTAL & 111 & 41 & 152 \\
& $(73 \%)$ & $(27 \%)$ & $(100 \%)$
\end{tabular}

NUMBER OE MISSING OBSERVATIONS $=10$

Reproduced with permission of the copyright owner. Further reproduction prohibited without permission. 
relationship between the age, tenure, grade and management experience attributes characteristic of the technical managers studied and their respective scores on the selfconcept variables. NASA technical managers are divided at the mean years characteristic of each of the respective four biographical attributes into "less than mean" and "more than mean" samples. The means of each samples" respective Lifestyle and Concern variables are tested for each attribute using standard techniques for a comparison of two means.

\section{Hypothesis Fourteen: Age}

Lifestyle and concern variables were tested between "less than mean age" and "more than mean age" samples of NASA technical managers. The results are reported in Table XIX. It is apparent that while notable differences were identified between samples in the oppositional lifestyle, satisfaction concern, task concern and total concern, the only significant difference is in achievement (.05).

The achievement motivation of NASA technical managers forty-eight years of age or older is 2.16 raw points higher than the achievement motivation of NASA technical managers forty-seven years of age or younger $(z=2.16)$. Older NASA managers are more motivated toward achievement in their self-concepts than are younger NASA managers. While they tend to be more oppositional, have a higher insecurity, have a higher task concern and a higher total concern than 
TABLE XIX

\section{TEST FOR HYPOIHESIS FOURTEEN}

1. NULL HYPOTHESIS FOURTEEN: The mean concern or lifestyle scores for NASA technical managers older than the mean age is not significantly higher or lower than the respective mean concern or lifestyle scrores for NASA technical managers younger than the mean age.

2. AITERNATE HYPOTHESIS FOURTEEN: There is no significant difference between the mean concern or lifestyle scores for NASA technical managers older than the mean age and those NASA technical managers younger than the mean age.

3. TEST: Significance $=.05$ (*Significant)

4. REJECTION REGION: $z>1.96$; or $z<-1.96$

$$
\begin{gathered}
\text { AGE } \\
\text { LESS THAN MEAN } \\
\text { (47 YRS OR LESS) } \\
n=56
\end{gathered}
$$

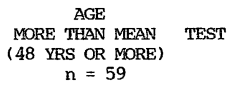

MEAN $\quad \underline{\text { S.D. }} \quad \underline{\mathrm{z}}$

$29.93 \quad 4.97 \quad .89$

$29.59 \quad 6.16 \quad .62$

$\begin{array}{lll}11.46 & 4.89 \quad .61\end{array}$

$\begin{array}{lll}15.31 & 4.81 & .75\end{array}$

$\begin{array}{lll}15.27 & 5.04 & .07\end{array}$

$\begin{array}{lll}5.58 & 5.27 & .29\end{array}$

$\begin{array}{lll}7.34 & 5.63 & 1.29\end{array}$

$\begin{array}{lll}6.00 & 4.90 \quad .72\end{array}$

$\begin{array}{lll}12.75 & 5.67-.02\end{array}$

$\begin{array}{lll}15 & 85 & 5.29 \quad .12\end{array}$

$31.98 \quad 4.34 \quad 2.16^{*}$

$29.15 \quad 5.45 \quad .84$

$49.49 \quad 21.85 \quad .77$

$140.51 \quad 18.42 \quad 1.20$

$\begin{array}{lll}101.56 & 16.42 \quad .55\end{array}$

$\begin{array}{lll}77.92 & 18.74 & 1.14\end{array}$

$214.20 \quad 32.48 \quad 1.09$

5. RESULTS: Rejected; Older NASA technical manager's are significantly more achievement oriented in their self-concepts than younger NASA technical managers. 
younger managers, it is in their pronounced achievement motivation that they are most distinctive in their selfconcepts.

The hypothesis is rejected. The older NASA technical managers' achievement lifestyle mean is significantly higher than the achievement lifestyle mean of the younger NASA technical managers.

\section{Hypothesis Fifteen: Tenure}

Lifestyle and concern variables were tested for "less than mean tenure" and "more than mean tenure" groups of NASA technical managers and the results are reported in Table $\mathrm{xx}$. While notable differences are found between the dependent, power, competitive, competence, achievement, self-actualize, people and task variables, when tested between managers with twenty years or less NASA tenure and managers with twentyone years of tenure or more, none of these variables were found to be significant $(.05)$. Tests confirmed hypothesis fifteen that significant differences do not exist between NASA managers with more than mean tenure and NASA managers with less than mean tenure.

\section{Bypothesis Sixteen: Years in Grade 14/15}

Lifestyle and concern variables were tested between NASA technical managers with "less than mean years in grade 14/15" and those with "more than mean years in grade 14/15." The results are depicted in Table XXI. Notable differences

Reproduced with permission of the copyright owner. Further reproduction prohibited without permission. 
TABIE XX

TEST FOR HYPOTHESTS FIFTEEN

1. NULI HYPOTHESIS FIFTEEN: The mean concern or lifestyle scores for NASA technical managers with greater than the mean number of years tenure is not significantly higher or lower than the respective mean concern or lifestyle scores for NASA technical managers with less than the mean number of years tenure.

2. ALTERNATE HYPOIHESIS FIFTEEN: There is no significant difference between the mean concern or lifestyle scores for NASA technical managers with greater than the mean number of years tenure and those NASA technical managers with less than the mean number of years tenure.

3. TEST: Significance $=.05$ ( ${ }^{\star}$ Significant)

4. REJECTION REGION: $z>1.96$; or $z<-1.96$

$$
\begin{gathered}
\text { TENURE } \\
\text { LESS THAN MEAN } \\
\text { (20 YRS OR LESS) } \\
\mathbf{n}=42
\end{gathered}
$$

VARIABLE

Helpfulness

Affiliative

Approval

Conventional

Dependence

Avoidance

Oppositional

Power

Competitive

Competence

Achievement

Self-Actualize

Security

Satisfaction

People

Task

Total

(All Lifestyles)

MEAN S.D.

29.55

30.38

12.05

15.05

15.88

5.14

6.29

4.86

11.95

18.60

30.05

28.38

47.21

136.95

102.91

71.74

208.17
4.89

5.71

4.50

5.59

5.13

4.81

4.51

3.40

6.08

6.00

6.20

6.92

18.48

23.63

16.64

20.09

36.76
TENURE

MORE THAN MEAN TEST

(21 YRS OR MORE)

$\mathrm{n}=74$

5. RESULTS: Accepted; There is no significant difference between the groups with more or less tenure. 
TABLE XXI

\section{TEST FOR HYPOIHESIS SIXTEEN}

1. NULU HYPOTHESIS SIXTEEN: The mean concern or lifestyle scores for NASA technical managers with greater than the mean number of years time in grade is not significantly higher or lower than the respective mean concern or lifestyle for NASA technical managers with less than the mean number of years time in grade.

2. ALTERNATE HYPOTHESIS SIXTEEN: There is no significant difference between the mean concern or lifestyle scores for NASA technical managers with greater than the mean years in grade and those NASA technical managers with less than the mean years in grade.

3. TEST: Significance $=.05$ (*Significant)

4. REJECTION REGION: $\mathrm{z}>1.96$; or $z<-1.96$

$$
\begin{gathered}
\text { YEARS IN GRADE } \\
\text { LESS THAN MEAN } \\
\text { ( } 8 \text { YRS OR LESS) } \\
n=69
\end{gathered}
$$

VARTABLE

Helpfulness

Affiliative

Approval

Conventional

Dependence

Avoidance

Oppositional

Power

Competitive

Competence

Achievement

Self-Actualize

Security

Satisfaction

People

Task

Total

(All Lifestyles)
MEAN S.D.

28.48

28.67

12.06

14.96

15.35

5.38

6.49

5.94

13.25

19.84

30.17

28.18

48.12

135.25

99.51

75.70

206.67
5.71

6.31

4.78

5.52

5.21

4.90

5.30

5.02

6.23

5.76

6.02

6.62

20.97

23.77

19.29

21.76

38.58
YEARS IN GRADE

MORE THAN MEAN TEST

( 9 YRS OR MORE)

$$
n=41
$$

5. RESULTS: Rejected: NASA technical managers with more years in grade have significantly higher scores in helpfulness and achievement lifestyle scores and in satisfaction concern then do NASA technical managers with less years in grade. 
are found in affiliation and self-actualize variables, but significant differences are tested in humanistichelpfulness, achievement and satisfaction variables between managers with less than eight years in gracie $14 / 15$ and nine years or more years in grade $14 / 15(.05)$. NASA managers with greater time in grade $14 / 15$ have a significantly higher motivation to help and achieve in their self-concepts and a much higher overall satisfaction than those managers with less time in grade.

The null hypothesis that significant differences do not exist between managers with less than mean time in grade $14 / 15$ and managers with more than mean time in these grades was not confirmed. NASA technical managers with more years in grades $14 / 15$ have significantly higher helpfulness and achievement lifestyle orientations and significantly more satisfaction concern in their self-concepts than younger technical managers.

\section{Hypothesis Seventeen: Management Experience}

Lifestyle and concern variables were tested for NASA managers with "less than mean management experience" and those with "more than mean management experience," and the results reported in Table XXII. Notable differences are found in approval, dependent, competence, and task variables, but humanistic-helpfulness, achievement, and satisfaction variables were found to be significantly different 
TABIE XXII

\section{TEST FOR HYPOTHESIS SEVENTEEN}

1. NULU HYPOTHESIS SEVENTEEN: The mean concern or lifestyle scores for NASA technical managers with greater than the mean number of years management experience is not significantly higher or lower than the respective mean concern or lifestyle for NASA technical managers with less than the mean number of years management experience.

2. ALTERNATE HYPOTHESIS SEVENTEEN: There is no significant difference between the mean concern or lifestyle scores for NASA technical managers with greater than the mean management experience and those NASA technical managers with less than the mean number of years management experience.

3. TEST: Significance $=.05$; (*Significant)

4. REJECTION REGION: $z>1.96$; or $z<-1.96$

$$
\begin{gathered}
\text { EXPERIENCE } \\
\text { LESS THAN MEAN } \\
\text { ( } 9 \text { YRS OR LESS) } \\
n=64
\end{gathered}
$$

VARIABLE

Helpfulness

Affiliative

Approval

Conventional

Dependence

Avoidance

Oppositional

Power

Competitive

Competence

Achievement

Self-Actualize

Security

Satisfaction

People

Task

Total

(All Lifestyles)

MEAN S.D.

28.45

28.89

12.25

15.22

15.89

5.33

6.67

5.34

12.81

19.27

29.91

28.23

48.45

134.75

100.70

74.00

208.27
5.20

6.20

5.06

4.71

5.18

4.66

5.14

3.61

5.15

4.99

5.99

6.67

18.98

22.66

17.26

18.23

34.77
EXPERIENCE MORE THAN MEAN TEST (10 YRS OR MORE) $\mathrm{n}=\mathbf{5 0}$

5. RESULTS: Rejected; NASA technical managers with more years managenent experience have significantly higher scores in helpfulness and achievement lifestyle scores and in satisfaction concern then do NASA technical managers with less management experience.

Reproduced with permission of the copyright owner. Further reproduction prohibited without permission. 
between the two groups (.05). Experienced NASA managers were found to be significantly more helpful and achievement oriented in their self-concepts, with a much greater satisfaction concern than less experienced managers.

The null hypothesis is not confirmed. NASA technical managers with more management experience have significantly more helpfulness and achievement 1 ifestyle orientation and significantly more satisfaction concern than NASA technical managers with less management experience. 


\section{Chiapter vi}

\section{DISCUSSION OF RESULT'S}

This chapter discusses the results of the study's hypotheses testing reported in chapter Five. It is the researcher's intention to evaluate the NASA technical managers' structure of lifestyle and concern variables as self-concept competencies. The objective is to extend the operational exploration of self-concept to include the ongoing process of adjustment and morlification between the self and the management role of the NASA Lechnical managers. ${ }^{1}$

This chapter is divided into two sections:

1. NASA technical managers' self-concept competencies

2. Summary of Significant Research Findings

\section{NASA TECHNICAL, MANAGERS' SELF-CONCEPT COMPETENCIES}

A significant aetiological question arises as to the relative influences of genetic or environmental factors on self-concept structures. The importance of genetic factors on these human mental structures is not discounted by the researcher (Wilson 1978, Lumsden and Wilson 1981; Piaget 1965). Where the present research addresses aetiological questions, it is more concerned with the effects of aging

\footnotetext{
${ }^{1}$ See General Statement of the problem in chapter One.
} 
and the environment on the adaptive competency of the selfconcept structure (white 1959). If it can be discerned that NASA technical managers have different management selfconcept competencies (i.e., helpfulness or achievement) than supervisors and mid-level managers in general, are these differences related to the effects of aging, the effects of cohort influences or the effects of period influences (Glenn 1977)?

If the researcher could clearly determine that there is an association of the job with effects of aging on the managers' self-concepts, he might pursue the examinination of how incremental increases in helpfulness and achievement. motivation emerge in self-concept structure with the biological effects of the managers' increase in age. Perhaps an increasing conscious or unconscious knowledge by aging managers of impending career limits generally triggers more, rather than less, desire to help associates (organizations) achieve important institutional research. If the researcher could clearly determine that there is an association of the job with effects due to cohort influences on the managers' self-concepts, then he might pursue different implications. He might choose to explore how within NASA a particular group of individuals associated with unique programs, center assignments or education from specific engineering school have developed higher levels of helpfulness and achievement motivation than other cohorts. 
Finally, if the researcher could clearly determine that there is an association of the job with effects due to period on the managers' self-concepts, he might pursue a third set of implications. He might choose to explore how the relationships between a generation of NASA managers, exposed to a certain pattern of economic, educational or cultural experiences, have responded in a unique way in helpfulness and achievement, different from a generation of NASA managers older or younger than the first.

But such clear distinctions in the processes of selfdefinition requires extensive cohort analysis or longitudinal study of a much grander scale than this research, examining the relationships between a broader array of biographical relationships over many careers. This kind of study is expensive and extremely difficult to pursue, usually requiring the dedication of a research team over a long period of time in complex and changing organizations. There remains, however, findings in the present research which begin to define important relationships between a NASA technical managers' self-concept competencies and their influences. The findings are better understood if a discussion of the differences between the biographical measures of age, tenure, years in grade and management experience precedes the report.

In a marked sense tenure, years in grade and management experience are all related to age. So it must be that 
the relative strengths of each of these four variables in association with lifestyle/concern variables are examined to determine the unique aspects of each. While tenure is defined as length of time an employee has worked for NASA, years in grade and management experience imply something different.

Generally, the promotion to GS/GM-14 is considered a reward for continued high technical and professional performance and leads to a more difficult level of work with an increasing scope of responsibilities, technical or supervisory, in the dual career track system, which exists in NASA. Some new supervisors are GM-13s, however, most new supervisors receive their appointment concurrent with assignment to the GM-14 level. But in a parallel track with them, new GS-14s (non-supervisors) still receive important rites of passage where scarce organizational positions, with a higher level of pay and increased project management responsibility, are assigned. These project roles may also lead from a nonsupervisory GS-14 assignment to a supervisory or mid-level management GM-14 or GM-15 role. First-line supervisors and mid-level managers exist at both GM-14 and GM-15. As a result, respondents may report little difference in time measured between management experience and time in grade GS/GM 14-15(Table XVII). An examination of the relative associations between biographical variables and self-concept competencies in NASA 
technical managers provides interesting results. It should be remembered that, excepting the sections on strain variables, significance in the means testing is at plus or minus $z=1.96$. The more deviance the $z$ scores indicate outside these parameters, the more significance (.05) exists.

It is also important to note that no groups of $R \& D$ mid-level managers or supervisors were tested by Lafferty. It is quite possible that $R \& D$ managers or supervisors in general, regardless of their employer, would score similarly to the NASA technical managers' pattern, both with respect to the structure of the competencies and with respect to associations with the biographical variables.

\section{Satisfaction Competencies}

The research finds that the helpfulness competency, recommended by Lafferty $(1980)$, is significantly higher in the orientations of NASA technical managers than in supervisors (Table V: $z=+4.14$ ) and mid-level managers (Table $v: \quad z=+5.73$ ) in general. Helpfulness for NASA technical managers scores only slightly less than the helpfulness reported by Lafferty's engineers (Table $\mathrm{V}: \quad z=-1.35$ ).

Evaluating helpfulness and its relationship to the biographical variables, one quickly determines that the association between the variable and age (Table XIX: $z=$ +.89 ) is well below that needed for significance and that in its association with tenure there is almost no relationship 
at all (Table $x x: z=-.01$ ). In contrast, a highly significant association exists between the variable and years in grade (Table XXI: $z=+2.94)$ and management experience (Table XXI1: $z=+2.92)$, where both relationships are nearly equal. In high performing NASA managers the high level of helpfulness competency is not significantly related to age or tenure in NASA, but rather is largely associated with years of management experience and time in grade. Evaluating achievement, again one can determine that there is a significantly higher competency in NASA managers than in supervisors (Table VI: $z=+5.51$ ) and mid-level managers (Table VI: $z=+9.35)$. The achievement orientation is not unlike that of the Lafferty engineers (Table VI: $z=$ +.601 . Further, there is no significant association between the lifestyle variable and measures of tenure (Table xx: z $=+1.43)$, although there is still a notably positive relationship. Age is marginally significant in its association with achievement (Table XIX: $z=+2.16$ ), and less significant than years in grade (Table XXI: $z=+2.32$ ) or management experience (Table XXII: $z=+2.65$ ). In high performing NASA technical managers, achievement competency is strongly associated with management experience. While satisfaction concern cannot be tested between NASA technical managers and the Lafferty groups, due to Lafferty's non-reporting of standard deviations, a simple comparison between the sum of the NASA satisfaction vari- 
ables' means and the Lafferty satisfaction variables' means can be completed. The sum of the NASA technical managers' five satisfaction means (138.47) totalled slightly higher than the sum of the Lafferty engineers' respective means $(137.80)$, and considerably higher than the sums of the Lafferty supervisors' (123.98) and Lafferty mid-level managers' means $(121.42)$. This would appear to indicate that the NASA technical manager continues with a strong overall satisfaction orientation, similar to that experienced by engineers in general.

Satisfaction concern in NASA technical managers is significantly associated with management experience (Table XXII: $z=+2.03$ ) and years in grade (Table XXI: $z=$ $+2.07)$. Satisfaction concern is also positively related with age (Table XIX: $z=+1,20$ ), and has a small positive relationship with tenure (Table $x x: z=+.65$ ).

These findings are important because they demonstrate that the general self-concept structure of satisfaction competency within NASA technical managers is based on two of the lifestyles discovered by Lafferty in his research to make especially important contributions to high performance by managers. 2

What can be noted about satisfaction competency in the present study is that NASA technical managers do not function with the same self-concept structure as most super-

${ }^{2}$ See Self-Concept Competency in chapter Three. 
visors and mid-level managers. When compared to the large Lafferty samples, they have superior satisfaction concern, as demonstrated by their higher levels of achievement and helpfulness. This exceptional self orientation toward helping and achieving is influenced by the duration of time spent as a member of the management team, and it is also reflected in its association with the NASA technical managers' years in grade. ${ }^{3}$ To a lesser extent, age is positively associated with these variables, and significantly related to achievement. NASA tenure has very little relationship with a NASA technical managers' satisfaction concern (Table XX: $z=+.65)$.

While NASA technical managers' satisfaction concern is higher than the Lafferty supervisors and mid-level managers' groups it is clearly significantly lower than that of the NASA non-technical managers (Table IV: $z=-2.04$ ).

\section{Security competencies}

The research finds dependent orientations are significantly strong in the self-concepts of NASA technical managers, and much higher than in mid-level managers in general (Table VIII: $z=+7.72$ ). It is also clear that there is a sizeable, yet less than significant, difference

\footnotetext{
${ }^{3}$ Competence and affiliation orientations are satisfaction variables discussed in following subsections under their respective alternative competencies: task and people. Also addressed in another subsection to follow is the unique relationship between satisfaction and self-actualizing.
}

Reproduced with permission of the copyright owner. Further reproduction prohibited without permission. 
between the mean dependent orientations of NASA technical managers and the mean scores of first line supervisors in general (Table VIII: $\mathrm{z}=+1.49$ ). A key to understanding the degree of this dependency is to evaluate the Lafferty sample of engineers. Here one may discern that the NASA technical managers have a lower mean than the Lafferty engineers, yet not significantly so (Table VIII: $z=-1.07)$. While most NASA respondents function in true middle management roles, not all respondents have spent appreciable time in these roles. Further, as previously implied, since we have no comparative samples of $R \& D$ managers it is possible that $R \& D$ managers in general demonstrate a similarity of dependency orientation to the NASA managers. An examination of the results with regard to the biographical relationships is imperative.

This is hard to evaluate as Lafferty gives no specific standard as to what score he feels that the dependency variable should be to demonstrate competency. In his videotaped lecture which accompanies the instrument for use in inter-... preting the results, Lafferty suggests that he believes that the achievement lifestyle should be at least ten raw points higher than the dependency lifestyle score. NASA technical managers tested 15.84 points higher in achievement than in dependency (Tables VI and XVIII). But Lafferty does not state on what basis he makes this judgment. It is clear that Lafferty believes that it is unsatisfactorily high in 
his testing of supervisors and managers, and that the NASA technical managers are higher than the Lafferty supervisors and significantly higher than the Lafferty mid-level managers.

Dependence shows almost no association with age (Table XIX: $\quad z=+.07)$, a slight association with years in grade (Table XXI: $z=-.47)$, more association with tenure (Table $x x: \quad z=+1.08$ ), and the greatest association with years of management experience (Table XXII: $z_{1}=-1.47$ ). More management experience means less dependency orientation, yet not so much as to be significant between test groups $(.05)$.

As the management experience of NASA technical managers increases their dependency appears to diminish. It might be argued that, in contrast to other mid-level managers, this dependency is beneficial for NASA managers. Other high performing groups of $R \& D$ managers have yet to be tested. Yet this would seem a dangerous assumption without further study. The existing level of dependent orientation is higher for NASA technical managers than among mid-level managers in general and this is interpreted to have a negative effect on their potential for high performance and, therefore, higher competency •

When the sum of the NASA technical managers' five security concern variables ${ }^{4}$ is compared with the sum of

${ }^{4}$ While no hypotheses were constructed for the avoidance, oppositional, conventional and power lifestyles they were tested and will be discussed in the final chapter.

Reproduced with permission of the copyright owner. Further reproduction prohibited without permission. 
security concern for the Lafferty variables, the NASA technical inanager's' sum (47.82) lies between sum for the Lafferty engineers $(51.00)$ and the sum of the Lafferty supervisors (50.38), on the one hand, and that of the Lafferty mid-level managers (44.59) on the other hand.

Security concern associations with biographical variables are strikingly absent. Security concern has little relationship with management experience (Table XXVI: $z=$ -26), years in grade (Table XXV: $z=-.19$ ), and NASA tenure (Table xxIV: $z=+.31$ ). Only a slightly higher, and still insignificant, relationship exists between security concern and age (Table XXIII: $z=+.77)$. The security concern of the NASA technical managers self-concept construction is not significantly higher than that of the NASA nontechnical managers ('lable VII: $z=+65$ ).

\section{Task Compeliencies}

The Lerm "compelence" competency, while semantically cumbersome, is used by the researcher to be consistent with both the use of the term by Lafferty to label one of the defined lifestyles and the use of the term by the management theory used as a foundation to this study (Boyatzis 1982; Hall 1982). Testing between groups disclosed a marked difference between the NASA technical managers and the Lafferty supervisors and mid-level managers. NASA technical managers are significantly more competency motivated than supervisors 
(Table $X: \quad z=+2.93$ ) and mid-level managers (Table $X:$ $z=+3.84$ ) in general. NASA technical managers also have a higher motivation to be competent than engineers (Table $\mathrm{X}$ : $z=+1.32$ ) but a lower motivation to be competent than NASA non-technical managers (Table $x: z=-.80$ ).

This high degree of competence orientation in the NASA technical managers is not associated to any marked degree with age (Table $x 1 x: z=+.12$ ) or years in grade (Table XXI: $z=+.991$. Competency is associated to the greatest, yet not significant, degree with tenure (Table XX: $z=+1.82$ ) and, to a lesser extent, management experience (Table XXII: $z=+1.39$. "Years tenure" has a small, yet important, influence on competency and that the longer the service in NASA by a technical manager, the greater the motivation to be competent.

Lafferty believes that too much drive for competency indicates a preoccupation with perfection and may be a proxy disclosing the tendency by managers to disregard the importance of team activity in an organization. A real issue emerging from an analysis of this lifestyle is whether high levels of competency orientation in NASA technical managers motivatate true organizational excellence and performance within the agency (and other $R \& D$ organizations). This issue will be discussed further in the final chapter of this dissertation.

Reproduced with permission of the copyright owner. Further reproduction prohibited without permission. 
Comparison between levels of task concern for NASA technical and non-technical managers yields no significant difference (Table IX: $z=.-.41)$. When the sum of the NASA technical managers task variables' means are totaled (76.06), this total is similar to the totals of the NASA non-technical managers (77.62) and the Lafferty engineers $(76.80)$. These three groups have greater task concern than the Lafferty supervisors (70.69), and certainly the Lafferty mid level managers $(67.25)$.

Task concern in NASA technical managers is associated least with years in grade (Table XXI: $z=+.26$ ). It is influenced to a greater degree by age (Table XTX:

$z=+1.14$ ) and management experience (Table XXII:

$z=+1.28)$. But the greatest influence on task concern is demonstrated by tenure where increased years in NASA employment is associated, to a near significant level (Table XX: $z=+1.85$ ), with increased task concern scores.

Lafferty believes that an unusually high task score is generally negative in its' effects (1980). While high scores are viewed as a general indication of a problem, decision makers must differentiate between the lifestyle with great benefit (i.e., achievement) 5 and those four with

sAchievement orientation has been discussed in this chapter under Satisfaction Competencies. Oppositional, power, and competitiveness are also task variables. While no hypotheses were constructed for these variables they were tested and some implications will be discussed in the final chapter. 
organizational disfunctions (i.e., oppositional, power, competitiveness, and competence). If task concern scores become unusually high, management should examine the organizational rewards for this thinking.

\section{People competencies}

The NASA technical managers' affiliation lifestyle scores are found to be similar to the lafferty engineers (Table XII: $z=-.49)$. This affiliation orientation is significantly greater in NASA technical managers, however, than that in supervisors (Table XII: $z=+4.14$ ) and midlevel managers (Table XII: $z=+3.79$ ). In contrast, the affiliation orientation is significantly less in NASA technical managers than in the of NASA nontechnical managers self-concept (Table XII: $z=-2.00$ ). The benefits of the affiliation lifestyle, as stated by Lafferty (1980), are contributing to NASA from both groups of managerial employees.

Affiliation lifestyle scores are not related to management experience (Table XXII: $z=+.04$ ) or age (Table XIX: $z=+.62)$. Stronger influences are indicated by associations with tenure (Table XXIV: $z=-1.55$ ) and years in grade (Table XXI: $z=+1.25)$. It appears that the more years a respondent experiences as an employee of NASA, the less he/she has a strong motivation to affiliate.

Reproduced with permission of the copyright owner. Further reproduction prohibited without permission. 
NASA technical managers are not significantly different from NASA non-technical managers in their people concern (Table XIII: $z=-.52$ ). However, the total sum of the five people variables for the five groups seems to vary widely. The highest people concern is from the Lafferty engineers (105), followed by the NASA non-technical managers (102.31). In the middle are the NASA technical managers $(100.70)$. Considerable lower people concern scores are recorded by the Lafferty supervisors (95.19) and mid-level managers $(90.47)$.

People concern in NASA technical managers is not significantly associated with age (Table XIX: $z=+.55)$, tenure (Table $x X: \quad z=-1.05)$, years in grade (Table XXI: $z=+87$ ) or management experience (Table XXII: $z=+.20$ ). The greatest influence on a technical managers' people concern is tenure, where an inverse relationship is noted, and this association is not strong.

Lafferty believes unusually high people concern scores, like unusually high task concern scores, are generally negative in their influence. He believes that positive lifestyle orientations (i.e., helpfulness, affiliation) contribute to organizations ${ }^{6}$, while negative lifestyle

\footnotetext{
${ }^{6} \mathrm{Helpfulness}$ and dependent orientations have been discussed in previous subsections under their respective alternative competencies: satisfaction and security. Approval and conventional lifestyles are also people variables. While no hypotheses were constructed for these variables they were tested and some implications will be discussed in the final Chapter.
} 
orientations (i.e., approval, conventional, dependent) have disfunctional qualities which detract from managerial performance (competency).

\section{Self-Actualize Competency}

The difference in the self-actualize competency between the NASA technical managers and the Lafferty supervisors (Table XIII: $z=+7.08$ ) and Lafferty mid-level managers (Table XIII: $z=+9.12$ ) is very pronounced. Even the insignificant relationship between the NASA technical managers and the Lafferty engineers (Table XIII: $z=+.68$ ) should not detract from the importance of this finding. Nor should another striking finding, that despite the high scores totalled by the NASA technical managers the NASA nontechnical managers scored even higher (Table XIII: $z=-1.25$ ) than their technical counterparts. Significant associations between the self-actualize variable and biographical variables do not exist. While the relationships between the self-actualize orientation and age (Table XXIII: $z=+.84)$, tenure (Table XXIV: $z=+.43)$ and management experience (Table XXVI: $z=+.92$ ) are quite low, even the strongest relationship between self-actualize and a biographical variable, that association with years-in-grade (Table XXV: $z=+1.35)$, is not significant.

Supervisors and managers in general reveal a strong self-actualize competency integrating the positive, satisfy- 
ing attributes of the task and people concerns held by these employees relative to the general population (Appendix B: Figures 6 and 7 ). When compared with the general population (Appendix B: Figure 4), the self-actualize competency of the NASA managers is strikingly significant $(z=+11.52)$. Yet it is not possible to find an overpowering relationship with any of the biographical variables. Whatever selfactualize competency exists on the part of NASA technical managers, seems to be an artifact of the technical professions. Further, while the people competency, helpfulness, varies with management experience (Table XXII: $z=+2.92$ ), and the task competency, achievement, vary with management experience (Table XXII: $z=+2.65$ ), the self-actualize competency, theoretically an integration of task and people concerns, shows little strength in its relationship with management experience (Table XXII: $z=+.92$ ). The question arises as to whether the theoretical construction of the variable proposed by Lafferty (1980), and supported by Hall (1980), is measuring an integration of task and people concerns or measuring something different--like a unique dimension of the self-concept construction.

\section{Strain profiles}

Significant strain profile differences between the rank order of the NASA technical managers and three groups of individuals reporting the three respective symptoms are

Reproduced with permission of the copyright owner. Further reproduction prohibited without permission. 
tested using Kendall's nonparametric coefficient of concordance. To be "not significant" $(.01)$, the F score for the comparison between the the rank ordered groups must meet or exceed +4.47 . The results of the tests for hypotheses eleven, twelve and thirteen found that significant differences exist between the NASA technical managers' selfconcept construction and the self-concepts of individuals experiencing depression (Table XVII: $F=+.23$ ), ulcers (Table XVIII: $F=+.64$ ) and high blood pressure (Table XIX: $\mathrm{F}=+.61)$. While individual managers may have profiles which resemble those of the groups experiencing these symptoms, the collective self-concept construction of NASA technical managers has little in common with the selfconcept constructions common in these strain groups.

\section{SUMMARY OF SIGNIFICANT RESFARCH FINDINGS}

The following list of important findings from this study is set forward by the researcher.

1. NASA technical managers are significantly more helpfulness oriented in their self-concept competency than are the Lafferty supervisors and mid-level managers.

2. The helpfulness competency in NASA technical managers is not significantly different from NASA non-technical managers or Lafferty engineers.

Reproduced with permission of the copyright owner. Further reproduction prohibited without permission. 
3. The helpfulness competency in NASA technical managers is significantly associated with the managers' years-in-grade and management experience.

4. NASA technical managers are significantly more achievement oriented in their self-concept competency than are the Lafferty supervisors and mid-level managers.

5 NASA technical managers are not significantly more achievement oriented in their self-concept competency than are the NASA non-technical managers or Lafferty engineers.

6. The achievement competency in NASA technical managers is significantly associated with the managers' age, years-in-grade and management experience.

7. NASA non-technical managers are significantly more satisfied overall than NASA technical managers .

8. Overall satisfaction concern in NASA technical managers is significantly associated with the managers' years-in-grade and management experience.

9. NASA technical managers have a significantly lower dependence competency (higher score) than Lafferty mid-level managers.

Reproduced with permission of the copyright owner. Further reproduction prohibited without permission. 
10. NASA technical managers do not have a significantly different dependence competency than NASA non-technical managers or Lafferty supervisors and engineers.

11. The dependence competency in NASA technical managers is not significantly associated with the managers' age, tenure, years-in-grade or management experience.

12. The security concern of the NASA technical managers is not significantly different that that of the NASA non-technical managers.

13. The "competence" competency of the NASA technical managers is significantly higher than the Lafferty supervisors and mid-level managers.

14. The "competency" competency of the NASA techni.cal managers is not significantly different from the NASA non-technical manager or Lafferty engineer.

15. "Competence" competence is not significantly associated with the NASA technical managers' age, tenure, years-in-grade or management experience.

16. Task concern in NASA technical managers is not significantly different than the task concern of NASA non-technical managers.

17. Task concern in NASA techinical managers is not significantly associated with the managers' age,

Reproduced with permission of the copyright owner. Further reproduction prohibited without permission. 
tenure, years-in-grade or management experience. Task concern is associated to near significant levels with the managers' tenure.

18 Affiliation competency is significantly lower in NASA technical managers than in NASA nontechnical managers.

19. Affiliation competency is significantly higher in NASA technical managers than in the Lafferty supervisors and mid-level managers.

20. Affiliation competency of NASA technical managers is not significantly different from Lafferty engineers.

21. The NASA technical managers' affiliation competency is not significantly association with the managers' age, tenure, years-in-grade or management experience.

22. The NASA technical managers' people concern is not significantly different from that of the NASA non-technical managers.

23. The NASA technical managers' people concern is not significantly associated with the managers' age, tenure, years-in-grade or management experience. This people concern is inversely associated with tenure.

24. The NASA technical managers' self-actualize competency is significantly higher than the

Reproduced with permission of the copyright owner. Further reproduction prohibited without permission. 
Lafferty supervisors and mid-level managers' self-actualize competency.

25. The NASA technical managers' self-actualize competency is not significantly different from the NASA non-technical managers or Lafferty engineer.

26. The NASA technical managers' self-actualize competency is not significantly associated with the managers' age, tenure, grade or management experience.

27. The NASA technical managers' self-concept profile is significantly different from the self-concept profile of individuals experiencing depression.

28. The NASA technical managers' self-concept profile is significantly different from the self-concept profile of individuals experiencing ulcers.

29. The NASA technical managers' self-concept profile is significantly different from the self-concept profile of individuals experiencing high blood pressure.

Reproduced with permission of the copyright owner. Further reproduction prohibited without permission. 


\section{CHAPTER VII}

\section{CONCLUSION}

The final chapter is divided into three sections in order to summarize the research. The first section, Specific Conclusions, describes the importance of the findings in relationship to defining the self concept competency of NASA technical (Research and Development) managers. The second section, General Conclusions, proposes some issues which seem important to an understanding of the ongoing process of adjustment and modification between the self and the management role of NASA technical (Research and Development) managers and, $\mathrm{R} \& \mathrm{D}$ managers in general. The final section, Recommendations for Research, suggests where additional study is needed to further the understanding of the self-concept competency of research and development managers.

\section{SPECTFIC CONCLUSIONS}

The researcher believes that the high satisfaction concern demonstrated by NASA managers, indicate the normal competency standard required for high performance in the agency. Where sustained, concentrated application of management skills is applied over the time periods required 
to complete $R \& D$ programs/projects, it is essential that the managers' involvement be sustained by strong satisfaction concern. This does not mean that individual high performing managers may not score significantly lower than this standard, but it does indicate that high performing NASA managers as a group appear to have a relatively high satisfaction concern, when compared to the largest existing samples of supervisors and mid-level managers available. A lower score by a NASA technical manager might be an indication of either past performance problems or a problem which is emerging. The competency, achievement, selfactualization, helpfulness and affiliative lifestyle scores, which together combine to define satisfaction concern, were each significantly high in the managers' tested, when compared to Lafferty's supervisors and mid-level managers, but not significantly different from Lafferty's engineers in any of the satisfaction lifestyles. NASA technical specialists may possess self-concept characteristics very similar to Lafferty's engineers and retain these characteristics, even after appointment to managerial roles. But if this is true, there still are data supporting the probability of changes to the substructure of the NASA technical managers' selfconcepts (Chapter Five: Tables XXI and XXII). The selfconcepts of NASA technical managers demonstrate a strong positive association between satisfaction and years-in-grade and management experience.

Reproduced with permission of the copyright owner. Further reproduction prohibited without permission. 
The high performing NASA managers appear to demonstrate normal overall security concerns, but the dependence lifestyle is significantly higher than in Lafferty's mid-level managers (Chapter Five: Table VIII). The rasearcher is left with two alternatives in interpreting dependence competency: either high performing $R$ \& $D$ technical managers in NASA are required to have a higher dependence orientation in order to succeed as a manager or NASA high performing managers retain a self-concept characteristic, typical of technical specialists, which might require intervention in order to improve managerial, and thus organizational, performance. Avoidance lifestyle scores of NASA technical managers indicated a significantly low mean when compared to Lafferty's supervisors and mid-level managers (Appendix D: Table XXIII). The oppositional lifestyle mean of the NASA technical managers was tested marginally significant and high when compared with the Lafferty mid-level managers (Appendix D: Table XXIII). As with the security concern scores of the NASA technical managers', the avoidance and oppositional lifestyle scores are not significantly related to any biographical variable (Tables XIX-XXII). The NASA technical manager does not appear to be overly preoccupied in his self-concept with security concerns when compared to the general supervisors and managerial samples tested. 
The task concern mean does appear to be high in NASA technical managers when compared to Lafferty's supervisors and mid-level manager groups. It is not associated with any biographical variable in the testing. The power lifestyle variable is signifjcantly lower in NASA technical managers than in the Lafferty supervisors and mid-level managers and the competitive lifestyle is significantly higher in NASA technical managers than in the same two Lafferty samples. A power orientation does not appear valued in accomplishing tasks, but a high degree of competitiveness appears appropriate to NASA technical managers. As with the dependence lifestyle, the high means of the competitive lifestyle also require the researcher to make a decision as to the organizational utility of the self-concept structure to $R \& D$ managers and their organizations. Either it is of more value than indicated by Lafferty, or it is an area which requires intervention in order to improve organizational efficiency. The achievement mean is, of course, high as previously stated, but the high "competence" mean presents an interpretation dilema for the researcher. Again, there would appear to be two "perfectionist"1 competency interpretations possible for NASA technical managers. Either it: is a requirement to have high perfectionism in order to manage research and development or it is an indication that the NASA manager is overly concerned with perfection,

${ }^{1}$ The author prefers the perfectionism label for the competence lifestyle (Cooke, et al. 1985). 
and it is an area that might warrent intervention. This high competence mean by NASA managers is not significantly associated with age, tenure, time-in-grade or management experience. NASA technical managers are slightly more task oriented in their self-concepts than were the supervisors and mid-level managers tested by Lafferty.

People concern by NASA technical managers does appear slightly higher than in the Lafferty's supervisors and midlevel managers' samples. The mean people score of the NASA technical managers is not significantly associated with any of the biographical variables. Approval and conventional lifestyle means are not significantly different from the Lafferty supervisors and mid-level managers (Appendix D: Table XXV). These two lifestyles are also not associated with any of the biographical variables. The high scores of the helpfulness and affiliative lifestyles by NASA technical managers have been previously mentioned and contribute to their high people concern. The NASA technical managers' norm reveals a higher people competency in their selfconcepts than do the general samples of supervisors and mid-level managers tested.

While the NASA technical managers demonstrated no significant association with any of the strain profiles there are two interesting characteristics of the NASA technical managers' profile. Eirst, it was previously mentioned that NASA technical managers demonstrated both significantly high 
helpfulness and significantly high oppositional lifestyles. Lafferty has suggested, in his videotape interpreting lifestyle results, that comparatively high scores on lifestyles opposing each other on the circumplex might give an indication of a tendency for disfunctional thinking and even physiological symptoms. He believes that possessing two logically opposite ideas in one's self-concept (i.e., one must help others and one must stand in opposition to them) is incongruent and that there might be a strain resulting from this thinking pattern which results in such a symptom as a migraine headache. Second, research has found that the frequency of physiological symptoms was significantly associated with only two lifestyles--competency and dependency--both significantly high in NASA technical managers. While the present study did not collect information on NASA technical managers' physical symptoms, it is possible that frequency of symptoms might be actually be present and higher in NASA technical managers than in other groups of respondents or managers, or that under stress NASA managers might demonstrate a higher than normal frequency of strain symptoms.

To summarize, high performing NASA managers demonstrated a high degree of helpfulness, affiliation, dependence, oppositional, competitiveness, "competence," achievement and self-actualization lifestyles in their self-concept competency. They also demonstrated a low de- 
gree of avoidance. Overall, they are very satisfaction oriented. This satisfaction in their self-concepts may be directly, and significantly, associated with a managers" years-in-grade and experience.

\section{GENERAL. CONCLUSIONS}

\section{Management Competency}

The design of this research was not longitudinal but rather 162 high performing NASA technical managers were each administered one test during their attendence at an agency management development program. The results of contrasting these test measurements with the measurements of the largest samples of engineers, supervisors and mid-level managers available, Lafferty's samples, suggests a strong similarity between the self-concepts of NASA technical managers and those of the technical group (Lafferty engineers) tested. The design of the research does not provide data on what the structure of their self-concepts were at an earlier time when they were specialists, but the similarity with Lafferty's engineers cannot be disregarded. Do $R \& D$ managers remain similar to $R \& D$ specialists in their seifconcepts, even after appointment to management roles? This finding would seem to be in contrast to the finding of Bayton and chapman (1972) which suggests that a change of role results in a change of self-perception.

Reproduced with permission of the copyright owner. Further reproduction prohibited without permission. 
Tagiuri (1965) tested three groups of employees (research managers, scientists and executives) in 1965 and the results indicated that the relative contrast in selfconcepts of each of these groups of individuals in research groups might create problems for organizations. Scientists may perceive the research manager as an executive and executives may perceive the research manager as a scientist. Tagiuri believes that the research manager may be an adapter and tends to behave somewhat more as a scientist when with the scientists and somewhat more as an executive when with the executives. This research would seem to support the idea that the $R \& D$ manager, in the case of NASA, is closer in self-concept to the scientist that to the Executive. Hail (1980b, pp. 217-218) in describing the differences in competency between managers and specialists states:

...Managing, at its core, is an issue of values. Our managerial practices are but reflections of our favorite assumptions about work and our notions about the best pathways to its attainment. Therefore, a change from one level of managerial conpetence to a greater level of competence may well involve a change in personal values as well. This data, while not measuring the self-concepts of NASA technical specialists or NASA executives raises questions such as if the NASA technical managers' self-concept competency is similar to that of NASA technician, does it create problems in working with the NASA executive? How different are the NASA executives' (technical and otherwise) 
self-concepts from the self-concepts of the NASA managers? If there is no real change of self-concept competency in the transition from technical specialist to manager, does it mean that there is a diminished organizational performance which results? Pexhaps in an $\mathrm{R} \& \mathrm{D}$ environment, it is important for the immediate leadership to retain a strong identity with the technical function and values. But perhaps it is important in $R \& D$ work to have important differences between the self-concept competencies of specialists and managers.

\section{Self-actualization}

Both Lafferty (1980) and Hall (1980a) believe that self-actualization increases as managers' synthesize the needed skills to integrate task and people conflicts in an organization and internalize their success to the self. Garfield (1986) believes that barriers to self-actualizing exist where models of management self-concepts and behavior do not exist to provide a manager with the cognitive structure used in orienting his goal-directed motivation and behavior.

Resuits from this research do not provide support for theorizing a significant change in self-actualization, as a result of a technical managers' experience or time-in-grade, where the manager increases his ability to reconcile task and people conflicts (Chapter Five: Tables XXI and XXII). 
While associations between these biographical variables and self-actualization in managers was positive in the NASA technical managers tested, the relationship was not nearly as strong as the associations between the experience of the NASA technical managers and achievement and helpfulness (Tables XXI and XXII), those lifestyles bracketing selfactualization on the circumplex (Chapter one: Figure i). It would appear that while the NASA technical managers are significantly more self-actualized than two comparison groups tested (Lafferty's supervisors and mid-level managers), the high self-actualization is only slightly greater in groups of more experienced managers, then it is in less experienced groups of managers.

There are three possible explanations for the lack of significant difference between more and less experienced groups of managers. The first explanation would be that NASA specialists receive enough modeling from their management in the accomplishment of tasks integrating task and people concerns that they have a high expectation for success and self-actualization motivation from the very appointment to their role, which increases only slightly over the duration of their career as their expectations are fulfilled.

The second explanation is to be found in temperament theory. Keirsey and Bates (1984) submit that a selfactualizing theorist or researcher attempting to find mean- 
ing in the thought and behavior of others is the most unlikely person to understand the temperament of others with respect to self-actualization. ...The search for meaning as a necessary pilgrimage for all people is advanced by the NF (Intuitive-Feeling Type) in their writings. Very often the other types... are troubled by the thought that they ought to be pursuing these values, even if, somehow, the search for meaning and integrity does not beckon to them. This reluctance of 88 percent of the world to join the search for self-actualization is a great source of mystification to the NFs. ${ }^{2}$

IL is possible that many NASA technical managers--like the majority of the general population studied by kiersey and Bates--are of a temperament which does not really have the self-concept structural potential to self-actualize. This temperament might be derived by heredity, early environment, or, most likely, by an interaction between both. The theories of Lafferty, Hall and Garfield may on ly apply to a minority of $R \& D$ managers who have a self-concept theory which will allow them to test such new hypotheses about their selves (See Definition of Self-Concept in chapter Twol.

The third possibility is that Garfield (1986) is correct in his concern that not enough powerful role models exist in organization to provide "concrete" examples of successful thought and behavior and that this linits the NASA

\footnotetext{
"The "type" name for those individuals with selfactualization potential is inserted by the writer in parens.
} 
manager from internalize the benefits of his success over time and significantly increasing his self-actualization. Whatever the reason it is apparent that selfactualization management style is significantly strong in NASA technical managers and they find an intrinsic value of the work, regardless of a role change in their career. It is a distinctive part of the NASA self-concept competency that NASA technical managers score higher than the comparative groups of supervisors and managers in their selfactualization. This is directly opposed to what Boeyens and de Jager (1982) propose is ideal for R \& D employees.

\section{RECOMMENDATIONS FOR RESEARCH}

As suggested in the previous two sections, some important questions concerning the self-concept competency of technical managers cannot be answered without a large, well-designed longitudinal study. A study is needed which addresses not only self-concept competencies, but other management competencies not addressed in previous research within technical organizations as well (Hall 1980b; Boyatzis 1982). Such extensive research should also be associated with models currently employed on the agency's culture and management practices, such as that accomplished in NASA by Warner Burke (1987) and on other groups of Aerospace managers (including NASA Kennedy Space Center managers) completed by Kinlaw (1987). This research should consider 
other dimensions of self-concept competency not addressed in this research (Schutz 1977; Myers 1980; Noppe 1979; and others) potentially important to the management of interpersonal conflict in technical organizations (Hill 1977).

Research on this scale should include data with actual performance evaluations to provide additional measures of assciations between self-concepts and behavior. The inclusion of this information, and the direct interview of supervisors would give additional assurance that the structure of competency for NASA technical managers rested on an adequate research framework.

Such a study of technical organizations should consider the self-concept competency of managers independently and in association with other competencies. It is believed that well-designed research would find that a managers' self-concept structure is not merely a threshold competency (Boyatzis 1982), but is a competency whose structure can statistically be associated with higher and lower levels of performance, as suggested by Lafferty (1980).

Finally, of particular interest in further research on understanding the self-concept competency of $R$ \& $D$ managers would be studies on the dependence, "competence" and competitive orientations of these managers. A more comprehensive way of measuring self-actualization in the self-concept and measurements over a managers' experience could also provide useful data. Studies taken to measure self-

Reproduced with permission of the copyright owner. Further reproduction prohibited without permission. 
concept should undertake to measure as much of the selfconcept structure as possible, over time, and to associate these measurements with as many biographical indicators as possible and with as many other management competencies (behaviors) as practicable. The study of the self-concept competency of managers in other areas, as well as in research organizations, should provide useful comparisons for scholars, consultants and practitioners. \$... Advice communicated by Eiduson (1962) and Mahoney (1974) recemmending the empirical study of scientists, engineers and their managers should be grasped. The norm excluding the incumbents of these important roles from study can only perpetuate half-truths and idealized misconceptions of technical employees. Research into the self-concepts of men and women working in $R \& D$ activities, and communication of the results, can assist in avoiding self-deception in science and its applications, facilitate the skills of guiding urban organizations toward productivity and assist in the satisfaction of those who contribute to those ends. 
Adler, A. What 1 ife should mean to you. Boston: Little, Brown, 1931 .

Adler, P. and Adler, P. A. Symbolic interactionism. in Introduction to the sociologies of everyday life, eds. Douglas, J. D., Adler, P. A., Adler, P., Fontana, A., Freeman, C. R., and Kotarba, J. A. Boston: Allyn and Bacon, Inc., 1980 .

Alderfer, C. P. Existence, relatedness, and growth: human needs in organizational settings. New York: The Free Press, 1972 .

Allport, G. Pattern and growth in personality. New York: Holt, Rinehart and Winston, 1961 .

Anthony, w. P. Management competencies and incompetencies. Reading, MA: Addison-Wesley, 1981.

Aquinas, T. Summa theologica. 1.87, c1273

Argyris, c. How normal science methodology makes leadership less addictive and less applicable. in Crosscurrents in leadership, eds., J. G. Hunt and L. L. Larson. Carbondale, IL: Southern Illinois University Press, 1977 .

Aristotle. On the soul. $3.4 .430 .30 .2, \mathrm{c} 330$ b.c.e.

Atkinson, J. W. Studying personality in the context of an advanced motivational psychology. American Psychologist, 1981, 36, 117-128.

Augustine. The city of God. 11.27, c426.

Aurelius, M. Meditations. 11.1, c175.

Babbie, E. R. Survey research methods. Belmont, CA: Wordsworth, 1973 .

Bacon, F. Advancement of learning. 2.23, 1605 .

Bailey, K. D. Methods of social research. New York: Free Press, 1978 . 
Barbour, I. G. Myth, models, and paradigms: a comparative study in science and religion. New York: Harper and Row, 1974 .

Barnard, C. The functions of the executives. Cambridge, MA: Harvard University Press, 1938.

Barnlund, D. C. A transactional model of communication. in Speech communication behavior perspectives and principles, eds., L. Barker and R. Kibler. Englewood Cliffs, NJ: Prentice-Hal1, 1971.

Bass, B. Stogdill's handbook of leadership. New York: 'The Free Press, 1981.

Bayton, J. A., and Chapman, R. L. Transformation of scientists and engineers into managers. Washington, DC: National Aeronautics and Space Administration, 1972.

Beard, R. M. An outline of Piaget's developmental psychology for students and teachers. New York: Mentor, 1972 .

Berger, P. L., and Luckmann, T. The social construction of reality. Garden City, NY: Doubleday \& Co., 1966.

Blake, R. R., and Mouton, J. S. The managerial grid. Houston, Texas: Gulf Publishing Co., 1964.

- Corporate excellence through grid organizational development. Houston, TX: Gulf Publishing, 1968.

- Theory and research for developing a science of leadership. Journal of Applied Behavioral Science, $1982, \underline{18}, 275-291$.

- The managerial grid III. Houston, Texas: Gulf Publishing Co., 1985 .

Block, H. Assimilation, accomodation and the dynamics of personality development. Child Development, 1982, 53 , 281-295.

Boeyens, M. J., and de Jager, J. J. Management style and research leader efficiency. Psychologia Africana, $1982,21,103-117$.

Bohrnstedt, G. W. Reliability and validity in attitude measurement. in Attitude measurement, ed., G. F. Summers. Chicago: Rand McNally, 1970.

Boyatzis, R. E. The competent manager: a model for effective performance. New York: John Wiley \& Sons, 1982. 
Broms, H. and Gahmberg, H. Communication to self in organizations and cultures. Administrative Science Quarterly, , 1983, 28, 482-495.

Brown, C. Philosophy and the Christian faith. Downers Grove, IL: Intervarsity Press, 1968.

Burke, R, Are Herzberg's motivators and hygienes unidimensional? Journal of Applied Psychology, 1966, 50, 193-197.

Burke, W. W. NASA culture study briefing. unpublished paper delivered to NASA managenent, 1987.

Burns, R. To a louse. in The complete poens of Robert Burns. New York: Houghton Mifflin, 1897.

Cain, L. D. Adding spice to middle age. Contemporary Sociology, 1979, $8,547-550$.

Campbell, D. T. and Fiske, D. W. Convergent and discriminant validation by use of the multitraitmultimethod matrix. Psychological Bulletin, 1959, 56, 81-105.

Cannarsa, J. Personal letter with enclosures containing four strain profiles researched with Level I: Lifestyles I Inventory Self-Concept to Mark Beymer dated January 26, 1988 .

Carroll, S. J., Jr., and Tosi, H. L., Management by objective. New York: Macmillan, 1973.

Cattell, R. B. The sree test for the number of factors. Multivariate Behavior Research, 1966, 1, 140-161.

Cattell, R. B. The scientific use of factor analysis in the behavioral and life sciences. New York: Plenum, 1978 .

Centers, R., and Bugental, D. Intrinsic and extrinsic job motivators among different segments of working population. Journal of Applied Psychology, 1966, 50, 317321 .

Conte, H. R., and Plutchik, R. Circumplex model for interpersonal personality traits. Journal of Personality and Social Psychology, 1981, 40, 701-711.

Cooke, R. A. and Lafferty, J. C. Level 1: life styles inventory--an instrument for assessing and changing the self-concept of organizational members. Plymouth, MI: Human Synergistics, 1981 . 
Cooke, R. A., and Rousseau, D. M. Relationship of life events and personal orientations to symptoms of strain. Journal of Applied Psychology, 1982a, 68, 446-458.

Cooke, R. A., and Rousseau, D. M. Factor structure of leve1 I: lifestyles inventory. Plymouth, MI: Human Synergistics, $1982 \mathrm{~b}$.

Cooke, R. A., et al. Personal orientations and their relation to psychological and physiological symptoms of strain. Unpublished paper from the J. L. Kellogg Graduate School of Management, Northwestern University, 1985 .

Cooley, C. H. Human nature and the social order, New York: Shocken Books, 1970 .

Cummings, L. L., and Elsalmi, A. M. Empirical research on the bases and correlates of managerial motivation. Psychological Bulletin, 1968, 70, 127-144.

Darwin, c. The origin of species. 1859 .

Davidson, M., and Cooper, c. Stress and the woman manager. New York: St. Martins Press, 1983.

Descarte, R. Meditations. 1641 .

Dewey, J. Human nature and conduct. New York: Henry Holt, 1922 .

Dore, R. L., Self concept and interests related to job satisfaction of managers. Unpublished dissertation, University of Washington, 1.970 .

Douglas, J. Introduction to the sociologies of everyday life. In Introduction to the sociologies of everyday life, eds. Douglas, J. D., Adler, P. A., Adler, P., Fontana, A., Freeman, C. R., and Kotarba, J. A. Boston: Allyn and Bacon, Inc., 1980.

Douglas, M. Natural symbols: explorations in cosmology. New York: Vintage Books, 1973.

Drucker, P. F. The practice of management. New York: Harper and Row, 1954 .

- Management. New York: Harper\& Row, 1973.

Drude, Kenneth P. A study of the construct validity of self-concept measures. Unpublished dissertation, University of Illinois at Urbana-Champaign, 1972. 
Dunnette, M. D. Factor structures of unusually satisfying and unusually dissatisfying job situations for six occupational groups. Paper presented at the meeting of the Midwest Psychological Association, Chicago, April, 1955.

Dunnette, M. D., Campel1, J. P., and Hakel, M. D. F'actors contributing to job satisfaction and job dissatisfaction in six occupational groups. Organizational Behavior and Human Performance, 1967, 2, 143-174.

Durant, $w$. The story of philosophy. New York: Time-Life, 1962 .

Edel, E. C. A study in managerial motivation. personnel Administration, $1966, \underline{29}, 31-38$.

Eiduson, B. Scientists: their psychological world, New York: Basic Books, 1962.

Eliade, M. The sacred and the profane. New York: Harcourt and Brace, 1961 .

Elmers, J. and Lafferty, J. C. Reliability of level I: life styles inventory split-half techniques.

plymouth, MI: Human Synergistics, 1980.

Elsalmi, A. M. Managerial motivation: the impact of some organizational and personality variables. Unpublished dissertation, Indiana University, 1968.

Epictetus. Discourses. 1.1, c125.

Epstein, S. The self-concept reconsidered, or a theory of a theory. American Psychologist, 1973, 28, 404-416.

Erikson, E. Childhood and society. New York: W. W. Norton $\&$ Co. , 1950 .

- Life history and the historical moment. New York: W.W. Norton \& Co., 1975.

Ewen, R. B., Smith, P. C., Hulen, C. L., and Locke, E. A. An empirical test of the Herzberg two-factor theory. Journal of Applied Psychology, 1966, 50, 544-550.

Fisher, R. The design of experiments. New York: Hafner, 1951 .

Frankl, V. E. Man's search for meaning. New York. Simon \& Schuster, 1963. 
Freedman, M. B., Leary, T. F., Ossorio, A. G., and Coffey, H. S. The interpersonal dimension of personality. Journal of Personality, 1951, 20, 143-161.

Freud, S. The interpretation of dreams. 1900 .

Friedlander, F. Underlying sources of job satisfaction. Journal of Applied Psychology, 1963, 47, 246-250.

- Job characteristics as satisfiers and dissatis-

fiers. Journal of Applied Psychology, 1964, 48, 388392 .

Fromm, E., and Maccoby, M. Social character in a Mexican village. Englewood Cliffs, NJ: Prentice-Hall, 1970.

Garfield, C. Peak performers. New York: William Morrow and Company, 1986.

Glaser, B. Differential association and the institutional motivation of scientists. Administrative Science guarterly, 1965, 10, 82-97.

Glenn, N. Cohort analysis. Beverly Hills, CA: Sage Publications, 1977.

Goffman, E. The presentation of self in everyday life. New York: Anchor Books, 1959.

- Encounters. Bobbs-Merrill Co.. 1961.

- Behavior in public places. New York: The Free Press, 1.963. 1971 .

Relations in public. New York: Basic Books,

1974. Frame analysis. New York: Harper Colophon,

Goldstein, K. The organism. New York: American Book, 1939.

Gordon, G. G., The relationship of satisfiers and disatisfiers to productivity, turnover, and morale. Paper presented at a meeting of the American Psychological Association, Chicago, September, 1965.

Gordon, R. A. Business leadership in the large corporation. Washington, DC: Brookings Institute, 1945.

Gorsuch, R. L. Factor analysis. Hillsdale, NJ: Erlbaum, 1983.

Reproduced with permission of the copyright owner. Further reproduction prohibited without permission. 
Gouldner, A. W. Cosmopolitans and locals: toward an analysis of latent social roles-I. Administrative Science Quarterly. 1957, 2, 281-306.

- Cosmonolitans and locals: toward an analysis of latent social roles-II. Administrative Science quarterly, 1958, 2, 444-480.

Graen, G. B. Addendum to "An empirical test of the Herzberg two factor theory." Journal of Applied Psychology, $1966 a, \underline{50}, 551-555$.

- Motivator and hygiene dimensions for research and development engineers. Journal of Applied Psychology. $1966 \mathrm{~b}$, 50, 563-566.

Griffin, C. E. Enterprise in a free society. Homewood, IL: Irwin, 1949.

Hall, C. A primer of Freudian psychology. New York: World Publishing, 1954.

Hall, C., and Lindzey, G. Theories of personality, 2nd edition. New York: John Wiley \& Sons, 1970.

Hall, J. Interpersonal style and the communications dilemma-I. Managerial implications of the Johari awareness model. Human Relations, 1974a, 27, 381-395.

- Interpersonal style and the communications dilemma-II. Managerial implications of the Johari awareness model. Human Relations, $1974 \mathrm{~b}, \underline{27}$.

- Management synthesis: an anatomy of management. style. in Models for management: The structure of competence, ed., J.S. Shtogren. The Woodlands, TX: Teleometrics International, 1980a.

Hall, J. The competence process. The Woodlands, TX: Teleometrics International, $1980 \mathrm{~b}$.

Hall, J., and Williams, M. S. Personnel relations survey. The Woodlands, TX: Teleometrics International, 1967.

Harbaugh, T. E. A validation study of the Maslow hierarchy of needs. Unpublished dissertation, University of Maryland, 1972 .

Henrichs, J. R., and Mirschkind, I. A. Empirical and theoretical limitations of the two factor hypothesis of job satisfaction. Journal of Applied Psychology, 1967, 51, 191-200.

Reproduced with permission of the copyright owner. Further reproduction prohibited without permission. 
Henry, W. E. Executive personality and job success. (Personnel Series No. 120). New York: American Management Association, 1948 .

Herrick, J. S. A comparison of the perceptions of need fulfillment and of their importance to government executives. Unpublished dissertation, George Washington University, 1968 .

Herzberg, F. Work and the nature of man. New York: Thomas Y. Crowell Co., 1966.

Hilgard, E. R. Human motives and the concept of self. American Psychologist, 1949, 4, 374-382.

Hill, R. Managing interpersonal conflict in project teams. Sloan Management Review, 1977, 18(2), 45-62.

Hobbes, Thomas. Introduction. The leviathon. 1651.

Holmes, T. H., and Rahe, R. H. The social readjustment rating scale. Journal of Psychosomatic Research, $1967,11,213-218$.

House, R. J., and Wigdor, L. A. Herzberg's dual-factor theory of job satisfaction and motivation: a review of the evidence and a critique. Personnel Psychology, $1967,20,121-132$.

Howard, A., and Bray, D. W. Career motivations in Mid-life managers. Paper prepared for the symposium: New perspectives in career planning and development. American Psychological Association Annual Convention, Montreal, Canada, September, 1980.

Hulin, C. L., and Smith, P. A. An empirical investigation of the two-factor theory of job satisfaction. Journal of Applied Psychology, 1967, 51, 396-402.

Hultsch, D.F., and Deutsch, F. Adult development and aging. New York: McGraw-Hill, 1981 .

Hume, D. Treatise of human nature. $1.4 .6,1740$.

James, W. The consciousness of self. in Principles of psychology, 1890 .

The social self. in Social psychology through symbolic interaction, eds., G. Stone and H. Farberman. Waltham, MA: Xerox Publishing, 1970 .

Jourard, S. M. The transparent self. New York: Van Nostrand Reinhold Co., 1964. 
Jourard, S.M., and Lasakow, P., Some factors in selfdisclosure. Journal of Abnormal and Social Psychology, $1958, \underline{56}, 91-98$.

Jung, C. G. The relation between the ego and the unconscious. in collected Works, vol. 7., eds., H. Read, M. Fordham, and G. Adler. Princeton, NJ: princeton University press, 1953.

Jung, C. G., von Franz, M. L., Henderson, J. L., Jacobi, J., and Jaffe, A. Man and his symbols. New York: Doubleday and Co., 1964.

Kant, E. The critique of pure reason. $1.20,1781$.

Kaplan, A. Measurement. in The conduct of inquiry. Scranton, PA: Chandler Publishing, 1964.

Katz, D., Maccoby, N., and Morse, N. C. Productivity, supervision, and morale in an office situation. Ann Arbor, MI: Institute for Social Research, The University of Michigan, 1950 .

Keirsey, D., and Bates, M. please understand me. Del Mar, CA: Prometheus Nemesis Book Co., 1984.

Kerlinger, F. Foundations of behavioral research, 2nd edition. New York: Holt, Rinehart and Winston, 1973.

Kerr, M. Chronic anxiely and defining a self. Ntlantic Monthly, September, 1988, PP. 35-58.

Kinlaw, D. Interpretation of NASA culture study for NASA Kennedy Space Center. Unpublished paper for Kennedy Space Center management, 1987.

Klemp, G. The assessment of occupational competence. Report to the National Institute of Education, Washington, D. C., 1980.

Kohlberg, L. Stage and sequence: the cognitive developmental approach to socialization. in Handbook of socialization theory and research, ed., D. A. Goslin. Chicago: Rand McNally, 1969.

Kuhn, T. S. The structure of scientific revolutions. Chicago: The University of Chicago Press, 1970.

Lafferty, J.C. A validation of Level I against assessment center techniques. Plymouth, MI: Human Synergistics, 1971 . 
Lafferty, J. C. Level 1: life styles inventory selfconcept. Plymouth, MI: Human Synergistics, 1973.

- Level 1: life styles self-development guide. Plymouth, MI: Human Synergistics, 1980.

Lafferty, J. C., Long, H., Morris, G., and Horian, L. Item frequency and distribution: Level 1: Life styles Inventory. Plymouth, MI: Human Synergistics, 1980.

Lahiri, D. K., and Srivastva, S., Determinants of satisfaction in middle-management personnel. Journal of Applied Psychology, 1966, 51, 254-265.

Laing, R. D. The divided self. London: Penguin, 1969.

Leary, T.F. Interpersonal diagnosis of personality: a functional theory and methodology for personality evaluation. New York: Ronald Press, 1957.

Levine, E. L. Introductory remarks for the symposium "Organizational applications of self-appraisal and self-assessment: another look." Personnel Psychology. $1980,21,202-218$.

Levinson, D. J. The seasons of a man's life. New York: Alfred A. Knopf, 1978.

Levi-Strauss, C. Totemism. Boston: Beacon, 1963a. $1963 b$.

Structural anthropology. New York: Basic Books,

Lindsay, C. A., Marks, E., and Godow, L. The Herzberg theory: a critique and reformulation. Journal of Applied Psychology, 1967, 51, 330-339.

Locke, J. An essay concerning human understanding. 4.9.3, 1690.

Lotman, J. Two models of communication. in Soviet semiotics: an anthropology, ed. and trans., D. P. Lucid. Baltimore: John Hopkins University Press, 1977.

Luft, J. of human interaction. Palo Alto, CA: National Press, 1969.

Luft, J. and Ingham, H. The Johari window, a graphic model of interpersonal awareness. Proceedings of the Western Training Laboratory in Group Development. Los Angeles: University of Georgia, Los Angeles, Extension Office, 1955. 
Lumsden, C. and Wilson, E. Genes, mind, and culture. Cambridge, MA: Harvard, 1981 .

Maccoby, M. The gamesman, the new corporate leaders. New York: Simon and Schuster, 1976.

Machiavelli, N. The prince. 1513.

Mahoney, M. Scientist as subject: the psychological imperative. Cambridge, MA: Ballinger Publishing Co., 1974 .

Manis, M. Social interaction and the self-concept. Journal of Abnormal and Social Psychology, $1955,51,362-370$.

Marcson, S. The scientist in American industry: some organizational determinents in manpower utilization. New York: Harper, 1960.

Maslow, A. Motivation and personality. New York: Harper, 1954.

- Eupsychian management, In A journal. Homewood, IL: The Dorsey Press, 1965.

- Toward a psychology of being, 2nd ed.. Princeton, NJ: Van Nostrand, 1968.

Mathes, E. W., and Edwards, L. L. An empirical test of Maslow's theory of motivation. Journal of llumanistic Psychology, 1978, 18, 75-77.

McClelland, D.C. Toward a theory of motive acquisition. American Psychologist, 1965, 20, 321-333.

- The achieving society. New York: Halstead Press, 1976.

McClelland, D.C., Atkinson, J.W., Clark, R.A., and Lowell, E.L. The achievement motive. New York: AppletonCentury-Crofts, 1953.

McGrath, J. E. Stress and behavior in organization. in Handbook of industrial and organizational psychology, ed., M. D. Dunnette. Chicago: Rand-McNally, 1976.

McGregor, D. The human side of enterprise. New York: McGraw-Hil1, 1960 .

Merton, R. K. Social theory and social structure. Glencoe, IL Free Press, 1957. 
Meyer, H., Walker, W., and Sitivin, G. Motive pattern and risk preferences associated with entrepreneurship. Journal of Abnormal and Social Psychology, 1961, 63, 570-574.

Mitchel1, V. and Moudgill, P. Measurement of Maslow's need hierarchy. Organizational Behavior and Human Performance, $1976, \underline{16}, 334-349$.

Miyamoto, S. F., and Dornbusch, S. A test of the symbolic interactionist hypotheses of self-conception. American Journal of Sociology, 1956, 61, 399-403.

Montaigne. Essays. 1588 .

Morris, G. J. A rhetorical study of adherency to integrated theories of management in executives, managers, and supervisors. Unpublished dissertation, Wayne State University, 1980 .

Murray, H. Explorations in personality. New York: John Wiley and Sons, 1938 .

Myers, I. Manual: The Myers-Briggs type indicator. Palo Alto, CA: Consulting Psychologists Press, 1.962.

Myers, I. Gifts differing. Palo Alto, CA: Consulting Psychologists Press, 1980.

NASA, Personnel management information system: strength distribution as of 09-30-85 (PMIS AP-420). Washington, DC: Personnel Programs Division, NASA Headquarters, 1985 .

Neumann, E. The origins and history of consciousness. Princeton, NJ: Princeton University Press, 1954.

Nietzsche. The will to power. 1889.

Noppe, I. C. The development of the self-concept: a piagetian interpretation of an affective and cognitive construct. Unpublished dissertation, Temple University, 1979 .

O'Brien, R. T. Using Jung more (and etching him in stone less). Training, May, 1985, pp. 53-66.

Oppenheimer, E. A., A self-concept approach to predicting occupational preferences. Unpublished dissertation, Columbia University, 1964 . 
Orpen, C., and Bush, R. The lack of congruence between self-concept and public image. Journal of Social Psychology, 1974, 93, 145-146.

Passmore, J. The perfectibility of man. New York: Charles Scribner's Sons, 1970 .

Pepper, S.C. World hypothesis. Berkeley, CA: University of California Press, 1942 .

piaget, J. The moral judgment of the child. New York: The Free Press, 1965.

plato. Philebus. 48, c355 b.c.e.

Porter, L.W. Job attitudes in management: $I$. perceived deficiencies in need fulfillment as a function of job level. Journal of Applied Psychology, 1962, 46, 375384.

- Job attitudes in management: II. perceived deficiencies in need fulfillment as a function of job level. Journal of Applied Psychology, 1963a, 47, 141-148.

- Job attitudes in management: III. perceived deficiencies in need fulfillment as a function of line versus staff type of job. Journal of Applied Psychology, 1963b, 느, 267-275.

- Job attitudes in management: IV. perceived

deficiencies in need fulfillment as a function of size of company. Journal of Applied Psychology, 1963c, 47, 386-397.

Pulaski, M. Understanding Piaget. New York: Harper \& Row, 1971.

Quarantelli, E. L., and Cooper, J. Self conceptions and others: a further test of the Median hypothesis. Sociological guarterly, 1966, $\underline{7}, 281-297$.

Raths, L. E., Harmin, M., and Simon, S. B. Values and teaching. Columbus, $\mathrm{OH}$ : Charles E. Merrill Publishing Co., 1966.

Reese, H. W. Consistency of the self-concept. Unpublished dissertation, Vanderbilt University, 1961.

Rhinehart, J. B., Barrell, R. P., De Wolfe, A. S., Griffin, J. E. and Spaner, F. E. Comparative study of need satisfactions in governmental and business hierar-

Reproduced with permission of the copyright owner. Further reproduction prohibited without permission. 
chies. Journal of Applied Psychology, 1969, 53, 230235 .

Rogers, C.R. A theory of therapy, personality, and interpersonal relationships, as developed in the clientcentered framework. in Psychology: a study of a science, vol. 3, ed., S. Koch. New York: McGrawHi 11, 1959.

- On becoming a person: a therapist's view of psychotherapy. Boston: Houghton-Mifflin, 1961 .

Rosen, H. Occupational motivation of research and development personnel. Personnel Administration, 1963, 26, $37-43$.

Rosen, H., and Weaver, C. Motivation in management: a study of four managerial levels. Journal of Applied Psychology, 1960, 44, 386-392.

Rousseau, J. A dissertation on the origin and foundation of the inequality of mankind. 1755.

Schein, E. H., Mc Kelvy, W.W., Peters, D. R., and Thomas, J. M. Career orientations of rewarded activity in research organizations. Administrative Science Quarterly: $1965,9,334-349$.

Schutz, A. Collected papers I. The problem of social reality. The Hague: Martinus Nijhoff, 1962.

Schutz, W. C. FIRo-B. Palo Alto, CA: Consulting Psychologists Press, 1977.

Schutz, w. C. The truth option. Berkeley, CA: Ten Speed Press, 1984 .

Sheehy, G. Passages. New York: E. P. Dutton \& Co., 1974.

Sherwood, J. J. Increased self-evaluations as a function of ambiguous evaluations by referent others. Sociometry, 1965 , 30, 404-409.

Shrauger, J. S., and Schoeneman, T. J. Symbolic Interactionist view of self-concept: through the looking glass darkly. Psychological Bulletin, 1979, 86, 549573 .

Shtogren, J. Models for management: the structure of competence. The Woodlands, TX: Teleometric Internationa 1, 1980 .

Reproduced with permission of the copyright owner. Further reproduction prohibited without permission. 
Siggers, K. W. Relationships between occupational self concept, occupational role concept, and occupational role performance. Unpublished dissertation, Rutgers University, 1971.

Snyder, C. D., and Ferguson, L. W. Self concept and job satisfaction. Psychological Reports, 1976, 38, 603610 .

Stephenson, W., The study of behavior. Chicago: The University of Chicago Press, 1953.

Stogdill, R. M. Manual for the leader behavior description questionnaire--form XII. Columbus, OH: Bureau of Business Research, Ohio State University, 1963.

Sullivan, H.S. The interpersonal theory in psychiatry. New York: Norton, 1953.

Sumner, W. Essays of William Graham Sumner, eds., A. G. Keller and M. R. Davie. New Haven, CN: Yale University press, 1934 .

Super, D. E., Starishevsky, R., Matlin, N., and Jordan, J. P. Career development: self concept theory. Princeton, NY: College Entrance Examination Board, 1963.

Tagiuri, R. Value orientations and the relationship of managers and scientists. Administrative Science guarterly, 1965, 10, 39-51.

Taylor, D. M. The consistency of the self concept. Unpublished dissertation, Vanderbilt University, 1953.

van den Berghe, p. C. Bringing beasts back in: toward a biosocial theory of aggression. American Sociological Review, 1974, 39, 777-788.

Veroff, J., Atkinson, J., Feld, S., and Gruin G. The use of thematic apperception to access motivation to achieve. Psychological Monographs, 1960.

Walhood, D. S., and Klopfer, W. G. Congruence between self-concept and public image. Journal of Consulting and Clinical Psychology, 1971, 37, 148-150.

Ware, M. E., Leak, G. K., Perry, N. W. Life styles inventory: evidence for its factorial validity. Psychological Reports, 1985, 56, 963-968.

Warwick, D. A., and Linger, C. A. The sample survey: theory and practice. San Francisco: McGraw-Hill, 1975 . 
Watson, J. G. An analysis of the self-concept, personal values, and levels of achievement motivation of black and white managers. Unpublished dissertation, Saint Louis University, 1974.

Wernimout, P. E. Intrinsic and extrinsic factors in job satisfaction. Journal of Applied Psychology, 1966, $50,41-50$.

White, R. W. Motivation reconsidered: the concept of competence. Psychological Review, 1959, 66, 297-332.

Whitsett, D. A., and Winslow, E. K. An analysis of studies critical of the motivation-hygiene theory. Personnel Psychology, 1967, 20, 121-132.

Wilson, E. On human nature. Cambridge, MA: Harvard, 1978.

Wolf, M. G. The relationship of content and context factors to attitude toward company and job. Personnel

Psychology, 1967, 20, 121-132.

Wylie, R. C. The self concept: a critical survey of pertinent research literature. Iincoln, NE: University of Nebraska Press, 1961.

Reproduced with permission of the copyright owner. Further reproduction prohibited without permission. 


\section{-. APPENDIX A}

LEVEU 1: LTFE STYIES INVENIORY 


\section{PLEASE NOTE:}

Copyrighted materials in this document have not been filmed at the request of the author. They are available for consultation, however, in the author's university library.

These consist of pages:

228-229

231-234

236-237

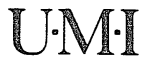

Reproduced with permission of the copyright owner. Further reproduction prohibited without permission. 
APPENDIX B

COMPARATIVE LAFFERTY SAMPLES

Reproduced with permission of the copyright owner. Further reproduction prohibited without permission. 
APPENDIX C

NASA MANAGEMENT SAMPLES

Reproduced with permission of the copyright owner. Further reproduction prohibited without permission. 


\section{APPENDIX D}

TESTS FOR OTHER SETF-CONCEPT VARTABLES 
TABLE XXIII

OTHER SECURTTY VARIABILS: TESTS

Significance Tests: NASA Technical Mgrs and respective samples.

Rejection Region: Sig. $=.05 ; \mathrm{z}>1.96$; or $\mathrm{z}<-1.96$

AVOIDANCE LIFESTYLE

\begin{tabular}{|c|c|c|c|c|}
\hline Sample & $\underline{\mathbf{n}}$ & Mean & S.D. & Significance \\
\hline NASA Technical Mgrs. & 117 & 5.38 & 5.14 & \\
\hline NASA Non-technical Mgrs. & 42 & 4.58 & 3.46 & $z=+1.13$ \\
\hline Lafferty Engineers & 52 & 6.10 & 5.90 & $z=-.85$ \\
\hline Lafferty Supervisors & 496 & 7.07 & 5.31 & $z=-3.12$ \\
\hline Lafferty Mid-level Mgrs. & 4500 & 6.55 & 6.22 & $z=-2.43$ \\
\hline
\end{tabular}

OPFOSITIONAL IIEESTYIIE

\begin{tabular}{|c|c|c|c|c|}
\hline Sample & $\underline{\mathbf{n}}$ & Nean & S.D. & Significance \\
\hline NASA Technical Mgrs. & 117 & 6.67 & 5.37 & \\
\hline NASA Non-technical Mgrs. & 42 & 6.44 & 4.55 & $z=+.27$ \\
\hline Lafferty Engineers & 52 & 8.30 & 5.40 & $z=-1.81$ \\
\hline Lafferty Supervisors & 496 & 6.90 & 5.23 & $z=-.41$ \\
\hline Lafferty Mid-level Mgrs. & 4500 & 5.66 & 5.35 & $z=+1.98$ \\
\hline
\end{tabular}

Reproduced with permission of the copyright owner. Further reproduction prohibited without permission. 
TABLE XXIV

OTHER TASK VARIABIES: TESTS

Significance Tests: NASA Technical Mgrs and respective samples.

Rejection Region: Sig. $=.05 ; z>1.96$; or $z<-1.96$

COMPETITIVE LIFESTYLE

\begin{tabular}{|c|c|c|c|c|}
\hline Sample & $\underline{\mathbf{n}}$ & Mean & S.D. & Significance \\
\hline NASA Technical Mgrs. & 117 & 12.83 & 5.77 & \\
\hline NASA Non-technical Mgrs. & 42 & 13.19 & 6.89 & $z=-.32$ \\
\hline Lafferty Engineers & 52 & 13.30 & 5.90 & $z=-.53$ \\
\hline Lafferty Supervisors & 496 & 11.16 & 6.14 & $z=+3.88$ \\
\hline Lafferty Mid-level Mgrs. & 4500 & 10.76 & 6.94 & $z=+5.91$ \\
\hline
\end{tabular}

PONER LIFESTYIE

\begin{tabular}{|c|c|c|c|c|}
\hline Sarmple & $\underline{\mathbf{n}}$ & $\frac{\text { Mean }}{71}$ & S.D. & Significance \\
\hline NASA Technical Mgrs. & $1 \overline{17}$ & 5.71 & $\overline{4.70}$ & \\
\hline NASA Non-technical Mgrs. & 42 & 5.90 & 4.55 & $z=-.23$ \\
\hline Lafferty Engineers & 52 & 6.00 & 5.60 & $z=-.33$ \\
\hline Lafferty Supervisors & 496 & 6.90 & 5.23 & $z=-2.38$ \\
\hline Lafferty Mid-level Mgrs. & 4500 & 6.71 & 5.84 & $z=-2.22$ \\
\hline
\end{tabular}

Reproduced with permission of the copyright owner. Further reproduction prohibited without permission. 
TABIE XXV

OIHER PEOPLE VARTABTES: TESTS

Significance Tests: NASA Technical Mgrs and respective samples.

Rejection Region: Sig. $=.05 ; z>1.96$; or $z<-1.96$

APPROVAL ITFESTYUE

$\begin{array}{lrlll}\text { Sample } & \underline{\mathbf{n}} & \text { Mean } & \text { S.D. } & \text { Significance } \\ \text { NASA Technical Mgrs. } & 117 & 11.79 & 4.87 & \\ \text { NASA Non-technical Mgrs. } & 42 & 11.58 & 5.01 & \mathrm{z}=+.23 \\ \text { Lafferty Engineers } & 52 & 13.90 & 5.60 & \mathrm{z}=-2.37 \\ \text { Lafferty Supervisors } & 496 & 11.67 & 5.48 & \mathrm{z}=+.35 \\ \text { Lafferty Mid-level Mgrs. } 4500 & 11.06 & 5.37 & \mathrm{z}=+1.62\end{array}$

\section{CONVENITONAL LIFESTYLE}

\begin{tabular}{|c|c|c|c|c|}
\hline Sample & $\underline{\mathbf{n}}$ & Mean & S.D. & Significance \\
\hline NASA Technical Mgrs. & 117 & 14.86 & 5.14 & \\
\hline NASA Non-technical Mgrs. & 42 & 14.26 & 5.29 & $z=+.63$ \\
\hline Lafferty Engineers & 52 & 14.50 & 4.40 & $z=+.46$ \\
\hline Lafferty Supervisors & 496 & 15.10 & 5.68 & $z=-.44$ \\
\hline Lafferty Mid-level Mgrs. & 4500 & 14.11 & 6.22 & $z=+1.56$ \\
\hline
\end{tabular}

Reproduced with permission of the copyright owner. Further reproduction prohibited without permission. 